\title{
II. Globalismus und Intervention: Der Aufstieg der USA zur Vormacht in $\underline{\text { Iran, 1941-1953 }}$
}

II. 1. Die Einbeziehung Irans in die amerikanische Sicherheitskonzeption während der Frühphase des Kalten Krieges, 1941-1946

Die frühen Kontakte zwischen Iran und den Vereinigten Staaten spiegelten die geografische Distanz zwischen beiden Staaten und Gesellschaften wider. Das bilaterale Verhältnis nach der vergleichsweise früh erfolgten formalen Aufnahme diplomatischer Beziehungen im Jahr 1856 entwickelte sich schleppend und beschränkte sich - analog zu der zu dieser Zeit für die USA charakteristischen weltpolitischen Rolle - in den darauffolgenden Jahrzehnten auf bescheidene wirtschaftliche Kontakte, Aktivitäten einiger weniger amerikanischer Missionare und der von ihnen errichteten Missionsschulen und archäologische Expeditionen. ${ }^{1}$ Der seit 1796 regierenden Ġāăāren-Dynastie gelang es derweil nicht, die Einmischung fremder Mächte auch auf iranischem Territorium wurde das „Great Game“ zwischen Großbritannien und dem Zarenreich um die Vorherrschaft in Südwest-, Süd und Zentralasien ausgetragen - in innere Angelegenheiten Irans zu verhindern. Zwar war man insofern erfolgreich, einer direkten Kolonialisierung durch europäische Mächte entgangen zu sein, doch war dies eher Ausdruck des britisch-russischen Dualismus in der Region und weniger einer besonderen Widerstandsfähigkeit der iranischen Bevölkerung bzw. ihrer politischen Führung zuzurechnen. Mit der Aufteilung Irans in Einflusssphären im Rahmen der Anglo-Russischen Konvention von 1907 schien dennoch die Eigenständigkeit Irans auf lange Sicht verloren. Die von iranischen Nationalisten erhoffte Erneuerung des Staatswesens auf Basis europäischer Ideen und immer auch in Bezug auf einstmalige historische Größe scheiterte nicht zuletzt am übermächtigen Einfluss auswärtiger Mächte. Interventionen Großbritanniens und des Zarenreiches trugen zum Niedergang der Protestbewegung bei, die in der Konstitutionellen Revolution von 1906-11 eine Verfassung und die Einberufung eines Parlaments (Mağles) erzwungen hatte. Somit schien der Weg zu mehr politischen Freiheiten und der von vielen iranischen Nationalisten erhofften umfassenden Reformierung und Modernisierung des Landes verbaut. Aus Sicht national fühlender Iraner wurde die anglo-russische Einflusssphärenabsprache von 1907 der wichtigste symbolische Bezugspunkt für das Scheitern der eigenen Ambitionen und zu einem in der Folgezeit immer wieder beschworenen nationalen Trauma.

\footnotetext{
${ }^{1} \mathrm{Zu}$ den frühen amerikanisch-iranischen Kontakten bis 1941 vgl. BILL, Eagle and Lion, S. 15ff.; RuBIN, Good Intentions, S. 3-17; COTTAM, Iran and the United States, S. 19-54; GASIOROWSKI, Client State, S. 28-42, 50; Einzelstudien zu den frühen Beziehungen bieten YESELSON, Diplomatic Relations; RAMAZANI, Developing; GRAYSON, United States-Iranian Relations, S. 3-26; vgl. BONAKDARIAN, U.S.-Iranian Relations.
} 
Der Ausbruch des Ersten Weltkriegs brachte für Iran zugleich eine Verletzung der Neutralität durch die Kriegführenden und erhebliche Zerstörungen und Menschenverluste, aber auch eine grundlegende Revision des bisherigen Sicherheitsumfeldes, zuvorderst durch das (zeitweilige) Ausscheiden Russlands als maßgeblicher Faktor in der iranischen Politik im Nachgang der Oktoberrevolution. Das (vorläufige) Ende der britisch-russischen Konkurrenz um Iran gab der iranischen Nationalbewegung neuen Auftrieb. So waren es vor allem nationalistische Kräfte, die 1919 den Versuch Großbritanniens vereitelten, Iran in ein de facto-Protektorat umzuwandeln und das Land dem neuen britischen Kolonialreich im Nahen und Mittleren Osten anzuschließen. Gegen die allzu offensichtliche britische Intervention hatte dabei auch die amerikanische Gesandtschaft in Teheran protestiert. In der Folgezeit verstärkte sich die Wahrnehmung der USA als grundsätzlicher, wenngleich entfernter Freund Irans und potentieller Unterstützer bei der Verteidigung der Unabhängigkeit und Souveränität des Landes, dessen Einbindung in innere Angelegenheiten Irans gerade wegen seines machtpolitischen Desinteresses wünschenswert erschien. Bevorzugte Methode der Einbindung der USA war die Berufung amerikanischer Berater.

Bereits vor dem Ersten Weltkrieg hatte man auf einen amerikanischen Experten, W. Morgan Shuster, zurückgegriffen, dessen Beratermission die Reformierung des Finanzsystems aufgetragen war. Washington war zu dieser Zeit zwar geneigt, Berater zu entsenden, betrachtete diese aber als Privatpersonen und ihr Wirken grundsätzlich als innere Angelegenheit Irans. Eine zweite Finanzmission, dieses Mal unter der Leitung von Arthur Millspaugh, weilte von 1922 bis 1927 in Iran. Auswärtige Berater in Iran litten aber im Grundsatz unter den Schwächen ihrer eigenen Position im inneriranischen Machtgefüge aufgrund des Fehlens eigentlicher Hausmacht und an der halbherzigen bis fehlenden Unterstützung durch ihre eigene Regierung. Millspaughs Bemühungen scheiterten letztlich am Widerstand von Rezā Xān, dem neuen „starken Mann“ in Iran. ${ }^{2}$ Rezā Xān hatte mithilfe einer unter seinem Kommando stehenden Kosakenbrigade 1921 gemeinsam mit pro-britischen Kräften in einem Staatsstreich die Kontrolle übernommen und in der Folgezeit seinen alleinigen Machtanspruch etabliert. Die konsequente Durchsetzung der Alleinherrschaft Rezās - 1925 hatte er den letzten Ġāăāren absetzen lassen und mit seiner Krönung zum neuen Schah die Dynastie der Pahlawi begründet - und die von ihm mit Nachdruck betriebene Modernisierung und Zentralisierung des Landes verringerten die Einflussmöglichkeiten fremder Mächte spürbar, wobei die grundsätzliche britische Dominanz aber weiterhin bestehen blieb. ${ }^{3}$ Der britischen Vormacht kam die neue Stabilität Irans unter autokratischer Führung angesichts geänderter Umstände nicht ungelegen, ließ sie doch die unangefochtene Stellung in der Erdölindustrie, den eigentlichen Kern der eigenen Machtstellung in Iran und zugleich das wesentliche ökonomische Interesse Londons,

\footnotetext{
${ }^{2} \mathrm{Zu}$ den Shuster- und Millspaugh-Missionen siehe CotTAm, Iran and the United States, S. 33ff., 53f.; RuBIN, Good Intentions, S. 10-15.

${ }^{3}$ Wie sehr sich das historische Bild Rezā Šāhs gewandelt hat, zeigt ein Vergleich des relevanten Kapitels in KEDDIE, Roots of Revolution [1981], S. 86-112, mit KEDDIE, Modern Iran [2003], S. 80-104.
} 
unangetastet. Vorsichtige Bemühungen durch Rezā Šāh, insbesondere amerikanische Ölinteressen auf Iran zu lenken, um das britische Monopol zumindest abzuschwächen, blieben ohne Ergebnis. ${ }^{4}$ In der Folgezeit ging das amerikanische Interesse an Iran merklich zurück. So wurde innerhalb der USA der zeitweilige Abbruch der diplomatischen Beziehungen durch Rezā Šāh von 1936 bis 1939 kaum wahrgenommen. Zu peripher waren Iran und die nahöstliche Region in der amerikanischen Wahrnehmung der Welt in der Zwischenkriegszeit. Bizarrer Auslöser des diplomatischen Zwists zwischen beiden Ländern war die Behauptung in einem amerikanischen Zeitungsartikel, Rezā Šāh sei in seiner Jugend ein Stalljunge in der britischen Botschaft gewesen. ${ }^{5}$ Erst der Ausbruch des Zweiten Weltkriegs sollte die Einschätzung Irans als zweitrangig für die strategischen Interessen der USA ändern, nun allerdings nachhaltig und langfristig.

Wie bereits im Ersten Weltkrieg, so gelang es Iran auch im zweiten großen globalen Mächtekonflikt nicht, die eigene Neutralität zu bewahren. Ein alternder Rezā Šāh versuchte sich vergeblich an einer Politik der Äquidistanz zwischen Achsenmächten und Alliierten. Unter dem Vorwand, dass die iranische Regierung den ultimativen Forderungen der Alliierten nach einer Ausweisung der deutschen Kolonie nicht nachgekommen sei, marschierten am 25. August 1941 gleichzeitig britische und sowjetische Streitkräfte in Iran ein. Die - recht überschaubare - deutsche Präsenz, ohnehin kaum von strategischer Relevanz, war, wenn überhaupt, nur ein sekundäres Motiv für die Invasion des neutralen Iran. Sie wird heutzutage nur mehr in der anglo-amerikanischen Forschung angeführt, meist zur Rechtfertigung einer augenfällig schwerwiegenden Verletzung des Völkerrechts durch die Invasion eines neutralen Staates. ${ }^{6}$ Hauptziele der Invasoren waren vielmehr die geographische Lage Irans in Kombination mit logistischen Voraussetzungen, die das Land zum perfekten Verbindungsglied für eine alternative Nachschublinie zur Unterstützung der Sowjetunion durch die Westalliierten, zuvorderst durch die USA, machten. Für diese Annahme spricht die spätere herausragende Bedeutung der Versorgungslinie vom Persischen Golf zum Kaukasus und zu den zentralasiatischen Sowjetrepubliken. Neben den Hoffnungen auf die Etablierung einer sicheren Versorgungsroute in die UdSSR spielte aus britischer Sicht auch die Absicherung der strategisch als zentral eingeschätzten Nahostregion im Falle eines deutschen Durchbruchs in den Kaukasus bzw. einer Eroberung Ägyptens mittels einer zweiten Verteidigungslinie, gleichermaßen zum Schutz der Ölquellen am Persischen Golf wie auch des Landwegs nach Indien, eine Rolle. Zudem erschien es wünschenswert, die gerade erst eingegangene „unnatürliche Allianz“ mit dem Sowjetkommunismus durch eine gemeinsam durchgeführte

\footnotetext{
${ }^{4}$ Zur frühen US-Politik in der Nahostregion vgl. DENovo, American Interests; LiTTLE, American Orientalism, S. 45-48.

${ }^{5} \mathrm{Zu}$ dieser Episode vgl. RuBIN, Good Intentions, S. 16ff.

${ }^{6}$ Dieses Motiv noch zentral bei LenCZOWSKI, Russia and the West, S. 162-6; ähnlich Rezun, Crisis of 1941; überraschend die spätere Übernahme dieser Position bei BILL, Eagle and Lion, S. 18; zu den deutsch-iranischen Beziehungen im Vorfeld siehe HIRSCHFELD, Deutschland und Iran; MADANI, Iranische Politik; KHATIB-SHAHIDI, Policy Towards Iran; JENKINS, Iran in Nazi New Order; eine Operationsgeschichte des kurzen Feldzuges bietet STEWART, Sunrise at Abadan.
} 
Operation zu bestätigen. ${ }^{7}$ Die Operation diente nicht zuletzt dazu, das Misstrauen Stalins gegenüber den langfristigen Absichten Großbritanniens zu entkräften. Die Pläne des französischen Generalstabs, im Juli 1940 von deutscher Seite veröffentlicht, belegten anglofranzösische Beratungen über einen Luftangriff auf die als Achillesferse ausgemachte sowjetische Ölförderung. ${ }^{8}$ Zwar standen diese Pläne im Zusammenhang mit dem Hitler-StalinPakt, doch hätte eine unilaterale britische Operation in Iran zweifelsohne die Besorgnis auf sowjetischer Seite vergrößert. Im beginnenden Kalten Krieg sollte die Verwundbarkeit der Ölforderung um Baku und der hinter den Ural verlegten industriellen Zentren vom Nahen und Mittleren Osten aus erneut eine zentrale Rolle einnehmen.

Im Anschluss an den raschen Zusammenbruch der militärischen Gegenwehr angesichts der fast vollständigen Überlegenheit der Angreifer stellte sich die Frage nach der Behandlung Irans während des Krieges. Briten und Sowjets einigten sich anfänglich auf eine Kontrolle Irans mittels klar definierter Besatzungszonen im Süd- und Nordwesten, wichen dann aber rasch von der Idee einer nur indirekten Kontrolle ab, und dehnten daher ihre Präsenz auch auf den Rest des Landes inklusive der Hauptstadt Teheran aus. Zugleich erwirkte man durch direkte Einflussnahme beziehungsweise diplomatischen wie militärischen Druck eine weitreichende innere Umgestaltung Irans, wobei die erzwungene Abdankung Rezā Šāhs am 16. September 1941 den markantesten Eingriff darstellte. An seiner statt wurde sein zweiundzwanzigjähriger Sohn Mohammad Rezā als neuer Schah eingesetzt. ${ }^{9}$

Im Gegensatz zu Zeiten der Diktatur Rezā Šāhs war der Hof nun allerdings nicht mehr alleiniges Macht- und Entscheidungszentrum. Tatsächlich ergaben sich im Anschluss an die Invasion trotz der erheblich eingeschränkten Souveränität des Landes aufgrund weitreichender Eingriffsrechte der beiden Besatzungsmächte - insbesondere einer gemeinsam ausgeübten Zensur - neue politische Freiheiten für politisch engagierte Iraner, die in diesem Ausmaß zu Zeiten der Diktatur niemals denkbar gewesen wären. Ein Novum war auch die lautstarke und volatile öffentliche Meinung, vor allem in Teheran, die sich nun über eine florierende Presselandschaft, Proteste und Demonstrationen, aber auch eine kaum zu überschauende und ständig wechselnde Landschaft von Interessengruppen und politischen Gruppierungen Ausdruck verschaffte. ${ }^{10}$ In den Provinzen wiedererstarkten die Großgrundbesitzer, die aufgrund ihres Einflusses auf die Wahlen auch die Zusammensetzung des Mağles bestimmten. Die unter Rezā Šāh erzwungenen Säkularisierungsmaßnahmen wurden größtenteils aufgehoben, eine ostentative Rückkehr zur Religiosität und die Restituierung der verstaatlichten

\footnotetext{
${ }^{7}$ Vgl. LouIs, Empire in the Middle East, S. $311 \mathrm{ff}$.

${ }^{8}$ Zum deutschen Propagandacoup siehe HIRSCHFELD, Deutschland und Iran, S. 242f.; zu den Kaukasusplänen der Briten und Franzosen zwischen 1939 und 1941 vgl. OsBORn, Operation Pike.

9 Vgl. FAWCETT, Iran and the Cold War, S. $141 \mathrm{ff}$.; offenbar wurde von britischer Seite kurzzeitig eine Wiedereinsetzung der ehemaligen Dynastie der Ġāğāren (1794-1925) erwogen, dann aber wieder verworfen. Der Ex-Schah wurde ins Exil nach Mauritius gezwungen und verstarb 1944 in Südafrika. Siehe WILBER, Riza Shah Pahlavi, S. 215-23; BAKHASH, Abdication of Reza Shah.

${ }^{10}$ Zum politischen System Irans in dieser Zeit Vgl. AZIMI, Crisis, S. 5-31.
} 
Ländereien machten den schiitischen Klerus einmal mehr zu einem nicht zu unterschätzenden Machtfaktor. ${ }^{11}$ Außerhalb der Hauptstadt wurden zentrifugale Kräfte spürbar. Die unter der Diktatur zwangsangesiedelten Nomadenstämme gaben teilweise ihre Sesshaftigkeit auf und kehrten zu ihrer herkömmliche Lebensweise zurück. Von den nationalen Minderheiten wie z.B. Aserbaidschanern, Kurden oder Arabern wurden Rufe nach kultureller Autonomie und Anerkennung ihrer Sprachen als gleichberechtigte Amtssprachen laut. ${ }^{12}$

Hauptnutznießer der Schwächung des Hofes im internen Machtgefüge Irans waren das Parlament sowie der Ministerpräsident, die ihre bisherige Rolle als Befehlsempfänger des Schahs schnell ablegten. Nicht zuletzt die im Gegensatz zu anderen nahöstlichen Ländern vorhandene parlamentarische Tradition erleichterte es dem 13. Mağles, die ihm in einer konstitutionellen Monarchie zugedachten Funktionen zu übernehmen. Die wichtigste Figur neben dem Schah im sich neu formierenden politischen System Irans wurde nun der Ministerpräsident, der jetzt vorrangig dem Mağles und nicht mehr dem Monarchen verantwortlich war, und bald begann, eine eigenständigere und auch aktiv politikgestaltende Rolle zu spielen. Geschickte Politiker wie Ahmad Ġawām, bekannter unter dem Ehrentitel Ġawām as-Saltana, nutzten sowohl die Divergenzen zwischen den Alliierten, wie auch zwischen Hof und Parlament aus, um auf diese Weise an Handlungsautonomie zu gewinnen. ${ }^{13}$

Trotz all dieser Machtverschiebungen waren für Außen- und Verteidigungspolitik, aber auch für viele innenpolitischen Bereiche, die Meinungen der beiden Besatzungsmächte maßgeblich, mit denen sich jede Regierung arrangieren musste. ${ }^{14}$ Die britische Besatzungsmacht gerierte sich dabei anfangs interventionistischer als die sowjetische, offenkundig mit der Absicht, die historisch dominante Stellung in Iran wiederzubeleben, dabei über die bereits vor der Okkupation gegebene finanzielle Abhängigkeit Irans von Einnahmen aus der Ölförderung der Anglo-Iranian Oil Company (AIOC) hinausreichend. ${ }^{15}$ Der US-amerikanische Gesandte Louis Dreyfus äußerte den Verdacht, dass Großbritannien die eigene Rolle als Besatzungsmacht zur Einsetzung einer ,puppet government“ in Iran auszunutzen gedachte. ${ }^{16}$ Nur wenig mehr

\footnotetext{
${ }^{11} \mathrm{Zu}$ den 'olamā nach 1941 siehe YAZDI, Clerical Behavior.

${ }^{12}$ Locus Classicus immer noch COTTAM, Nationalism in Iran, S. 110-133; zu Aserbaidschan siehe auch FAWCETT, Iran and the Cold War, S. 5-36; ATABAKI, Azerbaijan.

${ }^{13} \mathrm{Zu}$ Gawām grundlegend KaUZ, Politische Parteien; vgl. MiLAnI, Eminent Persians: I, S. 158-64.

${ }_{14}$ Zum sich wandelnden politischen System Irans siehe immer noch ABRAHAMIAN, Two Revolutions, S. 170-6; AzIMI, Crisis, S. 5-31.

${ }^{15}$ FAWCETT, Iran and the Cold War, S. 146f., zufolge waren wenigstens sechs von zehn während der Besatzung amtierenden Ministerpräsidenten eindeutig pro-britisch eingestellt.

${ }^{16}$ Vgl. ebd., S. 113; , ,puppet government“" in Tehran \#375, 14.11.42, FRUS 42, IV, S. 196; resolutes britisches Vorgehen gegen die Aktivitäten einer vermuteten „Fünften Kolonne“ unter Beteiligung zahlreicher höhergestellter Offizieller, darunter der spätere Ministerpräsident Fazlollāh Zāhedi und einer der Anführer der Gašğāi Konföderation, Nāser Xān (Mohammad Nāser Gašğà $\left.{ }^{\prime} i\right)$, hatte im Dezember 1942 zu Hungerunruhen in Teheran geführt, deren brutale Niederschlagung durch Militär und Polizei über 20 Tote und nahezu 700 Verletzte forderte. Vgl. KAUZ, Politische Parteien, S. 68-77; in einer scharf gehaltenen diplomatischen Note beschwerten sich die USA über das britische Vorgehen. Siehe State \#6280, 11.12.42, FRUS 42, IV, S. 214-7; den frühen angloamerikanischen Konflikt herunterzuspielend KuniHOLM, Origins, S. 154f.; für eine Studie, die den Wettbewerb zwischen Großbritannien und den USA in der Region in den Mittelpunkt stellt und die sowjetische Rolle dagegen nahezu komplett ignoriert, siehe WATRIN, Machtwechsel; ähnlich DAVIS, Contested Space; und ders., New
} 
Vertrauen brachte man dem sowjetischen Vorgehen entgegen. Zwar zeigte man in Moskau vorerst wenig Interesse an den politischen Auseinandersetzungen in der iranischen Hauptstadt. Allerdings hatten die sowjetischen Maßnahmen den Effekt, die eigene Zone in den Nordprovinzen gegenüber dem Rest des Landes abzuschotten, dabei den Einfluss der Zentralregierung schrittweise vermindernd. Was oberflächlich als Verzicht auf direkte Einmischung erschien, beförderte in der Realität das Entstehen regierungskritischer und teilweise sozialrevolutionärer bzw. reformistischer Bewegungen mit der, durchaus auch in Teheran registrierten Aussicht, diese zu einem späteren Zeitpunkt zur Einflussnahme auf das politische Geschehen in Teheran zu benutzen. ${ }^{17}$

Aus iranisch-nationalistischer Perspektive musste britisches wie sowjetisches Vorgehen gleichermaßen bedrohlich erscheinen. Ohnmächtig angesichts der zunehmenden Probleme und besorgt über eine denkbare Neuauflage der Absprache von 1907, also einer erneuten Aufteilung Irans in sowjetische und britische Interessensphären, griffen die strategischen Eliten auf die bewährte außenpolitische Strategie des „positiven Gleichgewichts“ (mowāzane-je mosbat) zurück, der Involvierung einer dritten Macht mit dem Ziel, die eigene Unabhängigkeit zu wahren. ${ }^{18}$ Ein erster Erfolg dieser Strategie war der Abschluss des sogenannten „Tripartite Treaty“ vom 29. Januar 1942, zustande gekommen aufgrund amerikanischen Drängens, im Zuge dessen sich die Besatzungsmächte verpflichteten, die territoriale Integrität, Souveränität und Unabhängigkeit Irans zu achten sowie, aus iranischer Sicht zweifelsfrei der zentrale Punkt, spätestens sechs Monate nach Kriegsende ihre gesamten Truppen abzuziehen. ${ }^{19}$ Enttäuschend aus iranischer Sicht war aber die Weigerung der Roosevelt-Administration, einen Beitritt der USA zu dem Abkommen in Erwägung zu ziehen, da ein solcher als amerikanische Garantie iranischer Souveränität hätte interpretiert werden können. ${ }^{20}$ Trotz dieser Zurückhaltung gewann die amerikanische Haltung im Laufe des Krieges zunehmend an Bedeutung. Ein gewichtiger Faktor war die sich aus Kriegsnotwendigkeiten ergebende, im Dezember 1942 im Rahmen des Persian Gulf Service Command (ab Dezember 1943 Persian Gulf Command) einsetzende amerikanische Truppenpräsenz in Iran, die zu ihrem Höhepunkt etwa 30.000 Mann

Trusteeship, der die anglo-amerikanischen Gegensätze in Iran während des Kriegs mit großem Nachdruck betont und diese als eigentlichen Auslöser der späteren Konfrontation mit der UdSSR sieht.

${ }^{17}$ Vgl. Kuniholm, Origins, S. 144f.; Lytle, Origins, S. 39f.; FAWCETT, Iran and the Cold War, S. 88f.; die allgemeine Kriegssituation und insbesondere die Eingriffe der Alliierten in das Wirtschaftsleben mittels Anheizen der Inflation und Requirierung von Teilen der Ernte brachten das Land mehrfach an den Rand einer Hungersnot. Vgl. MCFARLAND, Crises in Iran, S. 137ff.; im November/Dezember 1942 gab es auch erste Konflikte mit Moskau. Ein amerikanischer Nahrungsmittelberater der iranischen Regierung wurde von den Sowjets aus Aserbaidschan ausgewiesen, nachdem er einen Konflikt mit dem pro-sowjetischen Generalgouverneur vom Zaun gebrochen hatte. Im Anschluss folgte eine sowjetische Kampagne gegen den US-Konsul in Täbris, Bertel Kuniholm, der schließlich abberufen wurde. Siehe Tehran \#310, 24.3.43, FRUS 43, IV, S. 347f.; vgl. KAUZ, Politische Parteien, S.100f., ABRAHAminn, Two Revolutions, S. 198; Kuniholm Letter, 27.3.43, Post Records, Iran 1942-1944, 800 Conditions in Azerbaijan, RG 84, NACP; vgl. RoOSEVELT JR., For Lust of Knowing, S. 227; ein Überblick über die alliierten Beziehungen in Iran bei MARK, Allied Relations.

${ }^{18}$ Siehe Katouzian, Struggle for Power, S. 56f.; RAmaZAni, Iran's Foreign Policy, S. 70ff.

19 Der Vertragstext ist abgedruckt in DMYTRYSHYN/COX, Soviet Union and the Middle East, S. 360-5; zur Entstehungsgeschichte siehe RAMAZANI, Iran's Foreign Policy, S. 45-53; LyTLE, Origins, S. 22f.; FAWCETT, Iran and the Cold War, S. 110; KunIHOLM, Origins, S. 142f.

${ }^{20}$ Vgl. Tehran \#260, 19.12.41, in: AlEXANDER/NANES, United States and Iran, S. 80f.; die Briten gaben zu verstehen, dass sie eine US-Beteiligung ablehnten. Siehe zusätzlich RUBIN, Great Powers, S. 74-8. 
umfasste. Der Transport kriegswichtiger Lend-Lease-Lieferungen an die Sowjetunion durch den „Persischen Korridor“ ermöglichte eine überlebenswichtige, häufig als kriegsentscheidend eingeschätzte Versorgung der UdSSR. ${ }^{21}$ Zugleich etablierte er die USA als wichtigen Faktor in der iranischen Politik. Die Präsenz einer großen Zahl von GIs auf iranischem Territorium zog allerdings auch das vormals verklärte Image der USA etwas in Mitleidenschaft, nicht zuletzt da sich die Amerikaner fortwährend weigerten, die mit der Truppenstationierung zusammenhängenden rechtlichen Fragen zu regeln. In der Zukunft der beiderseitigen Beziehungen sollte die Frage eines Stationierungsabkommen 20 Jahre später noch eine geschichtsmächtige Rolle spielen. ${ }^{22}$

Erfolgreicher zeigte sich die iranische Strategie des ,positiven Gleichgewichts“ in der Frage der Anwerbung amerikanischer Berater, dem Vorbild der 1910er und 1920er Jahre nacheifernd. Innerhalb des U.S. State Departments machte sich insbesondere der Leiter der Division of Near Eastern Affairs (NE) ${ }^{23}$, Wallace Murray, für eine positive Antwort auf die iranischen Anfragen stark und es gelang ihm, Secretary of State Cordell Hull zu überzeugen. Murray, gleichermaßen anti-sowjetisch und anti-britisch eingestellt, hatte schon seit längerem für eine prononciertere Rolle der Vereinigten Staaten in Iran geworben, und hoffte mittelfristig auf eine ,dominante Rolle“ der USA in Iran. ${ }^{24}$ Im Laufe des Jahres 1942 trafen die ersten amerikanischen Berater ein. Arthur C. Millspaugh kehrte an der Spitze einer Finanzmission in den Iran zurück mit dem Auftrag, die iranischen Staatsfinanzen zu reorganisieren. Ausgestattet mit außerordentlichen Vollmachten wurde Millspaugh rasch zu einem bedeutenden Faktor in der iranischen Innenpolitik. ${ }^{25}$ Langfristig von größerer Bedeutung, da über das Kriegsende hinaus im Land verbleibend, waren die nach ihren Leitern benannten Ridley und Schwarzkopf-Missionen zur Unterstützung von Armee und Gendarmerie, die Ende 1942 ihre Arbeit aufnahmen. ${ }^{26}$ Zusätzlich war Iran bereits im März 1942 zum Empfängerland für Unterstützung im Rahmen des Lend-Lease-Programms erklärt worden und wurde somit formell als „vital für die Verteidigung der Vereinigten Staaten“ deklariert. ${ }^{27}$

\footnotetext{
${ }^{21}$ Zur Entstehungsgeschichte siehe MOTTER, Persian Corridor, S. 175-209; MACRIS, Persian Gulf Theater; vgl. jetzt JACKSON, Persian Gulf Command.

${ }_{22}$ Vgl. Alling Memo, 26.1.43, in: AlEXANDER/NANES, United States and Iran, S. 129; zu den Verhandlungen siehe RAMAZANI, Iran's Foreign Policy, S. 57-60; MOTTER, Persian Corridor, S. 437-47.

${ }^{23}$ Die Division of Near Eastern Affairs (NE) war der Nachfolger der älteren Near Eastern Division. Sie war nicht nur für den Nahen und Mittleren Osten zuständig, sondern zusätzlich für Afrika und den indischen Subkontinent. Eine administrative Reform vom Januar 1944 ersetzte die Division durch das Office of Near Eastern and African Affairs (NEA). NEA waren nun drei geografische Divisionen unterstellt (Division of Near Eastern Affairs; Division of Middle Eastern Affairs; Division of African Affairs). Murray wurde erster Direktor der neu geschaffenen Abteilung. Siehe KuniHOLM, Origins, S. 186f., 433; BARAM, Department of State, S. $67 \mathrm{ff}$.

${ }_{24}$ MemCon, 10.11.42, FRUS 42, IV, S. 190; Murray Memo, 3.8.42, in: ebd., S. $242 \mathrm{f}$.

${ }^{25}$ Millspaugh schilderte seine Erlebnisse in Iran in seinem Buch Americans in Persia; vgl. CoTTAM, Iran and the United States, S. 63.

${ }^{26}$ Major General Clarence S. Ridley leitete die Armeemission, Oberst H. Norman Schwarzkopf Sr., Vater des späteren Kommandeurs der Streitkräfte der multinationalen Golfkriegsallianz von 1990/91, die GendarmerieMission. Zu den Militärmissionen siehe LyTLE, Origins, S. 27-30; ausführlich MoTTER, Persian Corridor, S. 163173, 461-80; RicKS, U.S. Military Missions.

${ }^{27}$ Roosevelt Memo, 10.3.42, FRUS 42, IV, S. 289.
} 
Das anfängliche Desinteresse und die ostentativ zu Schau gestellte Äquidistanz der USA wich alsbald einer Neudefinition der eigenen Rolle in Iran. Häufig zitiert in diesem Zusammenhang wird ein programmatisches Memorandum vom Januar 1943, verfasst von John D. Jernegan, dem Iranian Desk Officer in NE. Der idealistisch eingestellte, erst 31-jährige Jernegan definierte Iran als einen „Test Case“ für die Prinzipien der Atlantik-Charta, als Fallbeispiel für die fortgesetzte Kooperation zwischen den Mächten der Anti-Hitler-Allianz im Anschluss an die erfolgreiche Beendigung des Krieges. Geographische Realitäten und historische Rivalität zwischen Großbritannien und der UdSSR machten ein Ausbrechen neuer Konflikte gerade an diesem Ort wahrscheinlich, was, so lehre die Geschichte, fast zwangsläufig entweder zur Errichtung einer dominanten Position einer Großmacht in Iran oder, alternativ, zur Aufteilung des Landes in Interessensphären führen werde, inklusive nahezu ,vollständiger Negation iranischer Souveränität und Unabhängigkeit.“ Aufgehoben werden könne dieses Dilemma einzig durch die bewusste und aktive Annahme einer „Third Power Role“ seitens der USA, als unabhängiger und altruistisch motivierter Vermittler und Schlichter zwischen Moskau und London: „In this connection, it seems hardly possible that either could suspect the United States of having imperialistic designs in a country so far removed from us and where we could never hope to employ military force against an adjacent Great Power. “28 Vernachlässigt wurde von Jernegan eine Klärung, ähnlich bereits wie bei der Entsendung der Beratermissionen, was denn konkret die Stärkung der Zentralregierung angesichts der ausgeprägten Fragmentierung des politischen Lebens in Iran bedeuten solle und ob man nicht früher oder später eine Antwort auf die Frage finden müsse, welche der politischen Kräfte in Teheran unterstützungswürdig seien und welche nicht. Ungeachtet dieser offenen Fragen verteilte Murray das Memorandum innerhalb des State Department als autoritative Zusammenfassung des Standpunktes der Nahostabteilung. Im August 1943 präsentierte Secretary of State Hull Präsident Roosevelt eine komprimierte Version. ${ }^{29}$

Roosevelt selbst war diesen Gedankengängen gegenüber durchaus aufgeschlossen. Major General Patrick J. Hurley, von Roosevelt im März 1943 als Sonderbevollmächtigten in den Nahen und Mittleren Osten entsandt, sekundierte den Vorschlägen des State Departement für eine aktivistische Iranpolitik. ${ }^{30}$ Der Präsident wiederum erklärte sich ,[[...] thrilled with the idea of using our efforts in Iran as an example of what can be done by an unselfish American policy.“31 Der sich abzeichnende neue Aktivismus der US-Außenpolitik blieb jedoch nicht

\footnotetext{
${ }^{28}$ State \#202, 13.3.43, enclosed: Jernegan Memo, 23.1.43, in: ALEXANDER/NANES, United States and Iran, S. 94; auch in FRUS 43, IV, S. 330-6; vgl. MARK, Allied Relations, S. 51f., KuniHOLM, Origins, S. 156ff.; COLLIER, Nature of Influence, S. 18, sieht entgegen der Quellenlage bereits 1941 ,,enormous leverage“ der USA.

${ }^{29} \mathrm{Zu}$ den Auswirkungen siehe LYTLE, Origins, S. 43-6; Hull Memo, 16.8.43, FRUS 43, IV, S. $377 \mathrm{ff}$.

${ }^{30}$ Vgl. Hurley Message, 13.5.43, ebd., S. 363-70; vgl. KuniHOLM, Origins, S. 148f.

${ }^{31}$ Roosevelt Letter, 25.3.44, 711.91/3-645, CF 45-49; einige der konkreten Vorschläge seines Emissärs wurden umgesetzt, wie z.B. im Februar 1944 die Umwandlung der Gesandtschaft in eine vollwertige Botschaft. Erster Botschafter in Iran wurde Leland Morris, der weitsichtige Gesandte Louis Dreyfus hingegen wurde aus Iran abgezogen. Zumindest teilweise ein Resultat der Empfehlungen Hurleys war die Aufnahme Irans in das Kriegsbündnis der Vereinten Nationen. Iran erklärte dem Deutschen Reich am 9.9.43, Japan am 1.3.45 den Krieg. Vgl. RamaZANI, Iran's Foreign Policy, S. 60-2.
} 
gänzlich ohne Widerspruch. Dean Acheson, zu dieser Zeit Assistant Secretary of State, warnte vor Hurleys Plänen, die ,[...] easily turn out to be more than an innocent indulgence in messianic globaloney“، ${ }^{32}$ Derartige Warnungen aber verhallten ohne Effekt - die Aufwertung der amerikanischen Iranpolitik war nun in vollem Gange, zumal man sich in Washington schrittweise der wachsenden Eigeninteressen an der Region bewusst wurde. Bereits im August 1943 hatte Hull betont, ,[...] that no great power be established on the Persian Gulf opposite the important American petroleum development in Saudi Arabia.“33 Zugleich wuchs innerhalb der Roosevelt-Administration die Aufmerksamkeit für das ansteigende ökonomische Interesse der USA an Iran selbst.

Lange vernachlässigt hat die historische Forschung die geheimdienstliche Dimension des Konflikts zwischen den Mächten im iranischen Kontext. Parallel zu dem wachsenden Interesse an der Nahostregion baute der US-Geheimdienst, das Office of Strategic Services (OSS), seine Präsenz in Iran aus, bis Kriegsende auf 29 Agenten, die wiederum ein Netz von über 500 Informanten abschöpften. ${ }^{34}$ In Iran rekrutierte das OSS mit dem Land vertraute Amerikaner, hauptsächlich aus der akademischen Welt und aus den Reihen der Familien christlicher Missionare. ${ }^{35}$ Leiter der OSS-Vertretung in Iran war Joseph M. Upton, ursprünglich Kurator am Metropolitan Museum of Art in New York, dessen Tarnung als Ausgrabungsleiter vielfältige Möglichkeiten zu Erkundungsreisen im Land bot. Sein Stellvertreter ab Ende 1942 war Donald N. Wilber, ein junger Orientalist und späterer Mitorganisator des Staatsstreichs von 1953 gegen Ministerpräsident Mosadde. ${ }^{36}$ Ursprünglich darauf gerichtet, Verteidigungsmaßnahmen gegen ein mögliches Vordringen der Deutschen zu unterstützen, war es in der Folgezeit das Ziel der OSS, jede Art von Informationen über die wirtschaftliche und soziale Struktur Irans zu sammeln. Gegen Kriegsende richtete sich das Hauptaugenmerk jedoch auf sowjetische Ambitionen und auf britische Versuche, ,die Nachkriegsmärkte in Iran zu kontrollieren“. Upton und Wilber wie auch andere Agenten wie Taylor Gurney, engagierten sich zugleich stark für den Aufbau kultureller Kontakte zwischen Iranern und Amerikanern wie z.B. mittels der zu dieser Zeit gegründeten Iran-America Relations Society. ${ }^{37}$ Sowohl die auswärtige Kulturpolitik der USA in Iran wie auch die frühe wissenschaftliche Beschäftigung

\footnotetext{
${ }^{32}$ Das von Clare Boothe Luce geprägte Portmanteau-Wort „Globaloney“ kann als „globaler Unsinn“ übersetzt werden. Zit. aus Kuniholm, Origins, S. 170.

${ }^{33}$ Hull to Roosevelt, 16.8.43, FRUS 43, IV, S. 378.

34 Siehe OfFICE OF STRATEGIC SERVICES, Overseas Targets War Report, S. 47, 53; diese offizielle Geschichtsschreibung wurde unter der Leitung von Kermit Roosevelt erstellt, selbst OSS-Veteran und später Mitorganisator des Staatsstreiches von 1953 in Iran. Siehe dessen Vorwort in ebd., S. vii-xix; eine Einschätzung der Langzeitfolgen des amerikanischen geheimdienstlichen Engagements in der Region bei LITTLE, Mission Impossible, S. $668 \mathrm{f}$.

35 Archibald Roosevelt und Donald Wilber haben über ihre OSS-Aktivitäten in Iran in Buchform berichtet. Siehe RoOSEVElT, For Lust of Knowing, S. 213-88; WILBER, Adventures; von der OSS aus dem Missionarsumfeld rekrutiert wurden z.B. Edwin Wright und Taylor Gurney.

${ }^{36}$ Siehe Crawford to Penrose, 22.6.44, und Report, ,History of the Near East Section', o.D., ,Fol. 10', OSS Records, Previously Withdrawn Material, Entry 210, Box 275, RG 226, NACP; dies sind OSS-Akten, deren Freigabe bis 1997 von der CIA verweigert worden war.

37 Vgl. WILBER, Adventures, S. $115 \mathrm{ff}$; zum Ausmaß der Operationen vgl. OSS, Overseas Targets War Report, Band 2, S. 50; GASIOROWSKI, TPBEDAMN Operation, S. 5-9; vgl. Loud (sic!) Notes, 11.-21.11.44, ,Fol. 10', OSS Records, Previously Withdrawn Material, Entry 210, Box 275, RG 226, NACP.
} 
mit iranischen Themen waren eng mit dem Aufbau eines umfangreichen geheimdienstlichen Apparates verbunden. ${ }^{38}$

Verglichen mit der geheimdienstlichen Durchdringung des Landes durch Sowjets und Briten waren diese ersten amerikanischen Operationen aber eher bescheiden. ${ }^{39}$ So unterstützten die Sowjets von Anbeginn an die sich angesichts der geschwächten staatlichen Repression in Iran nun rasch formierende Linke. So war die Gründung der neuen links stehenden Partei am 29. September 1941, bald bekannt unter dem Namen Tudeh (Massen)-Partei (Hezb-e Tude-je $\operatorname{Ir} \bar{a} n)^{40}$, mit der sowjetischen Botschaft abgestimmt, wenngleich die Partei durchaus auch auf eigenen Antrieb und teilweise gegen Moskauer Absichten handelte. Weitaus umfangreicher war vermutlich die britische geheimdienstliche Präsenz. Die Kriegsjahre wurden offenbar genutzt, um ein umfangreiches Netzwerk innerhalb der politisch einflussreichsten Schichten und Institutionen in Iran zu errichten. ${ }^{41}$ Zentrale Akteure des pro-britischen Netzwerkes waren die drei Brüder Asadollah, Godratollah und Sejfollah aus der Rašidijān-Familie, die, nicht zuletzt durch Ausnutzen ihrer britischen Kontakte, zu den erfolgreichsten Geschäftsleuten in Iran mit engen Kontakten zu Basar, Hof und Mağles, aufstiegen. ${ }^{42}$ Zugleich förderten die Briten den Politiker Sejjed Zijāe ad-Din Tabātabāe ${ }^{e} i$ und seine „Partei des Nationalen Willens“ (hezb-e erāde-je melli), die zu einem der wichtigsten Gegenspieler der Tudeh wurde. ${ }^{43}$

Vor dem Hintergrund des wachsenden Interesses der großen Mächte war Iran sodann Schauplatz einer der großen Kriegskonferenzen, zuvorderst bedingt durch die günstige geographische Lage für ein solches Treffen. Die Zukunft Irans selbst spielte allerdings so gut

\footnotetext{
${ }^{38}$ Sowohl Upton wie Wilber schrieben später häufig zitierte Standardwerke zur Geschichte Irans. Siehe UPTON, History of Modern Iran; Wilbers Überblick erreichte sogar neun Auflagen. Siehe WILBER, Iran: Past and Present; Wilber arbeitete bis zu seinem Ruhestand 1969 für die CIA.

39 Angeblich gab es 115 operativ tätige sowjetische Geheimdienstoffiziere allein in der Teheraner Botschaft während des Kriegs. Vgl. ANDREW/MITROKHIN, Mitrokhin Archive II, S. 169; bereits 1944 wurde der Offizier und spätere General Ahmad Mogarribi rekrutiert (1977 vom SAWAK entdeckt und später hingerichtet). Vgl. ebd., S. $178 \mathrm{ff} ., 533$ n39; eine andere Quelle spricht von einem anderen rekrutierten iranischen General ("Ali Akbar Deraxšanni), der allerdings bereits 1946 pensioniert worden sei. Vgl. KUZICHKIN, Inside the KGB, S. 222.

${ }^{40}$ Zur Geschichte der Tudeh-Partei siehe als locus classicus immer noch ABRAHAMIAN, Two Revolutions, S. 281415; zudem SCHIRAZI, Modernität; vgl. auch ZABIH, Communist Movement; BEHROOZ, Rebels With a Cause; BAYAT, Workers and Revolution; zum sowjetischen Beitrag zur Gründung vgl. CHAQUERI, Did the Soviets, S. 523; für allgemeine Einschätzungen der Rolle der Linken in der iranischen Geschichte des 20. Jahrhunderts CRONIN, The Left in Iran; MATIN-ASGARI, Twentieth-Century Odyssey.

${ }^{41}$ Genauere Informationen über die Tätigkeit von MI6 und der Special Operations Executive (SOE) im Nahen und Mittleren Osten wurden erst in den letzten Jahren verfügbar. Siehe KELLY, Succession of Crises; Schlüsselrollen spielten dabei die Orientalisten Robin Zaehner, Presseattaché zwischen 1943 und 1947, und Ann K. S. (Nancy) Lambton, ebenfalls Presseattaché während des Krieges. Letztere veröffentlichte nach ihrer Rückkehr in die akademische Welt das Standardwerk Landlord and Peasant; während der Ölkrise von 1951-53 waren ihre Ansichten innerhalb des Foreign Office weiterhin einflussreich. Siehe LouIs, Britain and the Overthrow, S. 130f., 136ff.; zu Zaehner siehe ebd., S. $131 \mathrm{ff}$.

${ }^{42}$ Siehe hierzu AzIMI, Unseating Mosaddeq, S. 43f.; für eine Einschätzung der Brüder siehe zusätzlich BILL, Eagle and Lion, S. 91.

${ }^{43}$ Sejjed Zijāé, zusammen mit Rezā Xān Mitorganisator des Putsches von 1921 und im Machtkampf mit diesem unterlegen und ins Exil getrieben, war im September 1943 nach Iran zurückgekehrt, und galt als ausgesprochen pro-britisch. Vgl. KeDDIE, Roots of Revolution [1981], S. 87f.; LoUIS, Britain and the Overthrow, S. 140; FAWCETT, Iran and the Cold War, S. 150; zur britischen Propagandastrategie vgl. ABDUL-RAZAK, Manipulation; die amerikanische OSS war an Informationen gelangt, dass Sejjed Zijā's s Partei durch die Rašidijān-Brüder finanziert wurde. Siehe ,Eliot Grant' \{Donald Wilber\} Letter, 14.6.43, ,Folder 14“, OSS Records, Previously Withdrawn Material, Entry 214, Box 3, RG 226, NACP.
} 
wie keine Rolle auf dem Treffen. Am Ende der Konferenz der „Großen Drei“ in Teheran einigten sich Roosevelt, Churchill und Stalin immerhin auf eine gemeinsame Erklärung über Iran. Die Declaration of the Three Powers Regarding Iran vom 1. Dezember 1943 wiederholte im Kern die Bestimmungen des Tripartite Treaty vom Januar 1942, erweitert um eine unbestimmt gehaltene Zusage wirtschaftlicher Unterstützungsmaßnahmen nach Kriegsende. Exakte Bestimmungen zum alliierten Truppenabzug waren aber nicht enthalten, wohl aber eine Bekräftigung der vorherigen Garantien bezüglich der Unabhängigkeit, Souveränität und territorialen Unversehrtheit Irans. Die Deklaration hatte somit weitestgehend symbolischen Charakter. Aus iranischer Sicht war sie aber gerade aufgrund der Tatsache wertvoll, dass nunmehr die Vereinigten Staaten zum ersten Mal öffentlich eine Verpflichtung gegenüber Iran eingegangen waren. ${ }^{44}$

Die Glaubwürdigkeit dieser neuen Garantie sollte allerdings viel früher auf die Probe gestellt werden, als es deren Erfinder geahnt hatten. Mit der nun absehbaren erfolgreichen Beendigung des Kriegs gegen Deutschland und Japan drängten bei allen Mächten Fragen in den Vordergrund, wie die globale Nachkriegsordnung zu gestalten sei. Im Grunde kann es im Rückblick wenig überraschen, dass es gerade in jenem Land, in dem alle drei ,großen“ Mächte eigene Truppen stationiert hatten, zu einem der ersten ernsthaften Konflikte über die zukünftige Verteilung von Macht und Einfluss kam. Das verstärkte Interesse der USA an der Region ging einher mit der Adaption einer neuen, strategisch orientierten Sichtweise der Bedeutung des Gesamtraumes für die eigenen Sicherheitsinteressen. Während es durch das Entgegenkommen der britischen Seite gelang, die anfänglich scharfe Konkurrenz zwischen den angelsächsischen Mächten rasch in - wenngleich „kompetitive“ - Kooperation zu verwandeln, zeigte sich bereits 1944, dass eine gleichzeitige Abstimmung mit den strategischen Interessen der Sowjetunion aus amerikanischer Sicht schwierig, potentiell sogar unerwünscht war.

Ausgangspunkt war erneut die iranische Strategie des mowāzane-je mosbat, des ,positiven Gleichgewichts“. Um die britische Dominanz in Iran nach Kriegsende zu verhindern, war es wünschenswert, ein fortgesetztes Interesse der USA zu erzeugen. Naheliegend war es daher, das Interesse amerikanischer Ölgesellschaften an einer Konzession in Iran zu diesem Zweck zu instrumentalisieren. ${ }^{45}$ Bereits im Februar 1943 hatten iranische Stellen ein amerikanisches

\footnotetext{
${ }^{44}$ Zur Konferenz von Teheran vgl. RamaZAni, Iran's Foreign Policy, S. 62-69; LyTLE, Origins, S. 55-8; der Text der Deklaration ist abgedruckt in FRUS 43, IV, S. 413ff.; auch in ALEXANDER/NANES, United States and Iran, S. 142f.; noch zwei Jahre zuvor war seitens des State Departments jedwede Verpflichtungserklärung zugunsten der Unabhängigkeit Irans als ,,unangemessen“" und ,abträglich“ bezeichnet worden. Siehe MemCon, 23.3.42, in: ebd. S. 84f.; auf der Konferenz von Teheran hatte Roosevelt Stalin den Vorschlag unterbreitetet, ein internationales „Trusteeship“ in Iran einzurichten, das die Treuhandschaft über die Trans-Iranische Eisenbahn für die gesamte Strecke vom Persischen Golf bis zur sowjetischen Grenze übernehmen könnte und darüber hinaus einen gemeinsam verwalteten Freihafen am Persischen Golf angeregt. Vgl. Roosevelt Memo, 8.12.44, FRUS 44, V, S.483; vgl. LyTLE, Origins, S. 56 f.

${ }^{45}$ Rezā Sāh hatte 1932 die ursprüngliche d’Arcy-Konzession von 1901 unilateral aufgekündigt, um die AngloPersian Oil Company zu Neuverhandlungen zu zwingen. Eines der Ergebnisse des 1933 ausgehandelten Kompromisses war die Reduzierung des Konzessionsgebiets um drei Viertel, was die - zumindest theoretische Möglichkeit eröffnete, andere Gesellschaften mit der Exploration in diesen Gebieten zu beauftragen. Die
} 
Ölunternehmen kontaktiert. Bald sprachen auch Repräsentanten der vorwiegend britisch kontrollierten Royal Dutch-Shell in Teheran vor, im März 1944 gefolgt von einer zweiten USGesellschaft. Angesichts der Attraktivität einer iranischen Ölkonzession gab man seitens der USA rasch die zuvor praktizierte Zurückhaltung auf und unterstützte die amerikanischen Unternehmen mit Nachdruck ,to gain this rich prize for American interests“, so die Wortwahl des amerikanischen Geschäftsträgers Richard Ford. ${ }^{46}$ Dabei schreckte man selbst nicht mehr davor zurück, die Unabhängigkeit der eigenen Beratermissionen aufs Spiel zu setzen, die nun dazu benutzt wurden, die Entscheidung der iranischen Regierung bei der Konzessionsvergabe zum eigenen Vorteil zu beeinflussen. ${ }^{47}$ Trotz sowjetischer Warnungen lehnte das State Department die Einbeziehung bzw. Konsultation der UdSSR in Erdölfragen, wie auch die Beteiligung an den parallel stattfindenden strategischen britisch-amerikanischen Ölverhandlungen in London, ab. ${ }^{48}$

Angesichts der nun offen ausgetragenen Konkurrenz amerikanischer und britischer Ölgesellschaften in Iran schien aus sowjetischer Sicht der Zeitpunkt gekommen, die eigenen Nachkriegsinteressen abzusichern. Im September 1944 erschien eine hochrangige sowjetische Delegation in Teheran, angeführt vom Vizekommissar für Auswärtige Angelegenheiten, Sergej Kavtaradze mit der Forderung eines sowjetische Exklusivrechts zur Ölexploration in einem 200.000 Quadratkilometer umfassenden Gebiet, das sich entlang der gesamten iranischsowjetischen Grenze von Xorāsān bis Aserbaidschan erstreckte. ${ }^{49}$ Angesichts der unerwarteten Beteiligung der Sowjetunion am Wettstreit um das (verbliebene) iranische Öl entschlossen sich London und Washington für einen Kurswechsel. Nunmehr unterstützten beide Mächte die Verschiebung sämtlicher Konzessionsverhandlungen auf die Zeit nach Kriegsende, wenngleich nicht völlig geklärt ist, ob und wie die Entscheidung des iranischen Kabinetts unter Ministerpräsident Săed von den anglo-amerikanischen Mächten beeinflusst worden war. So erfreut man auf britischer Seite über die neue amerikanische Unterstützung im Nahen und Mittleren Osten war, meldeten sich dennoch kritische Stimmen in London. Angesichts der parallel stattfindenden anglo-sowjetischen Verhandlungen in Moskau über die südosteuropäische Nachkriegsordnung wollte man eine Konfrontation und machtpolitischen Wettbewerb eigentlich vermeiden. Andererseits waren ja gerade diese Verhandlungen darauf gerichtet, durch eine Abgrenzung von Interessensphären eine zukünftige Bedrohung der

ursprüngliche d'Arcy-Konzession hatte ganz Iran mit Ausnahme der fünf an das Zarenreich grenzenden nördlichen Provinzen umfasst.

${ }^{46}$ Tehran \#577, 4.8.44, FRUS 44, V, S. 452; die US-Gesellschaften waren Standard Vacuum Oil Company (Stanvac) und die Sinclair Oil Company.

${ }_{47}$ Vgl. LytLe, Origins, S. 82-6; PFAu, Origins of Partnership, S. 182f.; Hinweise auf geheimdienstliche Beeinflussung des Bieterverfahrens in Houck (SSU) Memo, 20.5.46, ,Chrono, May 20, 1946'. OSS Records, Previously Withdrawn Material, Entry 210, Box 477, RG 226, NACP.

${ }^{48}$ Vgl. Tehran \#527, 23.7.44; State \#453, 27.7.44, FRUS 44, V, S. 342f.; offenbar verhandelten Briten und Amerikaner aber in erster Linie um eine mögliche Konzession in Balučestān, der südöstlichen Provinz Irans. Vgl. auch LYTLE, Origins, S.76, 86.

${ }_{49}$ Vgl. Tehran \#728, 2.10.44; Tehran Telegram \#737, 7.10.44, FRUS 44, V, S. 453ff.; unmittelbar nach der Besetzung Irans hatten die Sowjets bereits alte Ansprüche auf eine Nutzung der sog. Khostaria-Konzession aus dem Jahr 1925 in der kawir-e xorjān nahe Semnān wiederbelebt. 
eigenen Kommunikationslinien im Nahen und Mittleren Osten möglichst auszuschließen. Im Prinzip machte es daher wenig Sinn, die eigene politische Vormachtstellung in Griechenland gegenüber Stalin abzusichern und gleichzeitig weiter östlich eine sowjetische Penetration Irans widerstandslos hinzunehmen. Die Mahnungen des Botschafters Reader Bullard aus Teheran, bei Akzeptanz eines sowjetischen Festsetzen sei man letztlich ,worse off than under the 1907 agreement", überzeugte schließlich Außenminister Anthony Eden. ${ }^{50}$ In einer Vorwegnahme der gängigen Muster des späteren Kalten Krieges kritisierten die Anglo-Amerikaner den sowjetischen Druck auf die Zentralregierung als analog zur Politik des nationalsozialistischen Deutschlands - US-Botschafter Morris sprach von „Hitlerschen Methoden“ - und in einer konzertierten Aktion protestierten beide Mächte direkt in Moskau. Angesichts der geschlossenen Front wich Moskau zurück - das Verhältnis der drei Mächte in Iran aber blieb fortan vergiftet. ${ }^{51}$

Bedrohlich aus sowjetischer Sicht musste sicherlich erscheinen, dass man nun offenbar in Iran mit dem Widerstand einer gemeinsamen anglo-amerikanischen Front zu rechnen hatte. Dies entsprach genau dem Eindruck eines „Ganging-Up“ der anglo-amerikanischen Mächte gegenüber der Sowjetunion, den Präsident Roosevelt nur ein Jahr zuvor auf der Konferenz von Teheran durch seine wohlwollende Berücksichtigung sowjetischer Interessen zu vermeiden gehofft hatte. ${ }^{52}$ Die Ölkrise 1944 veränderte Moskaus Iranpolitik nachdrücklich. Zwar sind gewisse sowjetische Expansionsbestrebungen gen Süden belegbar, doch dominierte bis dahin die Prämisse, auf jeden Fall eine Eskalation zwischen den großen Mächten zu vermeiden. Offenbar hoffte man in Moskau lange Zeit, nach Kriegsende zusammen mit Großbritannien eine Art Kondominium über Iran ausüben zu können. ${ }^{53}$ Diese Absicht erklärt auch die Idee, in den nördlichen Provinzen ein sowjetisch-iranisches Pendant zur AIOC zu gründen und somit die britische Strategie im Süden zu kopieren. Eine solche Gesellschaft hätte in der Zukunft dazu benutzt werden können, auf die iranische Politik Einfluss zu nehmen. Zudem ließe sich so die Präsenz einer erheblichen Zahl sowjetischer Techniker und Ingenieure in Iran auch nach einem Abzug legitimieren. ${ }^{54}$ Die Lehre aus der Ölkrise aber war, dass mit einem Rückzug der Roten Armee auch jeder sowjetische Einfluss Iran verlassen würde. So warnte Sergej Kavtaradze intern im Anschluss an die Ölkrise von 1944, dass nach Abzug der sowjetischen

\footnotetext{
${ }^{50}$ Bullard to Eden, No. 978, 2.11.44, in: FOCP III, B, 9, S. 196f.; vgl. FAWCETT, Iran and the Cold War, S. 156ff.; für die britische Politik vgl. dies., Invitation.

${ }^{51}$ Vgl. State \#2566, 30.10.44; Moscow \#4190, 1.11.44, FRUS 44, V, S. 462f.; vgl. LYTLE, Origins, S. 92-5; offenbar ging die eigentliche Idee, direkt in Moskau vorstellig zu werden, von US-Seite aus. Wallace Murray erwähnte Ende Oktober die Möglichkeit gegenüber dem britischen Botschafter. Siehe Washington to Eden, No. 5809, 26.10.44, FOCP III, B, 9, S. 205; zum Nachlassen des Drucks siehe Tehran \#810, 3.11.44, und Tehran \#813, 4.11.44, FRUS 44, V, S. 466, 469; vgl. RAMAZANI, Iran's Foreign Policy, S. 99-101; KuniHolm, Origins, S. 1968; zur Reaktion der iranischen Eliten siehe AzIMI, Crisis, S. 107ff.; die Ölkrise in peri-zentrischer Sichtweise als bewusst von den iranischen Eliten provoziert interpretierend McFARLAND, Peripheral View, S. 351; die Rolle iranischer Akteure betont auch FAWCETT, Revisiting.

${ }^{52}$ Es gibt allerdings einen Hinweis darauf, dass die Sowjets ihr Vorgehen im Einklang mit Roosevelts Zusagen glaubten. So interessierte sich Kavtaradze nicht nur für eine Ölkonzession, sondern auch für einen Freihafen am Golf. Offenbar blieb dieser Sachverhalt im State Department unbemerkt. Siehe Tehran \#737, 7.10.44, FRUS 44, V, S. 454f.; vgl. Kuniholm, Origins, S. 201f.; EGorova, Stalin's Oil Policy.

${ }^{53}$ Vgl. PeChatnov, Big Three, S. 3f., 8-13.

${ }^{54}$ Siehe Yegorova, Iran Crisis, S. 2ff.; Hasanli, Dawn, S. $26 \mathrm{f}$.
} 
Truppen, die „reaktionären“ und ,pro-britischen“ Kräfte in Iran unmittelbar mit der Zerschlagung der „demokratischen Organisationen“ beginnen würden, um „unseren Einfluss und die Resultate unserer Arbeit in Iran zu eliminieren. “55

Da eine sowjetische Ölgesellschaft nicht durchgesetzt werden konnte, war daher die Etablierung pro-sowjetischer Kräfte in der iranischen Politik als Alternative naheliegend. Die sowjetisch protegierte Tudeh-Partei war zwar rasch gewachsen, doch hatte man in Moskau erhebliche Zweifel an deren Führungsriege. ${ }^{56}$ Bei den Wahlen zum 14. Mağles von November 1943 bis Februar 1944 errang die Tudeh nur acht der 53 Mandate aus der sowjetischen Zone. ${ }^{57}$ Der sowjetische Druck während der Ölkrise hatte das Ansehen Moskaus wie auch der Tudeh innerhalb Irans zudem beschädigt. Zugleich sahen die den Mağles dominierenden Schichten ihre Lebensweise durch die Verbreitung sozialrevolutionärer Ideen zunehmend bedroht und fanden zu einer gemeinsamen Position. Ausdruck der neuen Einigkeit war die Annahme eines vom Abgeordneten Mohammad Mosaddeg eingebrachten Gesetzentwurfs am 2. Dezember 1944, der jedem iranischen Offiziellen bei Androhung drakonischer Strafen untersagte, in irgendeiner Form ohne vorherige Konsultation und Zustimmung des Parlaments Verhandlungen über Ölkonzessionen zu führen. ${ }^{58}$ Eine vielversprechendere Möglichkeit, den eigenen Einfluss auch nach dem Abzug zu sichern, war die Förderung einer autonomen bzw. separatistischen Bewegung im Norden. Spannungen zwischen zentripetalen und -fugalen Kräften hatten die gesamte Geschichte des iranischen Nationalismus nachhaltig geprägt. ${ }^{59}$ Dabei setzte man insbesondere auf die ethnische Verwandtschaft der zu den Turkvölkern gehörigen Aserbaidschaner zu ihren nördlichen Nachbarn in der aserbaidschanischen Sowjetrepublik. ${ }^{60}$ Auf Drängen einer „kaukasischen Lobby“ innerhalb der sowjetischen Parteiführung beschloss das Politbüro am 6. Juli 1945, eine separatistische Bewegung im „südlichen“ Aserbaidschan und den anderen Nordprovinzen sowie in den kurdisch besiedelten Gebieten ins Leben zu rufen. ${ }^{61}$ Am 3. September 1945 erfolgte schließlich die zuvor in Moskau beschlossene Gründung einer neuen Partei in Täbris, der Demokratischen Partei Aserbaidschans (Ferge-je Demukrāt-e Āzarbājŏḡa [FDĀ]). ${ }^{62}$

\footnotetext{
${ }^{55}$ Yegorova, Iran Crisis, S. 8; vgl. FAwCETt, Iran and the Cold War, S. 93.

${ }^{56}$ General Tjulenev sprach davon, dass 19 der 21 „Präsidiumsmitglieder“ der Tudeh ,agents provocateurs“ seien. Siehe MAMOULIA, Les crises, S. 274.

${ }_{57}$ Vgl. Abrahamian, Two Revolutions, S. 198; für eine Einschätzung der Wahlen ebd., S. 186-203; KAUZ, Politische Parteien, S. 97-102.

${ }_{58}$ Aus Furcht vor unkontrollierbaren sozialen Unruhen ging die zeitweilig bestehende Mehrheit zugunsten einer Verkleinerung der Armee und der Abschaffung ihrer Sonderstellung gegenüber dem Schah verloren. Vgl. Abrahamian, Factionalism, S. 38-42; Katouzian, Struggle for Power, S. 58; KuniHolm, Origins, S. $200 \mathrm{ff}$.

${ }^{59} \mathrm{Zu}$ diesen Fragen immer noch COTTAM, Nationalism in Iran, S. 91-133.

${ }^{60}$ Zur Rolle der „,kaukasischen Lobby“ innerhalb der sowjetischen Regierungsbürokratie vgl. RAINE, Creation; ein Überblick in SHAFFER, Borders and Brethren.

${ }^{61}$ Vgl. RaINE, Creation, S. 9f.; die relevanten Dokumente sind abgedruckt in „New Evidence on the Iran Crisis 1945-46: From the Baku Archives“, in: CWIHP Bulletin 12/13 (2001), S. 310-2; MAMOULIA, Les crises, S. 27580; zu den sowjetischen Zielen vgl. FAwCETT, Iran and the Cold War, S. 97f., 162; dies., Revisiting, S. $386 \mathrm{ff}$.

62 Vgl. dies., Iran and the Cold War, S. 37-52; RAINE, Creation, S. 10-15; HASANLI, Dawn of the Cold War, S. 74-90; entgegen der Quellenlage die FDĀ als eigenständigen Ausdruck einer nationalen Bewegung betrachtend ATABAKI, Azerbaijan.
} 
Im November kam es dann zu dem seit Längerem erwarteten Aufstand. Milizverbände der FDĀ zwangen die Garnisonen der iranischen Armee sowie verbliebene Gendarmerie-Einheiten zur Kapitulation und die FDĀ übernahm die Kontrolle der Provinz. In den anderen nördlichen Provinzen unter sowjetischer Kontrolle - Gilān, Māzandarān und Xorāsān - erodierte parallel zu den Entwicklungen in Täbris in den kommenden Wochen der verbliebene Einfluss Teherans, doch kam es hier nur zu begrenzten autonomistischen Forderungen. ${ }^{63}$ Anders verhielt sich die Lage in Kurdistan. Eine seit 1942 bestehende kurdisch-nationalistische Partei unter ihrem Führer Ġāzi Mohammad wurde in Demokratische Partei Kurdistans umbenannt. Ähnlich wie die FDĀ umfassten die Forderungen der kurdischen Demokraten Autonomie für das Siedlungsgebiet der Kurden sowie die Anerkennung des Kurdischen als offizielle Sprache. Militärisch unterstützt durch den vor kurzem aus dem Irak geflohenen Teil des BārzāniStammes unter der Führung von Mollā Mostafā gelang bald die Beseitigung jeglichen Einflusses der Zentralregierung und die Etablierung einer selbstständigen Herrschaft rund um Mahābād. ${ }^{64}$ Die Autonomiebewegungen in Aserbaidschan und Kurdistan konnten zwar auf eine - allerdings begrenzte - Unterstützung seitens der Bevölkerungen in diesen Gebieten hoffen. Dennoch bestanden kaum Zweifel, dass ihr Überleben von der weiteren Präsenz der Roten Armee abhing. So stoppten die Sowjets nach Ausbruch der Aufstände den Vormarsch von Verstärkungen der iranischen Armee nach Norden und ermöglichten so die Machtübernahme in Täbris.

Mit der Ausrufung der Autonomie Aserbaidschans und der „Selbstständigkeit“ Kurdistan im Dezember 1945 und Januar 1946 stand die US-Politik vor einem Dilemma. Die sowjetische Vorgehensweise im Norden Irans drohte sich nun zu einer veritablen Krise in den sowieso bereits gespannten Beziehungen zwischen den Weltkriegsalliierten auszuweiten. Das State Departement, angeleitet vom neu geschaffenen Office of Near Eastern and African Affairs (NEA), plädierte für eine konsequente Unterstützung des iranischen Wunsches nach einem möglichst raschen Abzug aller ausländischen Truppen. Entsprechende diplomatische Bemühungen, denen sich die Briten kurz darauf anschlossen, blieben aber in Jalta, Potsdam und auf den anschließenden Treffen des Alliierten Außenministerrates ohne Erfolg. ${ }^{65}$ Formal befanden sich die Sowjets dabei im Recht, da der Tripartite Treaty von 1942 den Abzug spätestens sechs Monate nach Kriegsende vorsah - demzufolge war die Rote Armee nur zum Abzug bis zum 2. März 1946 verpflichtet. ${ }^{66}$ Der amerikanische Abzug wurde dennoch bis Ende Dezember 1945 vollzogen. Loy Henderson, der neue anti-kommunistische NEA-Direktor, wollte auf diese Weise auch die anderen Mächte vor der Weltöffentlichkeit unter Druck setzen und sie dazu zu bewegen, dem amerikanischen Beispiel zu folgen.

\footnotetext{
${ }^{63}$ Vgl. Tehran \#1171, 22.12.45, FRUS 45, VIII, S. 508f.; Tehran \#35, 8.1.46, 891.00/1-846, CF 45-49; zum Umsturz in Täbris siehe ATABAKI, Azerbaijan, S. $110 \mathrm{ff}$.; FAWCETT, Iran and the Cold War, S. 32-6.

${ }^{64} \mathrm{Zu}$ den Entwicklungen in Iranisch-Kurdistan vgl. A. ROOSEVELT JR., For Lust of Knowing, S. 271-88.

${ }^{65} \mathrm{Zu}$ den Verhandlungen über den Truppenabzug siehe KUNIHOLM, Origins, S. 270-7; LYTLE, Origins, S. 127-35, $142 \mathrm{ff}$; einen verlässlichen Überblick über die gesamte Krise bietet HESS, Iranian Crisis, S. 117-46, hier 123ff.

${ }^{66}$ Vgl. den Notenwechsel in FRUS 45, VIII, S. $413 \mathrm{ff}$.
} 
Allerdings war das amerikanische Verhalten inzwischen kaum noch von den idealistischen Grundgedanken des erwähnten Jernegan-Memorandum von 1943 angeleitet. Die Wahrnehmung der Nahostregion seitens der USA hatte sich grundlegend gewandelt. Bereits im November 1943 hatte Roosevelt eine von den Joint Chiefs of Staff (JCS) vorgelegte Studie über den Aufbau eines globalen Netzwerkes von Luftstützpunkten, darunter Basen in Nordwestafrika, bewilligt. ${ }^{67}$ Die Neuformulierung der amerikanischen Grand Strategy während dieser Zeit führte zu einer Verschiebung des ,strategischen Perimeters“, weg von einer auf die westliche Hemisphäre konzentrierten Sicherheitskonzeption hin zur Betonung der Notwendigkeit einer Verteidigung in der Tiefe mittels der Durchsetzung der eigenen Kontrolle über die atlantischen und pazifischen Ozeane. Dabei spielten anfänglich die Erfahrungen von Pearl Harbor und die Rezeption militärtechnologischer Innovationen eine größere Rolle als die Wahrnehmung der Sowjetunion als zukünftiger weltpolitischer Gegenspieler. Dem Gesamtkonzept lag die Vorstellung zugrunde, zukünftigen Gegnern mit Hilfe überlegener Luftstreitmacht frühzeitig die Kapazitäten zu offensiver Kriegsführung zu nehmen. Die Zielrichtung dieser Konzeption waren Europa und Asien - der strategischen Bedeutung der nahöstlichen Region war man sich vorerst nur zu Teilen bewusst. Wichtig war die Region allerdings hinsichtlich Fragen zukünftiger Transit- und Landerechte für Militärflugzeuge. ${ }^{68}$ Allerdings war diese strategische Konzeption anfänglich nicht gegen die UdSSR gerichtet. Tatsächlich plädierte eine Studie des Joint Strategic Survey Committee vom Mai 1944 für einen einvernehmlichen Ausgleich der strategischen Interessen Moskaus, Londons und Washingtons. ${ }^{69}$ Im Kern hätte dies die Verfolgung einer Politik von Einflusssphären impliziert. Aus dieser Grundhaltung erklärt sich auch die amerikanische Akzeptanz des Percentage Agreement zwischen Churchill und Stalin vom Oktober 1944 - die Aufteilung Südosteuropas in britische und sowjetische Einflussgebiete - wie auch der daraus resultierenden britischen Militärintervention in Griechenland im selben Monat. ${ }^{70}$ Im Kern stellte diese Vereinbarung trotz aller berechtigten Kritik angesichts des zur Schau gestellten machtpolitischen Zynismus eine solide Grundlage für eine stabile Nachkriegsordnung dar, die zudem verklausuliert in den Absprachen von Jalta und insbesondere in den Waffenstillstandsvereinbarungen von allen drei Mächten akzeptiert wurde. ${ }^{71}$

Alternativ zur kooperativen Lösung existierte die Idee, die fortgesetzte geopolitische Teilung insbesondere des industriellen Kerngebiets in Zentral- und Westeuropa durch politische,

\footnotetext{
${ }^{67}$ Zu JCS 570 siehe SCHNABEL, History of the JCS: I, S. 140-7; STOLER, Allies and Adversaries, S. $159 \mathrm{ff}$.

${ }^{68}$ Zur Nordafrika-Südostasien-Route siehe u.a. LEFFLER, Preponderance, S. 56ff.; CoHEN, Fighting World War Three, S. 1-28.

${ }^{69}$ Vgl. STOLER, Allies and Adversaries, S. $171 \mathrm{ff}$.

${ }^{70}$ Vgl. Roosevelts Telegramm an Stalin, zitiert in R-635 vom 24.10.44, in: KimBALL, Complete Correspondence: 3, S. 371; die Annahme, dass auch der amerikanischen Politik die Akzeptanz einer Einteilung in Interessensphären - wenn auch mit sich wandelnder Interpretation zwischen 1943 und 1946 bezüglich der tatsächlichen Beschaffenheit einer sowjetisch kontrollierten Sphäre in Osteuropa - zugrunde lag, findet sich z.B. bei Trachtenberg, Constructed Peace, S. 3-15; und Reynolds, New Synthesis, S. 19f.

${ }^{71} \mathrm{Zu}$ diesem Punkt siehe insbesondere LEFFLER, Adherence, S. $99 \mathrm{f}$.
} 
militärische und wirtschaftliche Förderung eines Westblocks seitens der USA zu garantieren, auf dessen Basis folgerichtig auch die neue Weltwirtschaftsordnung zu errichten wäre. Angesichts der offensichtlich gegen Moskau gerichteten Zielsetzung einer solchen Politik gab es keinen Zweifel, dass die Verfolgung dieser alternativen Linie zu einer erheblichen Belastung der amerikanisch-sowjetischen Beziehungen führen würde. Dennoch mehrten sich im Laufe des Jahres 1944 die Stimmen innerhalb der Planungsstäbe, die vor zu weit gehenden Zugeständnissen gegenüber der UdSSR auf Kosten der strategischen Interessen Großbritanniens im östlichen Mittelmeer und auf dem Balkan warnten. ${ }^{72}$ So hatte der einflussreiche Geopolitiker Nicholas Spykman bereits 1942 provokant formuliert: ,[...] a Russian state from the Urals to the North Sea can be no great improvement over a German state from the North Sea to the Urals." 73

Zwar verschlechterten sich die sowjetisch-amerikanischen Beziehungen nach dem - noch weitestgehend einvernehmlich verlaufenen - Gipfel von Jalta spürbar, doch blieb der Geist der Kooperation bis zum Tode Roosevelts am 12. April 1945 spürbar. Der Amtsantritt Trumans ermöglichte es den bisherigen Kritikern, die bislang verfolgte Kooperationspolitik gegenüber Moskau entscheidend zu revidieren. ${ }^{74}$ Innerhalb der Administration setzte sich ein Prozess in Bewegung, der zu einer zentralen Wende in der bislang verfolgten amerikanischen Grand Strategy führen sollte. Bereits im Juli 1945 wurde der zuvor axiomatische Grundsatz der amerikanischen Europapolitik, eine Involvierung in den ,historischen anglo-sowjetischen Konflikt" in Südosteuropa und in den Meerengen auf jeden Fall zu vermeiden, revidiert. Beunruhigt durch die sowjetischen Forderungen gegenüber der Türkei im vorausgegangenen Monat - eine bilaterale Einigung über eine Revision des Meerengenstatuts, sowjetische Stützpunkte an den Meerengen und die Abtretung der nordöstlichen türkischen Provinzen Kars und Ardahan ${ }^{75}$ - hatte das State Department eine Einschätzung der JCS angefordert. ${ }^{76} \mathrm{Im}$ Gegensatz zu ähnlichen vorherigen Gegebenheiten drängten bedeutende Stimmen nunmehr, in einer Vorwegnahme des geopolitischen Kerns der späteren Containment-Konzeption Kennans, auf eine direkte Einmischung der USA:

To argue that it is necessary to preserve a unilateral military control by the U.S. or Britain over Panama or Gibraltar and yet deny a similar control to Russia at the Dardanelles may seem open to the criticism of being illogical. It is, however, a logical illogicality. Neither the United States nor the British Empire can by the greatest stretch of the imagination be accused of expansionist or aggressive ambitions. [...] Russia, however, has not yet proven that she is entirely without expansionistic ambitions. ${ }^{77}$

\footnotetext{
${ }^{72}$ Vgl. STOLER, Allies and Adversaries, S. 173ff., $182 \mathrm{ff}$.

${ }^{73}$ SPYKMAN, America's Strategy, S. 460.

${ }^{74}$ Dies die vom Autor geteilte Einschätzung von STOLER, Joint Chiefs, S. 156, der einen ,turning point in SovietAmerican relations" konstatiert.

${ }^{75}$ Vgl. KuniHOLM, Origins, S. $257 \mathrm{ff}$.

${ }^{76}$ Für das Nachfolgende vgl. STOLER, Allies and Adversaries, S. 250-7; zur in ähnlichen Bahnen verlaufenden Strategiedebatte in Großbritannien vgl. ALDRICH/ZAMETICA, Rise and Decline, S. 236ff.; vgl. Attlee Minute to Churchill, 23.7.45, DBPO I, I, S. 574.

${ }_{77}$ Zit. aus LefFler, Preponderance, S. 78; vgl. StOLER, Allies and Adversaries, S. 253; Gladwyn Jebb vom Foreign Office kam interessanterweise zu einer fast gleich lautenden Interpretation. Siehe Jebb Memo, 29.7.45, DBPO I, I, S. 993.
} 
Andere militärische Planer äußerten sich ehrlicher, was die tatsächlichen amerikanischen Motive anging. Innerhalb der U.S. Navy sprach man nun vom ,new-found interest in the Mediterranean, not only by reason of our general post-war position and our strategic relationship to Britain, but because of our extending oil interests in the Middle East." ${ }^{\text {78 }}$ Im Juli 1945 entschieden die JCS zugunsten einer fundamentalen Wende in den Beziehungen zur Sowjetunion. Damit hatten die höchsten militärischen Stellen de facto eine Politik der präventiven Eindämmung eingeschlagen, die sich bald nicht nur auf die amerikanische Politik hinsichtlich der Meerengen und den maritimen Zugang zum Atlantik aus der Ostsee heraus beschränkten. Ein Memorandum des State-War-Navy-Coordinating Committee (SWNCC) betonte zeitgleich die herausgehobene strategische Bedeutung des Nahen und Mittleren Ostens. Die Region müsse aufgrund der in ihr vorhandenen Rohstoffe und ihrer wichtigen geografischen Lage ,[...] be guided by nations following the paths of Western democratic civilization rather than by Eastern dictatorships." ${ }^{\text {(79 }}$

Das Interesse innerhalb des US-Militärs an der Region hatte bereits zuvor merklich zugenommen, wobei neben Flug- und Landerechten insbesondere das Erdöl den Ausschlag gab. Zivile und militärische Planer befürchteten, dass die aus amerikanischer Sicht leicht zugänglichen Reserven in der westlichen Hemisphäre weitaus schneller ausgeschöpft sein würden als diejenigen in anderen Weltregionen. Im Falle eines zukünftigen Krieges könnte dies bedeuten, dass die USA von Ölimporten aus Übersee abhängig würden, um die Treibstoffversorgung der eigenen Streitkräfte sicherzustellen. ${ }^{80}$ Die USA hatten somit ein zentrales strategisches Interesse daran, die in der Hemisphäre verbliebenen Reserven so weit wie irgend möglich zu konservieren. Nur eine Weltregion war in der Lage, den erwarteten Rückgang der nord- und südamerikanischen Förderung auszugleichen: der Nahe und Mittlere Osten. Verschiedene Gutachten und Expertenmissionen untersuchten daher während des Krieges das nahöstliche Potential. Alle kamen sie zu demselben Ergebnis wie die Expertise des Ölsachverständigen Everette DeGolyer vom Februar 1944:, ,[...] the center of gravity of world oil production is shifting from the Caribbean to the Middle East - to the Persian Gulf." 81 Somit entwickelte sich der Ausbau der Ölförderung in der Region des Persischen Golfs und die Sicherung des Zugangs zu diesen Reserven für die westliche Welt zu einem zentralen und bald axiomatischen Bestandteil der eigenen nationalen Interessen. ${ }^{82}$

\footnotetext{
${ }^{78}$ Zit. aus StOLER, Allies and Adversaries, S. 254.

${ }^{79}$ Zit. aus Memo by Acting Chairman SWNCC, 25.7.45, abgedr. in MeJCHER, Die Politik und das Öl: II, S. 426f.; siehe ebd., S. 302f.; für die Grundsatzentscheidungen vom Juli vgl. STOLER, Allies and Adversaries, S. $255 \mathrm{f}$.

${ }^{80}$ Vgl. PaInTER, Oil and the American Century, S. 34f.; MeJCher, Die Politik und das Öl: II, S. 71, 79-83.

${ }^{81}$ Zit. aus StofF, Oil, War, and American Security, S. 135f.

${ }^{82}$ Erster Ausdruck der Neueinschätzung der strategischen Bedeutung der Nahostregion war das historische Treffen Roosevelts mit dem saudischen König 'Abd al-'Azīz Āl Sa'ūd, dem ägyptischen König Fārūq, und dem äthiopischen Kaiser Haile Selassie auf dem Großen Bittersee nahe Ismailia im Februar 1945. Im Gespräch mit Ibn Sa ūd versicherte der US-Präsident, das amerikanische Interesse am Golf bestünde auch nach Kriegsende weiter. Vgl. Jidda \#A-80, 3.3.45, FRUS 45, VIII, S. 7ff.; vgl. GARDNER, Three Kings, S. 16-25.
} 
Der eigentliche Widersacher gegen eine Ausweitung amerikanischer Ölinteressen in der Nahostregion war allerdings nicht die Sowjetunion, sondern die bisherige Vormacht im Golf, Großbritannien. Ausgangspunkt war Saudi-Arabien, naheliegender Einstiegspunkt amerikanischen Einflusses angesichts der Existenz von Konzessionsgebieten, die unter alleiniger Kontrolle amerikanischer Gesellschaften standen, zusammengefasst in der im Januar 1944 gegründeten Arabian American Oil Company (ARAMCO). ${ }^{83}$ Die resultierende heftige Rivalität zwischen den angelsächsischen Mächten wurde letztlich dank der Kompromissbereitschaft Londons beigelegt. Angesichts des wirtschaftlichen Ungleichgewichts und der während des Krieges augenfällig gewordenen Abhängigkeit von Washington fügte sich Großbritannien einer Kompromisslösung, die gleichbedeutend mit der Anerkennung einer amerikanischen Vormachtstellung in Saudi-Arabien war. ${ }^{84}$ In gewisser Weise stellten die während der Stettinius-Mission nach London im April 1944 getroffenen Vereinbarungen und das damit möglich gewordene anglo-amerikanische Ölabkommen vom August 1944 ein nahöstliches Pendant zum Percentage Agreement zwischen Churchill und Stalin vom Oktober 1944 dar. ${ }^{85}$ Kern dieser Absprachen war die Anerkennung der bestehenden Position Großbritanniens in der Region durch die USA, insbesondere die politische Vorherrschaft wie auch die Verantwortlichkeit Londons für die Verteidigung der Gesamtregion. Im Gegenzug verpflichteten sich die Briten, ihren politischen Einfluss nicht dazu zu missbrauchen, amerikanische wirtschaftliche Interessen wie in der Vergangenheit zu behindern und zu beschränken, vor allem was die von den USA gewünschte Ausdehnung der Ölförderung und die Vergabe von neuen Konzessionen in der Zukunft anging. Resultat war eine Art latentes anglo-amerikanisches Kondominium über den Nahen und Mittleren Osten, das - trotz aller fortbestehenden Friktionen und Rivalitäten - bei stetig sich verändernder Machtbalance zugunsten der USA bis in die frühen 1970er Jahre bestand. ${ }^{86}$ Zumindest im

\footnotetext{
${ }_{83}$ Ibn Sa ūd hatte 1933 Standard Oil of California eine Konzession in Saudi-Arabien gewährt. Um die Vermarktung des geförderten Öls zu ermöglichen, schloss sich Standard mit Texaco zusammen. Beide zusammen bildeten die California Arabian Standard Oil Company, aus der schließlich ARAMCO hervorging. Vgl. PAINTER, Oil and the American Century, S. 8f.; YeRGIN, The Prize, S. 396ff., 410-9; Standard Oil of New Jersey und Socony Vacuum kontrollierten ab 1934 die ursprünglich 1928 an ein größeres amerikanisches Konsortium übertragene 23,75\%-Beteiligung an der Iraq Petroleum Company. Die US-Gesellschaft Gulf Oil teilte sich ab 1934 mit der Anglo-Persian Oil Company, der späteren AIOC, die Konzession für Kuwait.

84 Vgl. PainTer, Oil and the American Century, S. 59-74; STOFF, Oil, War, and American Security, S. 104-77; YergIn, The Prize, S. 396-403; MeJCher, Politik und das Öl: II, S. 153-211; ANDERSON, ARAMCO, S. 68-107; zur britisch-amerikanischen Rivalität in Saudi-Arabien vgl. zusätzlich MILLER, Search for Security; DAVIS, Contested Space; MACRIS, Security of the Gulf, S. 33-80; VITALIS, Black Gold, White Crude.

${ }^{85} \mathrm{Zu}$ den Verhandlungen siehe STOFF, Oil, War, and American Security, S. 100-7; PAINTER, Oil and the American Century, S. 59-73; Venn, Oil Agreement; MeJcher, Die Politik und das Öl: II, S. 172-179; das angloamerikanische Ölabkommen vom 8.8.44 sah eine zukünftige enge Zusammenarbeit Großbritanniens und der USA in der internationalen Ölpolitik vor, die darauf gerichtet sein sollte, die Folgen des nach Kriegsende zu erwartenden Produktionsüberschusses auf dem Welterdölmarkt gemeinsam zu steuern, für beide Seiten nachteiligen Wettbewerb zu vermeiden und bestehende Konzessionen zu schützen. Der US-Senat verweigerte aber im Herbst 1945 und ein weiteres Mal im Juli 1952 die formale Zustimmung. Der ideelle Kern der Absprache wurde aber trotz der gescheiterten Ratifikation in der Folgezeit respektiert. Vgl. bereits Thornburg Memo, 26.5.43, ,Middle East Oil‘, Box 12, Henderson Papers, LOC.

${ }^{86}$ NEA wehrte sich in den 1960ern gegen jede Erwähnung der Absprache in der offiziellen FRUS-Reihe für 1944, gab sich dann aber mit der Entfernung eines Schlüsseldokuments zufrieden. Vgl. Davies Memo, 30.9.64, ,InterOffice Memos', Lot 66 D 5, NEA/NR, Subject Files, 1958-1966, Box 4.
} 
Prinzip wurde das Prinzip der „Offenen Tür“ verwirklicht - machtpolitisch aber waren die Absprachen gleichbedeutend mit einem Ausschluss dritter Mächte aus der Region. ${ }^{87}$

Die Bedeutung dieser Entwicklung ist angesichts ihre langfristigen, über die Zeit des Ost-WestKonflikts hinausreichenden Effekte kaum zu überschätzen. Gordon Merriam, der Leiter von NE, beschrieb im August 1945 in einem Memorandum an NEA-Direktor Henderson die saudischen Ölreserven als ,a stupendous source of strategic power" und als „,one of the greatest material prizes in world history [...]. “88 Mit der Anerkennung des ökonomischen Gewichts der Ölreserven ging die bald innerhalb der US-Administration weit verbreitete Einschätzung einher, dass die eigene Position am Persischen Golf nun als „lebenswichtiges Interesse“ (vital interest) im Sinne der eigenen nationalen Sicherheit anzusehen sei. ${ }^{89}$

Der Richtungswechsel vom Sommer 1945 war somit auch eine konsequente Fortsetzung der seit spätestens 1944 einsetzenden strategischen Neubewertung der nahöstlichen Region. So hatte die kurzzeitige Konfrontation in der bereits geschilderten iranischen Ölkrise vom Oktober und November 1944 die Wahrnehmung in Washington gestärkt, dass eine prononciertere Rolle der UdSSR in der Region nicht wünschenswert sei. De facto entsprach die Haltung der beiden anglo-amerikanischen Mächte zur Frage einer sowjetischen Ölkonzession im Nordiran einer Eindämmungspolitik. Nach Abzug der sowjetischen Truppen, zu dem sich Moskau bereits vertraglich verpflichtet hatte, und ohne Zustandekommen einer sowjetisch kontrollierten Ölgesellschaft nach dem Vorbild der AIOC war für die Zukunft mit einem nahezu vollständigen Zurückdrängen des Einflusses des nördlichen Nachbarn zu rechnen. Auf sowjetischer Seite musste neben der nun weitaus weniger kooperativen Haltung gegenüber den eigenen Ambitionen im Nahen und Mittleren Osten zudem das zunehmende militärische Engagement der Amerikaner in der Region bedenklich wirken. So fiel im Juni 1945 eine Grundsatzentscheidung in Washington, zur Sicherung der eigenen Position in Saudi-Arabien einen Militärflughafen nahe Dhahran (az-Zahahrān) am Golf zu errichten. ${ }^{90}$ Angesichts der mittlerweile bekannt gewordenen anglo-französischen Kaukasuspläne von 1939 und 1940, dem Bewusstsein der Verwundbarkeit der eigenen Ölförderung am Kaspischen Meer zusammen mit der durch die Entwicklung der Atombombe einsetzenden Revolutionierung der Kriegsführung konnte die Projektion amerikanischer Militärmacht am Persischen Golf aber aus sowjetischer

\footnotetext{
${ }^{87}$ In erster Linie war davon die Sowjetunion betroffen, doch galt dies auch für andere Staaten. Markantes Beispiel für die Wirksamkeit des ,latenten Kondominiums“" war die von Briten und Amerikanern gemeinsam durchgesetzte Verdrängung Frankreichs aus der Levante. Vgl. BiLls, Empire and Cold War, S. 23-58.

${ }^{88}$ Zit. aus Draft Memo to Truman, Annex zu Acheson Memo, 9.10.45, FRUS 45, VIII, S. 43-8 \{Hervorheb. v. Verf.\}; zu Henderson siehe KUNIHOLM, Origins, S. 236-44; BRANDS, Inside the Cold War;

${ }^{89}$ So bereits der damalige Secretary of State Hull im August 1943 gegenüber Roosevelt. Siehe oben S. 54, Anm. 33. Auf den fundamentalen Wandel der amerikanischen Einstellung seit Kriegsbeginn sei hier erneut hingewiesen. Noch im Juli 1941 hatte Roosevelt empfohlen, die Unterstützung des saudischen Königs Großbritannien zu überlassen. Vgl. StoFf, Oil, War, and American Security, S. 44.

${ }^{90}$ Die eigenen Beratermissionen in Iran wurden nunmehr als strategisches Gut bewertet. Auf Betreiben des State Department wurden die Missionen zur Unterstützung von iranischer Armee und Gendarmerie verlängert, im ersten Fall für einen unbegrenzten Zeitraum. Vgl. Stettinius Memo, 21.12.44; Stimson Memo, 27.12.44, FRUS 44, V, S. $442 \mathrm{f} ., 444$.
} 
Sicht nur ein Gefühl der Bedrohung auslösen. Folgerichtig wuchs in der sowjetischen Wahrnehmung auch die Bedeutung der strategischen Umgebung des Kaukasus, des Nordirans und der Osttürkei. ${ }^{91}$ Tatsächlich gingen die amerikanischen Planungen im Falle eines zukünftigen Konflikts genau in die sowjetischerseits befürchtete Richtung. In einer Art Neuauflage der britisch-französischen Kaukasuspläne identifizierten die US-Planer die Verwundbarkeit der industriellen Zentren und insbesondere der Ölquellen um Baku: „Destruction by air of the Caucasian and Ploesti oil fields and the Ukraine and Ural industrial centers would prevent Soviet prosecution of war." 92

Dieser Wandel der globalen Sicherheitsvorstellungen und strategischen Konzeptionen auf allen Seiten bildete den Hintergrund der Anfang 1946 eskalierenden Irankrise. Hauptsächlicher Konfliktgegenstand war weiterhin die Weigerung der Sowjets, iranisches Territorium vor der Erfüllung der eigenen Forderungen zu räumen. Offenbar war man innerhalb von NEA durchaus zutreffend - zu dem Schluss gekommen, dass die zentrale Forderung diejenige nach einer sowjetischen Konzession in den nördlichen Ölfeldern war. Gerüchten zufolge sollten diese so ergiebig sein wie diejenigen der AIOC im Süden. ${ }^{93}$ Die USA wurden nun die treibende Kraft gegen die sowjetische Bedrohung in Iran: Lokale britische Ansätze zugunsten einer Kompromisslösung mit Moskau wurden zurückgewiesen und als versuchte Neuauflage einer anglo-sowjetischen Sphärenabsprache nach dem Muster von 1907 betrachtet. ${ }^{94}$ Statt auf einen gemeinsamen Kompromiss der Mächte zur Lösung der iranischen Frage zu setzen - der britische Außenminister Ernest Bevin hatte in Moskau eine Dreierkommission vorgeschlagen - unterstützte man nun die Absicht der iranischen Regierung, ihr Anliegen der gerade erst gegründeten UNO vorzulegen. ${ }^{95}$ Anfang 1946 hatte sich auch Präsident Truman selbst auf die Seite der Kooperationsgegner geschlagen. Direkt auf das sowjetische Vorgehen in Iran

\footnotetext{
${ }^{91}$ Vgl. OsBORN, Operation Pike, S. 252ff.; in der Tat begründeten sowjetische Offizielle in Iran die sowjetische Haltung mit der möglichen militärischen Bedrohung der kaukasischen Ölförderung und wehrten sich daher gegen die Ausdehnung des britischen Einflusses nach Nordpersien. Botschafter Maximow warnte die Iraner bereits im Januar 1945: ,[...] The British might some day use Qaleh Murgheh and Mehrabad airfields for offensive air action against the Caucasus. Stalin might lose his patience before long and draw a line across N. Persia and order Russian troops to occupy Persia up to that line.“; zit. aus Report, ,Persian Government and Internal Situation', 3.1.45, FO 248/1452, TNA:PRO; das durch den Bau des Dhahran (az-Zahrān)-Flughafen ausgelöste Sicherheitsdilemma betont LAWSON, Iranian Crisis; der strategische Zusammenhang zwischen Bekanntwerden der Kaukasuspläne, der Möglichkeit nuklearer Kriegführung und dem Flughafen in Dhahran wird in den meisten Darstellungen zur Entstehung des Ost-West-Konflikts schlicht ignoriert. Eine Ausnahme ist LEFFLER, Preponderance, S. $79 \mathrm{ff}$.

${ }_{92}$ Zit. aus LefFler, Strategy, Diplomacy, S. 814; vgl. SCHNABEL, History of the JCS: I, S. $70 \mathrm{ff}$.

93 Diese Information hatte Schwarzkopf an Washington weitergegeben. Angeblich handelte es sich um hochwertiges Erdöl. Vgl. Tehran \#1156, 20.12.45, 891.6363/12-2045, CF 45-49; offenbar waren die sowjetischen Probebohrungen zu ähnlichen Ergebnissen gelangt. Vgl. RaIne, Creation, S. 9; HASANLI, Dawn, S. 63-66.

${ }^{94}$ Ende November 1945 vermutete Murray, dass sich London nun entschlossen habe, eine informelle Teilung Irans mit der UdSSR in Kauf zu nehmen. Vgl. FAWCETT, Iran and the Cold War, S. 162f.; vgl. Tehran \#1075, 6.12.45, FRUS 45, VIII, S. 479f.; tatsächlich gab es in London Stimmen, die angesichts der Politik Gawāms eine Neuauflage der Interessensphärenabgrenzung von 1907 erwogen. Siehe vor allem FAWCETT, Invitation, S. 198f.; dies., Iran and the Cold War, S. 171-76; ähnlich DAVIS, New Trusteeship, S. 56ff.; ein Beispiel für derartige britische Überlegungen ist ein Memorandum des Under-Secretary Robert Howe vom 16.4.46, in: DBPO I, VII, S. 94-8; tatsächlich hatte das Russia Committee Bevin im Juni als sofortige Maßnahme ,,[...] using or threatening to use, our influence with the tribes to set up in South Persia a movement favourable to us" empfohlen. Vgl. DBPO I, VII, S. $164 n 3$; zu den iranischen Sorgen einer solchen Neuauflage von 1907 vgl. Hakimi No. 454 to London, 7.1.46, abgedr. in TALÉ/TALÉ, Failed Soviet Landgrab, S. 54f.

${ }_{95}$ Vgl. Henderson Memo, o.D. \{ca. 29.12.45\}, FRUS 46, VII, S. 1-6; vgl. BRANDS, Inside the Cold War, S. $141 \mathrm{ff}$; zu Bevins Vorschlägen vgl. FAWCETT, Iran and the Cold War, S. 163f. KuniHOLM, Origins, S. 288ff.; LyTLE, Origins, S. 150.
} 
verweisend - ,an outrage if I ever saw one“ - erklärte er in einem Memorandum an seinen Außenminister unmissverständlich: „I'm tired \{of, R.P.\} babying the Soviets. “96

Erleichtert wurde die Haltung der USA durch die wiederholten Hilfsgesuche seitens der iranischen Regierung. Abgesehen von der extremen Linken waren sich iranische Politiker einig darüber, dass nur eine entschlossene amerikanische Haltung die Aufteilung des Landes in Interessensphären analog zu 1907 verhindern würde. Bereits im November 1945 hatte der Schah einen seine engsten Vertrauten, Hosejn 'Alā, zum neuen Botschafter in Washington bestimmt, der in der Folgezeit gleichermaßen die US-Öffentlichkeit wie auch die TrumanAdministration von der Notwendigkeit der Unterstützung Irans zu überzeugen suchte. ${ }^{97}$ Der junge Schah sah zudem in der Krise und im entstehenden strategischen Interesse der USA eine Gelegenheit, seine konstitutionell eingehegte Rolle auszuweiten und mittelfristig in die Fußstapfen seines Vaters zu treten. ${ }^{98}$ Während der Widerstand gegen diese Ambitionen innerhalb des Mağles aufgrund der sowjetischen Bedrohung nachgelassen hatte, wurde nun wieder das Amt des Ministerpräsidenten zum wichtigsten Kontrahenten, als Ġawām as-Saltana auf den Posten zurückkehrte. Ġawām, zu dieser Zeit wohl der bekannteste iranische Staatsmann mit der Reputation eines undurchsichtigen und gewieften Taktikers, war der Wunschkandidat Moskaus, obwohl keineswegs eine Marionette der Sowjets. ${ }^{99}$

Mit dem Amtsantritt Ġawāms als iranischer Ministerpräsident am 27. Januar 1946 trat die Aserbaidschan-Krise in eine neue Phase ein. Erwartungsgemäß äußerte er seine Bereitschaft sowohl mit Moskau wie auch mit den nördlichen Rebellen direkt zu verhandeln und stellte die Verfolgung linker Kräfte ein. Von der älteren Historiographie des Kalten Krieges lange übergangen, war es in der Tat Ġawām, dem es mit gewandter Ausnutzung der strukturellen Gegebenheiten gelang, die Krise zu überwinden und zugleich Voraussetzungen zu schaffen, die Minderung iranischer Souveränität infolge der Interventionen der drei großen Mächte in die inneren Angelegenheiten des Landes zu beenden. Ġawām, ohne Zweifel ein iranischer Patriot, hatte aber offenkundig auch eigene politische Ambitionen und seine Amtszeit war das erste Fallbeispiel für ein in der Nachkriegsgeschichte Irans sich nun mehrfach wiederholendes Muster. Unter Ġawām wie auch später unter Mosaddeg oder Amini schien die verfassungsmäßige Balance zugunsten des Amts des Ministerpräsidenten zu kippen, was die monarchische Prärogative in Frage stellte und eine weitreichende Konstitutionalisierung des gesamten politischen Systems Irans einzuleiten schien. In der Zukunft sollten externe Akteure

\footnotetext{
${ }_{96}$ Truman Memo, 5.1.46, in: FERRELL, Off the Record, S. 79f.

${ }^{97} \mathrm{Zu}$ den iranischen Aktivitäten vgl. MCFARLAnd, Peripheral View, S. 350f.; zu Hosejn 'Alā siehe MilanI, Eminent Persians: I, S. 37-43.

${ }_{98}$ Am nachdrücklichsten bei LADJEVARDI, Origins of Support; bisweilen findet sich in der Literatur weiterhin das Bild eines jungen und unentschlossenen Monarchen, der abseits des alltäglichen politischen Lebens stand und sich eher in der Rolle eines Dandys gefiel. Tatsächlich kämpfte Mohammad Rezā verbissen und letzten Endes erfolgreich um die Kontrolle über die Streitkräfte.

${ }_{99}$ Die zuverlässigste und ausgewogenste Darstellung des politischen Werdegangs Ġawāms bei KAUZ, Politische Parteien; ein treffendes Kurzportrait bei ABRAHAmian, Two Revolutions, S. 225-8; vgl. Minor Memo, 24.1.46, 891.00/1-2446, CF 45-49.
} 
diesen Prozess immer wieder verlangsamen bzw. stoppen. Die Verfassungsentwicklung Irans in der zweiten Hälfte des 20. Jahrhunderts ist im Grundsatz geprägt von dieser Interaktion zwischen ausländischer Intervention und innerem Bemühen, den Grundgedanken der iranischen Verfassung reale Geltung zu verschaffen. ${ }^{100}$

Im Konflikt um die sowjetische Truppenpräsenz im Norden zeigte Ġawām sein diplomatisches Ausnahmekönnen. Den bestehenden diplomatischen Druck der anglo-amerikanischen Mächte geschickt als Hebelwirkung nutzend und sich zugleich aufgeschlossen zeigend gegenüber den sowjetischen strategischen Interessen, gelang Gawām in der Tat ein Kompromiss. Dilatorisch in Moskau verhandelnd, ließ Ġawām die Frist zum Abzug der ausländischen Truppen am 2. März 1946 verstreichen und somit hatte Moskau formal den Tripartite Treaty von 1942 verletzt. Im Anschluss an die erwarteten scharfen Protestnoten der beiden anglo-amerikanischen Mächte zeigte sich Ġawām alsbald Kompromissen aufgeschlossen und stimmte umgehend der später als Ġawām-Sadčikow-,,Abkommen“ titulierten Lösung zu. ${ }^{101}$ Moskau sagte dabei den Abzug der Roten Armee aus Iran bis zum 6. Mai zu, während Iran im Gegenzug die Errichtung einer gemeinsamen iranisch-sowjetischen Gesellschaft zur Ausbeutung des Erdöls in den nördlichen Provinzen konzedierte. Die Lösung der Frage der Autonomie Aserbaidschans sollte direkten Verhandlungen zwischen Täbris und Teheran überlassen bleiben. Der Kompromiss stärkte das Ansehen des Ministerpräsidenten erheblich - da die Vereinbarung über das nördliche Erdöl der Ratifikation durch den erst noch zu wählenden Mağles innerhalb von sieben Monaten bedurfte, um Gültigkeit zu erlangen, war das Erreichen der sowjetischen Ziele praktisch an das politische Überleben Ġawāms und an dessen Vertrauenswürdigkeit gebunden.

Hinsichtlich der Beziehungen zwischen den Weltkriegsalliierten stellte die Irankrise vom Frühling 1946 einen Tiefpunkt dar. Die USA zielten bewusst auf eine Bloßstellung Moskaus in den neu gegründeten Vereinten Nationen ab. Auf die ostentative Weigerung, dem sowjetischen Vorschlag einer Vertagung zuzustimmen, erfolgte schließlich am 27. März der Aufsehen erregende Auszug Gromykos aus dem Sicherheitsrat. ${ }^{102}$ Die präzedenzlose Schärfe der amerikanischen Reaktion war nicht zuletzt einer - zumindest temporär - dominierenden Sichtweise innerhalb der Truman-Administration geschuldet, derzufolge die UdSSR nunmehr nach Einverleibung Irans in die eigene Sphäre strebte, nötigenfalls unter Einsatz militärischer Mittel. Ausgelöst wurde diese Sorge zuvorderst durch alarmistische Berichte des USVizekonsuls in Täbris über einen massiven sowjetischen Truppenaufmarsch mit dem

\footnotetext{
$\overline{100} \mathrm{Zu}$ befürchten stand nunmehr, dass Ġawām die Unterstützung Moskaus dazu benutzen könnte, seine Widersacher in der iranischen Innenpolitik zur Seite zu räumen und womöglich die Alleinherrschaft anzustreben. Vgl. Summary of Telegrams, 25.2.46, White House Daily Summary, 1946-50, Box 1, RG 59, NACP.

${ }_{101}$ Wohl wissend, dass die Sowjetisierung Irans oder die Abspaltung Aserbaidschans eine unmittelbare Konfrontation mit den Westmächten auslösen würde, verweigerte sich Stalin diversen Vorschlägen der «kaukasischen Lobby» und insbesondere Bagirows und setzte stattdessen auf eine Verhandlungslösung. Vgl. Yegorova, Iran Crisis, S. 18ff.; Raine, Creation, S. 14f.; HASAnli, Dawn of the Cold War, S. $181 \mathrm{ff}$.

${ }_{102}$ Zum eigenmächtigen Vorgehen des iranischen Botschafters 'Alā entgegen der Wünsche Gawāms vgl. McFarland, Peripheral View, S. 347; zur Konfrontation in der UNO vgl. LyTLE, Origins, S. 160-8; KuniHOLM, Origins, S. 326-33; Hess, Iranian Crisis, S. 135-41.
} 
vermeintlichen Ziel der gewaltsamen Machtübernahme in Teheran - offenbar hatte er einige sowjetische Aktivitäten stark überbewertet, wenngleich die genauen Umstände bis heute nicht vollumfänglich geklärt sind. ${ }^{103}$ Zweifelsfrei ist aber, dass diese Episode eine katalysierende Wirkung auf amerikanische wie britische Offizielle hatte. ${ }^{104}$ Im Kontext der Krise wurde nun ein zukünftiger Krieg gegen die Sowjetunion vorstellbar. Noch im März 1946 gaben die JCS Planungen für eine zukünftige militärische Auseinandersetzung mit der UdSSR in Auftrag. ${ }^{105}$ Das „Containment-Konzept“, das im berühmten „Langen Telegramm“ George F. Kennans vom 22. Februar 1946 nur wenige Wochen zuvor seinen kanonischen Ausdruck gefunden hatte, wurde jetzt zur handlungsleitenden Maxime der Außenpolitik. Tatsächlich hatte die TrumanAdministration bereits seit Anfang März eine diplomatische Offensive gegen die Sowjetunion gestartet, die - darüber waren sich die Beteiligten allesamt im Klaren - eine unmittelbare Kriegsgefahr heraufbeschwören konnte. ${ }^{106}$ Im Falle eines sowjetischen Angriffs wären die Amerikaner und wohl genauso wenig die Briten in der Lage gewesen, effektive militärische Unterstützung für die Türkei oder Iran zu leisten. Die US-Führung aber spekulierte zutreffend, wie sich zeigte -, dass in Moskau die Aufrechterhaltung der fortgesetzten Kooperation mit den Westmächten Vorrang vor der Erfüllung der Ambitionen entlang der eigenen Südgrenze hatte. So zeigte sich Truman am 12. März im Gespräch mit einem Vertrauten überzeugt: ,,[...] the Russians were bluffing in the sense of not being willing to risk a new world war." 107

\section{„Legitime“ Sicherheitsinteressen der UdSSR fanden kaum noch Berücksichtigung.} Insbesondere der Widerstand der JCS vereitelte die vorerst letzten Bemühungen, den Sowjets entgegenzukommen. Zwischenzeitliche Versuche der sowjetischen Führung, im Anschluss an die Konfrontation in der Irankrise durch einseitige Verzichtserklärungen

\footnotetext{
${ }^{103}$ Vgl. Tabriz \#40 to State, 5.3.46; Tabriz \#41 to State, 6.3.46; Tabriz \#42 to State, 7.3.46, FRUS 46, VII, S. 340, 342f., 344f.; vgl. aber dagegen DBPO I, VII, S. 56f. ni; Eintrag vom 21.6.46, ,Diaries 1946 January-September', Box I:1, A. Roosevelt Papers, LOC; YegorovA, Iran Crisis, S. 19 n75; für die historisch zweifelhafte Verwertung dieses Vorkommnisses in der post-revisionistischen Historiographie siehe KunIHOLM, Origins, S. 317-26, 379; 381 n207; MARK, War Scare, S. 391.

${ }_{104}$ Byrnes war bereits am 7. März über das sowjetische Vorgehen informiert worden. Er zeigte sich überzeugt, dass ,die UdSSR nun zur politischen Subversion in Iran militärische Invasion hinzufüge“ und kündigte entschlossenen Widerstand an: „Now we'll give it to them with both barrels.“; die Reaktion in Washington ist rückschauend beschrieben in Wright Memo, 16.8.65, FRUS 46, VII, S. 346ff.; vgl. KunIHOLM, Origins, S. 321-6; Edwin M. Wright OHI, 26.7.74, OH-HSTL.

${ }_{105}$ Siehe COHEN, Fighting World War Three, S. 6, 49-52; MARK, War Scare, S. 387.

106 Vgl. SCHNABEL, History of the JCS: I, S. $70 \mathrm{ff}$.

${ }^{107}$ Eintrag vom 15.3.46, in: BERLE/JACOBS, Navigating the Rapids, S. 573; in der Tat begründete Stalin in einem Schreiben von Anfang Mai an den aserbaidschanischen „Ministerpräsidenten“ Ğa far Pišewari den sowjetischen Rückzug mit dem Gewicht globaler Fragen. Ein Verbleib der Roten Armee in Iran, so Stalin, hätte den AngloAmerikanern einen Vorwand geliefert, ihre eigenen Truppen in Ägypten, Syrien, Indonesien, Griechenland, China, Island und Dänemark zu belassen. Stalin Letter, 8.5.46, abgedr. in YeGOROVA, Iran Crisis, S. 23f.; das Ausmaß der Krise im März 1946 blieb insbesondere Präsident Truman selbst im Gedächtnis haften. Auf einer Pressekonferenz im April 1952 erwähnte er Krise ein (wohl nukleares) „Ultimatum“ an Moskau, das schließlich das sowjetische Zurückweichen bewirkt habe. Zeitgenossen und spätere Forschung widerlegten die Behauptungen Trumans und auch das Weiße Haus dementierte umgehend. Dennoch deutete Truman ein solches Ultimatum auch in seinen Memoiren an. Siehe. TRuMAN, Memoirs: II, S. 94f.; vgl. ed. note in FRUS 46, VII, S. 348f.; das State Department untersuchte 1960 intern die Frage des Truman-Ultimatums erneut, nachdem der Schah im Kontext der Abfassung seiner Memoiren diesbezüglich Fragen gestellt hatte. George Allen und andere ehemalige NEAOffizielle bestätigten die offizielle Version, dass Truman die Protestnote vom 6. März unzutreffend und überzeichnend als „Ultimatum“ qualifiziert habe. Vgl. Tehran \#A-187 to State, 20.6.60, 788.00/6-760, CF 60-63; ähnlich in Henderson Letter, 6.6.69, ,Iran - Misc', Box 9, Henderson Papers, LOC.
} 
Kompromissbereitschaft zu signalisieren, wie z.B. durch die implizite Aufgabe der territorialen Forderungen an die Türkei, die Zustimmung zur Übereignung des Dodekanes an Griechenland und die Aufgabe der Forderung nach einer sowjetischen Treuhandschaft im vormals italienischen Tripolitanien, blieben allesamt ohne Wirkung. ${ }^{108}$ Der Ausmaß des Wandels des Dispositivs auf der amerikanischen Seite zeigte sich mit Nachdruck, als die Sowjetunion in einer diplomatischen Note vom 7. August an die türkische Regierung eine Revision der Konvention von Montreux verlangte und ihre Forderung von Potsdam nach einem Stützpunkt an den Meerengen wiederbelebte. ${ }^{109}$ Präsident Truman bewilligte nun eine militärische Beistandsgarantie an die Türkei. Auf Nachfrage Achesons, ob ihm bewusst sei, dass diese Entscheidung einen bewaffneten Konflikt mit der UdSSR bedeuten könnte, erwiderte Truman: „[...] we might as well find out whether the Russians were bent on world conquest now as in five or ten years." $" 110$

Ähnlich entwickelte sich nun die Strategiedebatte in London. Die lange erhoffte Einbindung der Vereinigten Staaten in die Verteidigung des Nahen und Mittleren Ostens war nunmehr Realität geworden. Somit waren auch die ikonoklastischen strategischen Vorstellungen von Premier Attlee überholt, der das Festhalten an der britischen Hegemonie in der nahöstlichen Region als antiquiert, gegenüber den Sowjets provokant, finanziell nicht zu bewältigen und angesichts der technologischen Revolution in der Kriegführung obsolet empfand. ${ }^{111}$ Unterstützung erhielten die Kritiker Moskaus vom Joint Intelligence Committee (JIC), das im Juni feststellte, die Sowjetunion verfolge die strategische Absicht, „freundliche“ Regierungen in der Türkei und Iran zu etablieren. ${ }^{112}$ Die Debatte wurde schließlich im Januar 1947 zugunsten Bevins und der britischen Chiefs entschieden und es bedurfte offenbar der Rücktrittsdrohung der letzteren, um den widerspenstigen Premier von seiner Haltung abzubringen. Allerdings hatte Bevin bereits im Juli 1946 der Einleitung ,politischer Kriegführung“ in Iran zugestimmt. ${ }^{113}$

Das stark gewachsene US-Interesse an den drei Staaten des Northern Tier - Griechenland, Türkei und Iran - machte sich in diesen Jahren prioritär gegenüber den ersten beiden Ländern

\footnotetext{
${ }^{108} \mathrm{Zu}$ den verschiedenen sowjetischen Konzessionen in Paris siehe KENT, British Imperial Strategy, S. 101-9; zur Frage der Zukunft der ehemals italienischen Kolonien in Nord- und Nordostafrika vgl. LouIS, Empire in the Middle East, S. 265-306; vgl. auch die historiografische Funktionalisierung der Frage als Teil einer sowjetischen Gesamtstrategie in Mittelmeer und Nahost bei GADDIS, The Cold War, S. 28ff.

${ }^{109}$ Für die Meerengenkrise vom August siehe KunihOLM, Origins, S. 359-82; MARK, War Scare, S. 399-408; siehe die sowjetische Note in FRUS 46, VII, S. 827ff.; vgl. LeFFLER, Preponderance, S. 124.

${ }^{110}$ Eintrag vom 15.8.46 in MiLlis, Forrestal Diaries, S. 193.

${ }^{111}$ Vgl. Attlee Memo, 1.9.45, DBPO I, II, S. 42f.; vgl. dagegen Bevins Haltung zu dieser Zeit in Bevin/Hall Memo, 25.8.45, ebd., S. 26-35; vgl. AldRich/ZAMETICA, Rise and Decline, S. 242.

${ }^{112} \mathrm{Vgl}$. Report by Joint Intelligence Sub-Committee, JIC (46) 38 (O) Final (Revise), 6.6.46, DBPO I, VII, S. 1614.

${ }^{113}$ Im Oktober stimmte Bevin einem erweiterten Programm in Iran zu. Den Aufbau einer Propagandaabteilung in Iran leitete der Nachrichtenoffizier Geoffrey Wheeler zusammen mit Zaehner und dem MI6-Stationschef Harry Steptoe. Zu den u.a. aus diesem Maßnahmen später hervorgehendem Information Research Department (IRD) vgl. VAUGHan, Cloak Without Dagger; SHaw, Azerbaijan Crisis, S. 290ff.; ebenfalls im Juli 1946 hatte das Kabinett für den Fall von Unruhen in der Ölförderregion Vorbereitungen für eine militärische Intervention in Ābādān beschlossen. Siehe Extract from the Conclusions, 15.7.46, DBPO I, VII, S. 179ff.
} 
bemerkbar. Bezüglich Iran wurde trotz Beilegung der unmittelbaren Krise gezögert, vorwiegend aufgrund der weiterhin unsteten Lage dort nach dem Ġawām-Sadčikow„Abkommen“ und dem anschließend erfolgten Abzug der Roten Armee. ${ }^{114}$ Erst im September 1946 im Kontext von Unruhen in den südlichen Provinzen rang sich die TrumanAdministration zu einer offiziellen Anfrage an die JCS über die Bedeutung des Landes für die nationale Sicherheit der USA durch. ${ }^{15}$ Die Antwort der JCS vom 12. Oktober 1946 enthielt eine Einschätzung der strategischen Bedeutung Irans, die als geradezu exemplarisch für den besonderen Stellenwert Irans während des gesamten Kalten Kriegs bezeichnet werden kann. Den JCS zufolge ergab sich die herausgehobene strategische Bedeutung Irans sowohl aus den dort liegenden Ölreserven wie auch aus der geografischen Lage des Landes. Im Kriegsfall böten insbesondere die topographischen Gegebenheiten des Landes die Möglichkeit, ein Vordringen sowjetischer Kräfte zu verzögern und somit Zeit zu gewinnen, um weitere Kräfte im Golf und entlang des vitalen Kairo-Suez-Gebiets zu positionieren. Unverblümt war nun die Rede von einem „strategic interest in the Near and Middle East“, dessen Verteidigung ein zentrales Anliegen war. ${ }^{116}$

Iran kam dabei eine Schlüsserolle zu. In der Folgezeit eskalierte der Konflikt zwischen den anglo-amerikanischen Mächten und der Sowjetunion trotz der vom findigen Ġawām ausgehandelten Kompromisslösung und dem darauffolgenden Abzug der Roten Armee im Mai 1946. Spätere historiographische Debatten drehten sich um die Verantwortung für diese Eskalation, die Zuschreibung hegemonialer und expansiver Absicht an die jeweils als schuldig identifizierte Macht und um die Rolle der untergeordneten Akteure in den Regierungen und Gesellschaften der betroffenen Weltregion. ${ }^{117}$ Die weitgehend unvereinbaren Argumentationen wurden im Zuge der New Cold War History im Jahrzehnt nach dem Ende des Kalten Kriegs zugunsten einer erneuten Betonung der sowjetischen Expansionsgelüste gen Süden aufgelöst, wenngleich die nunmehr zugänglichen Dokumente auf sowjetischer Seite - übrigens ähnlich wie im Falle der sowjetischen Osteuropapolitik - im Grunde kaum mit einer solchen Interpretation zu vereinbaren waren. ${ }^{118}$ Die Truman-Doktrin vom 12. März 1947 war denn

\footnotetext{
${ }^{114}$ So schrieb Berle noch im November, das Resultat der „half-settlement“ in Iran sei der Ausschluss des Westens aus Iran und die kampflose Übergabe an die Sowjets. Siehe Eintrag vom 19.11.46, in: BERLE/JACOBS, From the Papers, S. 575.

${ }_{115}$ Vgl. JCS History Iran, S. $14 \mathrm{f}$.

${ }^{116}$ Siehe Hilldring Memo, 26.9.46; SWNCC Memo, 12.10.46, FRUS 46, VII, S. 515f., 529-32; vgl. SCHNABEL, History of the JCS: I, S. $55 \mathrm{ff}$.

${ }^{117}$ Für eine Kritik der frühen revisionistischen Interpretation der nahöstlichen Entwicklungen siehe COTTAM, United States, Iran and Cold War; DOENECKE, Revisionists; ders., Iran's Role; entgegen der Annahmen der frühen „Revisionisten“ kam das Prinzip der „Offenen Tür“ im Nahen und Mittleren Osten kaum zur Anwendung tatsächlich waren die Arrangements im Ölgewerbe und in der zivilen Luftfahrt eher von Exklusivität denn von freiem Wettbewerb geprägt.

${ }^{118}$ Vgl. beispielhaft LEFFLER, Cold War in the Near East; dabei handelt es sich um eine ausführliche Besprechung der Monografie Kuniholms. Siehe auch die Kommentare von Gaddis und Kuniholm sowie die Erwiderung Lefflers im Anschluss an LefFleR, American Conception; vgl. den Überblick in KunIHOLM, Reflections; exemplarisch SICKER, Bear and Lion, der einen, ,[... [ historically unrelenting Soviet drive for expansion and absolute hemispheric preponderance in Eurasia" identifiziert; ebd., S. 6; Leffler betonte dagegen, dass die amerikanische Kodifizierung des eigenen vitalen Sicherheitsinteresses zeitlich vor der iranisch-türkischen Doppelkrise von 1946 lag und somit kaum als reaktiv zu verstehen sei. Siehe die Replik im Anschluss an ders., American Conception, S. 394; zur Frage des auch von Leffler propagierten Sicherheitsdilemmas in diesem Kontext vgl. LAWSON, Iranian
} 
auch keine Reaktion auf sowjetische Aggression, sondern auf eine britische diplomatische Note. ${ }^{119}$ Zudem bedeutete der Inhalt der Verlautbarung des Präsidenten vor dem Kongress keine Abkehr von der bisherigen Politik. Tatsächlich hatte das State Department bereits im Oktober 1946 im Anschluss an die Meerengen-Krise die eigene Politik sowohl gegenüber der Türkei, aber auch gegenüber Iran und Griechenland, einer grundsätzlichen Revision unterzogen. Die Bewahrung der Unabhängigkeit der drei Länder und ihrer territorialen Integrität waren dabei als wichtig bzw. „vital“ für die Sicherheit der USA definiert und Wirtschafts- wie Militärhilfe in Aussicht gestellt worden. ${ }^{120}$

II. 2. Initiierung und Etablierung amerikanischer Interventionspolitik in Iran, 19461953

Mit dem Abzug der Roten Armee aus Iran im Mai 1946 verschwand die weltpolitische Aufmerksamkeit für Iran ebenso rasch, wie sie zuvor entstanden war. Für zeitgenössische Beobachter wie auch für spätere „Cold War Historians“ war die Konfrontation der Supermächte in dem Staat entlang der Peripherie damit beendet. Tatsächlich aber dauerte der Konflikt auch nach dem Mai fort und verlagerte sich nunmehr von der diplomatischen zurück auf die innenpolitische Ebene in Iran, mit langfristigen gravierenden Folgen für dessen weitere politische Entwicklung, aber auch für die machtpolitisch-interventionistische Zukunft der USA in der Nahostregion.

Das Umschwenken der amerikanischen Haltung zu einer Politik der (präventiven) Eindämmung gegenüber der Sowjetunion, tatsächlich eher eine nachfolgende Legitimierung der eigenen machtpolitischen Penetration des Nahen und Mittleren Ostens, und die Integration dieser Weltregion in die globale Sicherheitskonzeption der USA machte grundsätzliche Überlegungen notwendig, wie westlicher Einfluss in der Region auch für die Zukunft dauerhaft sichergestellt werden konnte. Welche politischen, wirtschaftlichen bzw. militärischen Maßnahmen waren vonnöten, um den dominierenden westlichen Einfluss in den Frontstaaten entlang des Northern Tier aufrechtzuerhalten und wie konnte die eigene Intervention in die internen Verhältnisse dieser Gesellschaften gerechtfertigt werden? Intervention - nach Odd Westad weit definiert als ,,any concerted and state-led effort by one country to determine the political direction of another country “121 - zielte dabei im Wesentlichen auf eine antisowjetische Orientierung der bestehenden Führungsgruppen. Überlegenes Machtpotential der

Crisis, S. 323; siehe TrACHTENBERG Leffler and the Origins, S. 448f.; breiter angelegt JeRVIS, Security Dilemma; zu Moskaus Motiven vgl. auch RoBerTs, Stalin's Wars, S. 309, 311; und ders., Cold War on the Periphery.

${ }^{119}$ So die Formulierung von Leffler in seiner Antwort in ders., American Conception, S. 396; zur Entstehung der Doktrin siehe ders., Preponderance, S. 142-7; die Gegenposition bei KunIHOLM, Truman Doctrine.

${ }^{120} \mathrm{Vgl}$. Memo on Turkey, encl. to Henderson Memo, 21.10.46; NEA Memo, encl. to Henderson Memo, 18.10.46; NEA Memo, encl. to Henderson Memo, 21.10.46; FRUS 46, VII, S. 893-7, 533-6, 240-5.

${ }^{121}$ WESTAD, Global Cold War, S. 3. 
westlichen Alliierten und wirtschaftliche wie finanzielle Leistungsfähigkeit garantierten dabei zu Beginn die Kooperationsbereitschaft vieler nahöstlicher Regierungen auch ohne Überschreiten einer Zwangsschwelle. Konfrontiert mit Konstellationen wie z.B. den iranischen Entwicklungen im Herbst 1946, die eine Abkehr von der gewünschten politischen Ausrichtung einer Staatsführung befürchten ließen, zeigte sich die Truman-Administration allerdings rasch bereit, Maßnahmen zu ergreifen, welche die Schwelle zwischen Penetration und eigentlicher Intervention überschritten.

Die Annahme einer Führungsrolle durch die USA bei der Verteidigung der iranischen Souveränität und territorialen Integrität während der Aserbaidschankrise führte zu einem nachdrücklichen Wandel in der Wahrnehmung Amerikas im Kontext der Innenpolitik des Landes. Die neue amerikanische Rolle wurde von den politischen Gruppen in Teheran analog zur traditionellen britischen Rolle interpretiert. Vertreter verschiedenster politischer Gruppierungen und Kräfte in Iran suchten nun fortgesetzt den Kontakt zu amerikanischen Repräsentanten, um die Unterstützung der USA zu erhalten. Der Nachfolger Murrays in Teheran als US-Botschafter, George Venable Allen ${ }^{122}$, berichtete verwundert, er sei gezwungen unzählige iranische Delegationen zu empfangen, die allesamt von den USA eine ,more positive role in internal Iranian affairs“ einforderten, also amerikanische Unterstützung für ihre jeweiligen politischen Ziel und Ambitionen. ${ }^{123}$ In seiner Korrespondenz mit Washington vertrat Allen selbst anfänglich eine prinzipielle Äquidistanz zwischen den politischen Kräften Irans. In seinem eigenen Verhalten im Anschluss an den erfolgten Abzug der letzten sowjetischen Truppen im Mai $1946^{124}$ und der danach bald offen ausgetragenen Konfrontation zwischen Schah und Ministerpräsident Ġawām um die politische Macht im Land hielt er sich allerdings nur bedingt an diese Leitlinie. Von Beginn an tendierte Allen zum Standpunkt des Monarchen und stellte sich somit gegen den Ministerpräsidenten, dessen Haltung er für gleichermaßen undurchschaubar wie politisch zweifelhaft befand. ${ }^{125}$ Weit weniger kritisch sah der neue US-Botschafter die diktatorischen Ambitionen des jungen Schahs Mohammad Rezā die Nähe Allens zum imperialen Hof vertiefte sich in den Folgemonaten über gemeinsames Tennisspiel und Diners. Hier liegt der Ausgangspunkt der sich bis zur Revolution vertiefenden Bindungen zwischen Pahlawi-Dynastie und aufeinanderfolgenden US-Administrationen und insbesondere der bedeutsamen Mittlerrolle des jeweiligen US-Botschafters in dieser Beziehung. ${ }^{126}$

\footnotetext{
${ }^{122}$ George V. Allen, ein enger Vertrauter Loy Hendersons, war mit 42 Jahren der jüngste US-Botschafter überhaupt. Zu Allen vgl. KuniHOLM, Origins, S. 343f.; PFAU, Containment in Iran, S. 361.

${ }^{123}$ Allen Letter, 6.6.46, FRUS 46, VII, S. 495f.

${ }^{124}$ Der Abschluss des Truppenabzugs zum 9. Mai und damit drei Tage nach dem Ablauf der vom Sicherheitsrat gesetzten Frist wird in sowjetischen Dokumenten erwähnt. Siehe YEGOROVA, Iran Crisis, S. 20; man vermutete aber den Verbleib vieler sowjetischer Soldaten in Aserbaidschan in Zivil. Ein CIA-Bericht von 1947 sprach zudem von 5.000 sowjetischen Agenten in der Provinz. Vgl. CIG, ORE 19, 4.6.47, CIA-FOIA, S. 5.

${ }_{125}$ „Qavam has made clearly every endeavor to remain in the good graces of Azerbaijan and Leftist elements.“; Tehran \#699, 15.5.46, FRUS 46, VII, S. 464.

${ }^{126} \mathrm{Zu}$ Allens Rolle vgl. PfaU, Containment in Iran, S. 361f.; AzIMI, Unseating Mosaddeq, S. 98.
} 
Ġawāms Politik im Sommer und Herbst 1946 zielte auf eine Konsolidierung seiner Machtposition ab, wobei die konservativen Kreise zwangsläufig seine hauptsächlichen Widersacher darstellten. Er hoffte, mittels einer weiteren Parlamentarisierung des konstitutionellen Systems in Iran, insbesondere der Durchsetzung der zivilen Kontrolle über das Militär, eine Rückkehr zu einer autoritären Herrschaft wie unter Rezā Šāh vereiteln zu können. Linke und reformistische Kräfte waren dabei seine natürlichen Verbündeten. Tudeh und andere Kommunisten unterstützten zudem die Gawām-Regierung, um die Ratifizierung des Ölabkommens mit der Sowjetunion wie auch dessen anschließende Implementierung sicherzustellen. Für Ġawām zentral waren die Vorbereitungen auf die Wahlen zum 15. Mağles, mit dem Ziel die traditionelle Manipulation seitens der konservativen Kräfte zu vereiteln und eine eigene reformistisch-progressive Mehrheit zu sichern. ${ }^{127}$ Eine für seine weitergehenden Plänen vorteilhafte Parlamentszusammensetzung hoffte Ġawām Ende Juni 1946 durch die Gründung einer eigenen Partei, der Hezb-e Demukrāt-e Irān (HDI) zu erreichen, sich zusammensetzend aus einer eigentümlichen Kombination Ġawām freundlich gesinnter Aristokraten und Landbesitzer aus den Nordprovinzen einerseits und reformistischer, eher links eingestellter Intellektueller jenseits der Tudeh andererseits. ${ }^{128}$ Im Juni erreichte Ġawām sodann eine vertragliche Regelung des Verhältnisses zwischen der Zentralregierung in Teheran und dem weiterhin bestehenden autonomen Regime in Täbris. Kern der Vereinbarung waren die vorläufige Anerkennung der von der Regierung Ğa'far Pišewaris in Täbris geschaffenen aserbaidschanischen Nationalversammlung als Provinzrat, kulturelle Autonomie, weitgehende finanzielle Eigenständigkeit der Provinz und Inkorporierung der aserbaidschanischen Armee und der Miliz der FDĀ in die regulären iranischen Streitkräfte. Vermutlich ist diese Vereinbarung als weiterer taktischer Schachzug Ġawāms zu interpretieren, der auf diese Weise ein weiteres Hindernis für die baldige Abhaltung von Wahlen aus dem Weg räumte. ${ }^{129}$

US-Botschafter Allen aber interpretierte Ġawāms Annäherung an die linken politischen Kräfte als „Appeasement“ gegenüber Moskau. Ganz im Geiste des aufkommenden „Cold War Consensus“ betonte er die Gefahr, Gawām sei ,[...] gone so far over to the pro-Soviet camp he cannot retract." ${ }^{130}$ Während Allen vergeblich um Unterstützung des State Department für eine Intervention seitens der USA nachsuchte, reagierte die traditionelle Vormacht in Iran, Großbritannien, skrupellos und mit großem Nachdruck auf die Bedrohung von Links, die

\footnotetext{
${ }^{127}$ Die Gefahr, die vonseiten des Militärs drohte, verringerte Ġawām, indem er gegen den Willen des Schahs die Berufung von 'Ali Razmārā als Generalstabschef durchsetzte. Eine Verhaftungswelle gegen pro-britische Politiker, Offiziere und Geistliche wie Sejjed Zijāe ${ }^{e}$, Hasan Arfa ${ }^{`}$ und Ājatollāh Kāšāni sollte die Manipulation der Mağles-Wahlen durch diese Gruppen unterbinden.

128 Die umfassendste Untersuchung zur HDI bei KauZ, Politische Parteien.

${ }^{129}$ Kaum einer der vereinbarten Schritte wurde im Anschluss umgesetzt. Vgl. ebd., S. 163f.; vgl. HASANLI, Dawn, S. 285-325; zum Abkommen vgl. FRUS 46, VII, S. 497f.

${ }^{130}$ Tehran \#850, 17.6.46, ebd., S. 500f.; dennoch lehnte man im Juni 1946 eine von London vorgeschlagene gemeinsame anglo-amerikanische Aktion mit dem Ziel, Ġawām zu einem entschlosseneren Vorgehen gegen die Linke zu zwingen, ab. Vgl. British Embassy Memo, 11.6.46, 891.00/6-1146, CF 45-49NACP; Tehran \#844, 15.6.46, FRUS 46, VII, S. 498f.; im Anschluss meldeten sich innerhalb Londons erneut Stimmen, die sich zugunsten einer Sphärenabsprache mit Moskau aussprachen. Vgl. Bevin Minute, 23.6.46; Sargent Minute, 26.6.46, $D B P O$ I,VII, S. S. $169-73,178$ nii.
} 
vorherige Zurückhaltung angesichts des Endes der sowjetischen Truppenpräsenz aufgebend. Initiiert anfangs von „Men on the Spot“ wie dem Assistant Military Attaché in der britischen Botschaft, Oberstleutnant Underwood, tatsächlich im Dienste des britischen Geheimdiensts, ex post facto aber gebilligt von Außenminister Bevin, unternahmen die Briten nun Aktionen zur Sicherung der eigenen Ölinteressen in Xuzestān. Als Antwort auf den wachsenden Einfluss der von der Tudeh kontrollierten Gewerkschaften in Ābādān unterstützten sie die Bildung einer Union der arabischen Stämme in Xuzestān, mit der Folge bewaffneter Auseinandersetzungen im Anschluss an einen Generalstreik der Arbeiter auf den Ölfeldern, die etwa 50 Menschen, größtenteils Arbeitern, das Leben kosteten. ${ }^{131}$ In einer reichlich zynischen „Reaktion“ auf die eigenhändig verursachten Unruhen entschied das britische Kabinett im Juli 1946, eine indische Brigade ins irakische Basra zu verlegen und zugleich eine Flottendemonstration vor Ābādān abzuhalten. ${ }^{132}$ Der amerikanische Konsul in Basra berichtete von britischen Militärplanungen „on a scale far in excess of that required for any occupation of Khuzistan. "133 Eine gleichzeitig rasch um sich greifende Aufstandsbewegung unter den bedeutendsten südlichen iranischen Stämmen der Baxtijāri und der Ġašğāi wurde offenkundig ebenfalls von britischer Seite ermuntert und logistisch unterstützt. ${ }^{134}$ Allen gab sich währenddessen am 28. September überzeugt, man habe sich in London entschlossen, ,to cut off the rotten part of the apple rather than let it infect the remainder", also Aserbaidschan aufzugeben und sich auf die Sicherung der eigenen Positionen in den südlichen Provinzen zu konzentrieren. ${ }^{135}$

Im Kern war dies „klassisch-imperialistische“ Kanonenbootpolitik. Tatsächlich stellte der britische Aufmarsch im Südirak eine weitaus offenkundigere Bedrohung der Souveränität eines regionalen Staates dar als z.B. die letztlich sehr begrenzten Drohgebärden der UdSSR gegen die Türkei. Dennoch verhinderten die USA eine anfangs geplante neuerliche Beschwerde Teherans vor dem Sicherheitsrat, die dieses Mal gegen Großbritannien gerichtet gewesen wäre. ${ }^{136}$ Starker britischer Druck - die Parallelen zur Sphärenregelung von 1907 waren für jeden iranischen Patrioten unübersehbar - zwang die Ġawām-Regierung zum Einlenken. General Fazlollāh Zāhedi beendete im Auftrag des Ministerpräsidenten den Aufstand im Süden mit dem Versprechen der Einführung von Provinzräten in Fārs analog zur Vereinbarung vom

\footnotetext{
${ }^{131}$ Viele Details bez. des Generalstreiks auf den AIOC-Ölfeldern im Juli sind ungeklärt. Die meisten Informationen bietet LadjeVArdi, Labor Unions, S. 66ff., 129-36; vgl. KauZ, Politische Parteien, S. 196-200; FAwCETT, Iran and the Cold War, S. 169-72; in jüngerer Zeit freigegebene SOE-Quellen belegen die Organisation der Unruhen im Süden durch Underwood und andere britische Offizielle. Siehe KELLY, Succession of Crises, S. 140; für Bevins Zustimmung siehe DBPO I, VII, S. 175f. $n 3$.

${ }^{132}$ Vgl. Extract, 15.7.46, DBPO I, VII, S. 179ff.; vgl. SHAw, Internationalization, S. 512-8.

133 ,Summary of Telegrams', 9.9.46, White House Daily Summary, 1946-50, Box 1, RG 59, NACP; wenngleich chronologisch unsinnig, erinnerte man sich Jahre später, die Entsendung der indischen Brigade nach Basra ,„[...] had perhaps had as much to do with $\{$ the, R.P. $\}$ Soviet withdrawal from Azerbaijan as had the U.N. action."; Minutes, 26.10.50, FRUS 50, V, S. 233-238, hier 235.

134 Ġawām präsentierte Allen offenbar überzeugende Beweise für die britische Beteiligung am Aufstand. Vgl. Tehran \#1231, 14.9.46, 891.00/9-1446, CF 45-49.

135 Tehran \#1289, 28.9.46, FRUS 46, VII, S. 517 f.

${ }^{136}$ Exemplarisch für die Balance zwischen Eigeninteressen und Patriotismus im Charakter Mohammad Rezās war seine Bemerkung zu Allen, dass ,[...] if the British had taken steps to protect their vital interests in southern Iran and to balance Soviet action in Azerbaijan he could not blame them."; ,Summary of Telegrams', 19.7.46, 22.7.46, White House Daily Summary, 1946-50, Box 1, RG 59, NACP.
} 
Juni mit den Aserbaidschanern. ${ }^{137}$ Angesichts des drohenden Zerfalls des Landes versprach Ġawām eine grundsätzliche Wende in seiner Politik einzuleiten und sein gleichzeitig gegenüber Allen geäußerter Wunsch nach umfangreichen Militär- und Finanzhilfen signalisierten ein Ende der Aussöhnungspolitik mit der Linken und die ernsthafte Erwägung einer militärischen Lösung der aserbaidschanischen Frage. ${ }^{138}$

Trotz der „Korrektur“ der Politik Ġawāms im Herbst 1946 und dem Ende der Versöhnungspolitik mit linken und progressiven Kräften entschloss sich der US-Botschafter nun zugunsten eines Eingreifens in die innere iranische Machtbalance - im Übrigen nahezu zeitgleich zur bereits erwähnten Einschätzung der JCS vom 12. Oktober 1946 zum gewachsenen strategischen Interesse an Iran. Ġawāms Vorgehen erschien für Allen als ein gefährliches Vabanquespiel eines ältlichen iranischen Politikers, der nur seine eigenen Machtambitionen auf Kosten derjenigen des jungen Schahs zu verwirklichen trachtete. ${ }^{139}$ Anlass für Allens Intervention war ein sowjetischer Vorschlag zur Schaffung einer iranischsowjetischen Fluglinie für den Luftverkehr in den Nordprovinzen, in den Einzelbestimmungen dem Ölabkommen sehr ähnlich. ${ }^{140}$ Später erinnerte sich der US-Botschafter, er habe bereits seit Längerem nach einer Gelegenheit gesucht, um Ġawām zu einer Kabinettsumbildung zu bewegen, offenbar auch in Reaktion auf den Erlass eines Wahldekrets für die Wahl des 15. Mağles und die dann zu erwartende Ratifikation des Gawām-Sadčikow-,,Abkommens“ durch ein von der HDI dominiertes Parlament. ${ }^{141}$ Nachdem Ende September Ġawām dem recht unverhohlen Drängen des US-Botschafters zur Entlassung der drei Tudeh-Minister im Kabinett nicht nachgegeben hatte, entschloss sich Allen nun zum Sturz des Ministerpräsidenten. ${ }^{142}$ Allen

\footnotetext{
${ }^{137}$ In einer Vorwegnahme der späteren engen Beziehung zu amerikanischen Geheimdienstkreisen hatte einer der

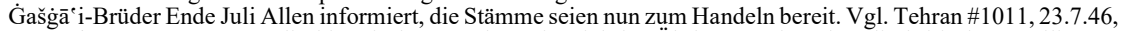
891.00/7-2346, CF 45-49; die historische Forschung ist sich im Übrigen uneins über die britische Beteiligung. Kuniholm, Origins, S. 385; Kauz, Politische Parteien, S. 217f.; AzImi, Crisis, S. 156f., bezweifeln diese, überzeugender hier FAWCETT, Iran and the Cold War, S. 171f.

138 Vgl. Tehran \#1293, 30.9.46; gegen linke Widerstände setzte Ġawām im Sommer 1946 zudem eine Verlängerung der Gendarmerie-Mission unter Schwarzkopf um weitere zwei Jahre durch. Vgl. Tehran \#852, 17.6.46, FRUS 46, VII, S. 518, 501f.

${ }_{139}$ Allerdings war sich Allen der charakterlichen Schwächen des jungen Monarchen bewusst, der zwar den Machtwillen und das übersteigerte Selbstbild seines Vaters, aber nur einen Bruchteil dessen Mutes geerbt habe. In Krisenmomenten neige Mohammad Rezā zu einem panischen Fluchtreflex. Vgl. Tehran \#691, 14.5.46; Tehran \#965, 8.7.46; Tehran \#215, 15.3.46; Iran, Tehran Embassy, Top Secret Telegrams, RG 84, NACP; Allens Sorgen vor einer raschen Sowjetisierung Irans infolge des Ablebens Gawāms in Tehran \#1196, 7.9.46, 891.00/9-746, CF 45-49.

${ }^{140}$ Aus amerikanischer Sicht war ein sowjetisches Eindringen in den Luftfahrtsektor in Iran noch unerwünschter und bedrohlicher als eine Umsetzung der Ölvereinbarung. Mit Unterstützung der US-Botschaft hatte sich die USLuftfahrtgesellschaft Transcontinental and Western Air/TWA zuvor Eintritt in den iranischen Markt verschafft und war mit 10\%-iger finanzieller Beteiligung und diversen Management- und anderen Vereinbarungen mit der neu gegründeten nationalen Fluglinie Iranian Airways verbunden. Das vorgesehene Monopol für die nördlichen Routen wäre ein ,,severe blow to Iranian airways“, so Allen. Vgl. Tehran \#1294, 30.9.46, 891.00/3-3046, CF 4549; zu den kommerziellen Interessen der USA im Bereich der zivilen Luftfahrt in der Region siehe GENDZIER, United States Intervention, S. 101-7.

${ }^{141} \mathrm{Vgl}$. LADJEVARDI, Origins of Support, S. 232f.

142 Vgl. Summary of Telegrams, 23.9.46, White House Daily Summary, 1946-50, Box 1, RG 59, NACP; Allen rechnete sich selbst später einer Gruppe von amerikanischen Offiziellen zu, die sich selbst als ,determined interventionists" bezeichneten. Vgl. PISANI, CIA and Marshall Plan, S. 167 n73; Allen war später neben Henderson und Kennan einer der Teilnehmer der entscheidenden Sitzung des Policy Planning Staff am 3.5.48, in der beschlossen wurde, dem NSC einen Vorschlag zur Aufnahme politischer Kriegführung gegen die Sowjetunion zu unterbreiten. Es folgte die Verabschiedung von NSC 10/2 und die Gründung des berüchtigten Office of Policy Coordination (OPC) unter Leitung Frank Wisners. Vgl. ebd., S. 69f; Office of Policy Coordination 1948-1952,
} 
improvisierte zu dieser Zeit, nicht instruiert zu solchem Handeln seitens des State Departments, aber offenkundig auf die Rückendeckung seines Mentors, NEA-Direktor Loy Henderson, vertrauend. Am 14. Oktober suchte Allen den Schah zu einem Gespräch auf. Er überzeugte den zögerlichen Mohammad Rezā, er habe die Unterstützung der amerikanischen und britischen Botschafter, eine Umbildung des Kabinetts zu erzwingen. Offenbar empfahl Allen im Falle einer Weigerung des Ministerpräsidenten nicht nur den Arrest Ġawāms. Er garantierte darüber hinaus, dass die Gendarmerie unter Schwarzkopfs Führung nicht eingreifen werde, somit die einzige militärische Macht, die unter Kontrolle der Regierung stand, neutralisierend. ${ }^{143}$ Allens Vorgehen - de facto die Ermunterung zu einem Staatsstreich - stellte eine unmissverständliche Intervention in die inneren Angelegenheiten Irans dar und es gab später durchaus Stimmen in Washington, die seine Handlungen missbilligten, doch wurde er vehement von Loy Henderson verteidigt. ${ }^{144}$ Trotz des Eingreifens Allens kam es zu diesem Zeitpunkt noch nicht zum Sturz des Ministerpräsidenten, da Ġawām, vermutlich informiert über das sich ankündigende Vorgehen von Hof und anglo-amerikanischen Mächten, nun selbst präventiv den Bruch mit der Tudeh und anderen linken Kräften umsetzte und damit den Vorwand des Vorgehens gegen seine Person entkräftete.

„No two historians will probably agree upon the exact circumstances which brought about the new cabinet", bemerkte Allen eine Woche nach den Ereignissen. ${ }^{145}$ Offenbar gingen Allens Beteiligung und die der US-Botschaft erheblich über das Gespräch mit Mohammad Rezā am 14. Oktober hinaus - vom Schah noch Jahre später als „,famous talk“ glorifiziert. Tatsächlich hatte Allen noch vor dem Gespräch mit dem Schah Kontakt mit einer Gruppe prominenter iranischer Persönlichkeiten und Offizieller, offenbar Teile der iranischen Armeeführung einschließend, die einen Staatstreich gegen Ġawām planten, und amerikanische Unterstützung für ihr Vorgehen erhofften. Allen betonte oberflächlich seine Verpflichtung zur Neutralität, gab aber unverhohlen seiner Meinung Ausdruck, dass die gegenwärtige Regierung des Landes ,[...] was leading $\{$ the; R.P. $\}$ country in $\{a\}$ path which would result in $\{$ the $\}$ loss of

o.D., CIA-FOIA; WARNER, Office of Policy Coordination, S. 211-20; Forschungsüberblick bei RuDGERS, Origins of Covert Action; für eine offizielle Zusammenfassung der Entwicklung verdeckter Operationen vom Zweiten Weltkrieg bis zur Johnson-Administration siehe ,U.S. Covert Action and Counter-Insurgency Programs', FRUS 64-68, XXVII, S. XXXV-XLI; NSC 10/2 und der Vorläufer NSC 4-A abgedruckt in FRUS 45-50: Emergence, S. 649ff., $713 \mathrm{ff}$.

${ }^{143}$ Details zum Gespräch vom 14.10. bei Kuniholm, Origins, S. 389f.; PFAU, Containment in Iran, S. 366f.; die unmittelbare Meldung an das State Department ist in Tehran \#1371, 15.10.46, 891.00/10-1546, CF 45-49; in Auszügen auch in FRUS 46, VII, S. 533; ein erheblicher Teil dieser Nachricht ist allerdings unkenntlich gemacht. Zur Koordinierung mit dem britischen Botschafter Le Rougetel vgl. Tehran \#1358, 14.10.46, 891.00/10-1446, CF $45-49$.

${ }^{144}$ Vgl. Henderson Memo, 16.10.46, 711.91/10-1646, ebd.

${ }_{145}$ Zit. aus Tehran \#A-231, 24.10.46, 891.00/10-2446, ebd.; dies ist aber eher als Teil der Vernebelungsstrategie Allens im Hinblick auf seine eigene Rolle zu verstehen, die allerdings nicht mehr im Detail zu rekonstruieren ist, zumal wichtige Quellen, z.B. Allens private Briefe an Henderson, offenbar vernichtet wurden. Siehe KUNIHOLM, Origins, S. 389 n18; Henderson Letter to Kuniholm, 20.6.76, ,Iran - Personal Correspondence‘, Box 9, Henderson Papers, LOC; einige Monate später bagatellisierte Allen seine eigene Rolle: „Many people wanted the change, not least of whom was Qavam himself, but someone had to take the decision that the time had come to act. Once the Shah made up his mind (and this probably resulted from our conversation), everyone was pleased and relieved."; zit. aus Allen Letter, 3.12.46, 891.00/12-346, CF 45-49; dagegen Allen Letter to Jernegan, 21.1.48, ,Miscellaneous‘, Lot 54 D 363, Iranian Files 1947-50, NEA/GTI, Box 36. 
independence and I knew what course I would take if I were an Iranian."146 Die Hauptverschwörer kamen aus dem Umfeld der Informanten, angeworben von der OSS noch während der Besatzungszeit. Sie waren organisiert in der Iran-America Relations Society und umfassten bekannte iranische Persönlichkeiten wie z.B. 'Abbās Mas'udi, Herausgeber der führenden Zeitung Ettelā' $\bar{a} t$, der bereits 1945 mit einer Gruppe iranischer Journalisten in die USA eingeladen worden war. ${ }^{147}$ Wenngleich von der Forschung häufig ignoriert, sind die Geschehnisse im Oktober 1946 grundlegend für die weitere amerikanisch-iranische Beziehungsgeschichte. Tatsächlich ähnelte das amerikanische Vorgehen gegen den eigenwilligen Ministerpräsidenten Ġawām in vielem der späteren Operation TPAJAX von 1953 gegen den ebenso eigenwilligen Ministerpräsidenten Mosaddeg. ${ }^{148}$

Zwar erscheinen die Begebenheiten vom Herbst 1946 - zumindest im Vergleich zu 1953 oder 1978/79 - wie eine Petitesse. Dennoch ist George Allens Bewertung der Ereignisse als „,turning point in Iranian history“ nicht unangemessen. ${ }^{149}$ Mit der entscheidenden Schwächung des Amts des Ministerpräsidenten und der Verdrängung der linken und reformistischen Kräfte aus der Regierungsverantwortung war eine Vorentscheidung gefallen, die einen Richtungswechsel weg vom (wenngleich chaotischen und häufig instabilen) Pluralismus und begrenzten Parlamentarismus hin zu staatlicher Repression und Konzentration von Regierungsgewalt mittels der Autorität von Schah und Hof einleitete. Drei Jahre und neun Monate nach dem idealistischen Jernegan-Memorandum hatte die angeblich wohlwollende und interessenfreie US-Macht massiv und nachhaltig den Fortgang der politischen Entwicklung Irans beeinflusst. Die pfadabhängige Wirkung dieser Intervention auf die innere Verfasstheit Irans bis zur Revolution ist eine der zentralen Leitlinien der vorliegenden Studie.

Mittelfristig bedeutete der erzwungene Kurswechsel vom Oktober 1946 den vollständigen

\footnotetext{
146 Tehran \#1359, 14.10.46, 891.00/10-1446, CF 45-49.

${ }^{147}$ Mas'udi war seit Dezember 1944 Direktor von Iranian Airways. Zu seiner USA-Reise siehe Shepherd to Younger, No. 39, 1.6.50, FOCP IV, B, 9, S. 147; Ġolām-Hosejn Ebtehāğ und Rezā Afs̃ār, die Besitzer von Iranian Airways, waren die wichtigsten Informanten Allens bezüglich der Luftfahrtkonzession - beide hatten langjährige Kontakte zum OSS und seinen Nachfolgeorganisationen. Vgl. LADJEVARDI, Origins of Support, S. 232f.; PFAU, Containment in Iran, S. 366; KunIHOLM, Origins, S. 387; Tehran \#A-231, 24.10.46, 891.00/10-2446, CF 45-49; insbesondere die Gebrüder Ebtehāğ tauchen immer wieder in den Akten als stark pro-amerikanisch eingestellte Akteure auf. Abu 1-Hasan, Direktor der Nationalbank (bank-e melli), orientierte sich früh Richtung Amerika, nicht zuletzt aufgrund der langjährigen Patronage durch Hosejn 'Alā. Abu 1-Hasan war für die US-Botschaft einer der wichtigsten Zuträger über Vorgänge in Kabinett und Hof. Siehe z.B. Tehran \#383, 22.3.46, FRUS 46, VII, S. 369f.; zur Karriere von Abu l-Hasan Ebtehāğ siehe Bostock/JONES, Planning and Power; vgl. VAGHEFI, Entrepreneurs of Iran, S. 31-41; zur Gründung der Iran-America Relations Society und der Rolle des OSS-Agenten Wilber vgl. ders., Adventures, S. $115 \mathrm{ff}$.

${ }^{148}$ In der Forschung etablierte sich die - allerdings wenig glaubwürdige - spätere Schilderung des Schahs über die Kabinettsumbildung, derzufolge Mohammad Rezā eigenhändig Gawām zum Einlenken gezwungen und Drohungen des sowjetischen Botschafters furchtlos zurückgewiesen habe. Vgl. LADJEVARDI, Origins of Support, S. 233; die Version des Schahs ist zusammengefasst in Tehran \#1391, 20.10.46, FRUS 46, VII, S. 537ff.; zur Übernahme in der Forschung siehe z.B. KuniHOLM, Origins, S. 391; vgl. dagegen PFAU, Containment in Iran, S. 367f.; RAmAZANI, Iran's Foreign Policy, S. 148-50; RuBIN, Good Intentions, S. 35f., verschweigt die Intervention in tendenziöser Manier. Ähnlich für die britische Rolle LouIS, Empire in the Middle East, S. 73, 632; trefflich dagegen BILL, Eagle and Lion, S. 39, 49; bizarr die Wertung von COLLIER, Nature of Influence, S. 56, über Allens Wirken in Iran als Bestandteil von Trumans angeblicher Politik einer Unterstützung von „Iran's nascent democratic breakthrough".

${ }_{149}$ Zit. aus LADJEVARDI, Origins of Support, S. 233 \{Hervorheb. v. Verf.\}.
} 
Ausschluss sowjetischer Macht und Einflusses aus Iran. Der politisch nun stark geschwächte Ġawām musste sich der Repression gegen linke Kräfte in Iran fügen, damit auch seine wahltaktischen Ziele aufgebend, zumal die HDI, sein hauptsächliches Instrument zur Herrschaftssicherung, nun systematisch von den rechten Kräften zersetzt wurde. ${ }^{150}$ Ermuntert seitens der USA, die im Anschluss an die Kabinettsumbildung Militär- und Wirtschaftshilfe und den Erhalt der beiden Militärmissionen zusagten und darüber hinaus eine - wenngleich verklausulierte - Beistandsgarantie abgaben, entschloss sich Ġawām nun zur Beseitigung des Autonomen Regimes in Aserbaidschan. ${ }^{151}$ Trotz sowjetischer Drohgebärden marschierte die iranische Armee im Dezember 1946 in die abtrünnige Provinz ein. Entmutigt angesichts der Übermacht und einer Anweisung Stalins an die Führung in Täbris, den bewaffneten Widerstand aufzugeben und sich der Zentralregierung zu unterwerfen, zerfiel die Autonome Republik fast ohne jede Gegenwehr. ${ }^{152}$ Ğa far Pišewari selbst floh zusammen mit über 6.000 Anhängern der FDĀ über die sowjetische Grenze. Viele andere Mitglieder des Regimes fielen der Lynchjustiz der Täbriser Bevölkerung und den harten Unterdrückungsmaßnahmen der nun eingesetzten Militärregierung zum Opfer. ${ }^{153}$ Kurz nach Täbris kapitulierten auch die kurdischen Führer um Ġāzi Mohammad in Mahābād. ${ }^{154}$

Mit dem Abzug der sowjetischen Armee, der Auflösung der autonomen Regime im Norden und der politischen Marginalisierung der Tudeh hatte die UdSSR sämtliche Einflussinstrumente innerhalb Irans eingebüßt. Damit waren auch die Chancen für eine Ratifizierung des ĠawāmSadčikow-,Abkommens“ stark gesunken. Der „Erfolg“ der Aserbaidschankrise und insbesondere Moskaus Preisgabe der autonomen Regime hatte Skeptiker einer Konfrontationsstrategie innerhalb der Truman-Administration eines Besseren belehrt Undersecretary of State Dean Acheson erinnerte sich später: „I would have bet a thousand to one that such a thing would not happen, and I was just as wrong as I could be." ${ }^{\text {*155 }}$ Wieder einmal ermuntert von Botschafter Allen, der in einer Aufsehen erregenden Rede im September

\footnotetext{
${ }^{150}$ Zum „Rechtsruck“ der HDI vgl. ABRAHAMIAN, Two Revolutions, S. 238.

151 Allen bestätigte das US-Interesse am Erhalt der iranischen Unabhängigkeit und die Zusage der Unterstützung gegen externen Druck ,[...] not only by words but also by appropriate acts.“; State \#976, 22.11.46, FRUS 46, VII, S. 546f.; das zuvor zögerliche State Department hatte dem von den JCS empfohlenen Verkauf militärischer Güter über \$10 Millionen zugestimmt. Vgl. Henderson Memo, 18.10.46, ebd., S. 533-6, 535 n1; die Grundsatzentscheidung über die Gewährung militärischer Unterstützung an die Staaten des Northern Tier fiel am 29.10.46. Vgl. Hilldring Memo, 29.10.46, ebd., S. 255; vgl. SCHNABEL, History of the JCS: I, S. 56ff.; siehe auch JCS History Iran, S. $17 \mathrm{f}$.

${ }_{152}$ Vgl. HASANLi, Dawn, S. 370.

153 Die Zahlenangabe entstammt ebd., S. 379ff.; Hasanli erwähnt 760 Hinrichtungen und über 3.000 weitere Todesopfer in den ersten Tagen. Vgl. Tabriz \#263, 12.12.46, FRUS 46, VII, S. 561f.; Stalin untersagte der FDA $\bar{A}$ die Aufnahme eines Partisanenkampfs. Die FDĀ führte im sowjetischen Exil ein Schattendasein bis zum Jahr 1960, als sie sich wieder mit der Tudeh zusammenschloss. Pišewari kam bei einem Autounfall ums Leben, wobei nicht auszuschließen ist, dass es sich in Wirklichkeit um einen von oberster Stelle angeordneten Mord handelte. Siehe RAINE, Creation, S. 30, 38 n138; zum späteren Zusammenschluss von Tudeh und FDĀ siehe ABRAHAMIAN, Two Revolutions, S. 455.

154 Vgl. MCDowALl, History of the Kurds, S. 240-7; die kurdische Führung unter Gāzi Mohammad hatte wiederholt um amerikanische Vermittlung bei der Zentralregierung gebeten und dabei sogar militärische Unterstützung gegen Aserbaidschan in Aussicht gestellt. Vgl. SSU, No. 394, 27.6.46, ,Folder \#4', OSS Records, Previously Withdrawn Material, Entry 210, Box 324, RG 226, NACP; der Schah ließ Gāzi Mohammad und einige Verwandte trotz amerikanischer Proteste hinrichten. Vgl. RooseVELT, For Lust of Knowing, S. 288.

${ }^{155}$ Zit. aus BEISNER, Patterns of Peril, S. 335; zur Durchsetzung des konfrontativen Standpunktes vgl. KunIHOLM, Origins, S. 396-9.
} 
1947 vor der Iran-America Relations Society die Entscheidungsfreiheit des iranischen Parlaments mit Nachdruck unterstützte ${ }^{156}$, votierte schließlich der 15. Mağles am 22. Oktober 1947 mit 102:2 Stimmen gegen das Ġawām-Sadčikow-,,Abkommen“. Der in den Debatten zum Vorschein kommende nationalistische Schwung sorgte dafür, dass mit dem Entscheid nicht nur jegliche neue Konzessionsvergabe untersagt wurde. Der Beschluss enthielt zudem eine etwas kryptische Klausel, welche die Regierung beauftragte nun auch Verhandlungen mit der AIOC aufzunehmen mit dem Ziel, die ,nationalen Rechte“ Irans auch im Süden des Landes durchzusetzen. Somit enthielt das Mağles-Gesetz vom Oktober 1947, das den Ausschluss sowjetischen Einflusses aus Iran besiegelte, zugleich den Nukleus der späteren Nationalisierung der AIOC. ${ }^{157}$

Das war allerdings zu keinem Zeitpunkt die Intention der Truman-Administration gewesen, die ihre strategischen Planungen bezüglich der Region weiterhin auf Grundlage des 1944 entstandenen latenten anglo-amerikanischen Kondominium entwarf, wenngleich der Verfall britischer Macht Anfang 1947 bereits unübersehbar war. Bereits im September 1946 hatte USAußenminister Byrnes informell mit Bevin vereinbart, dass die USA einspringen würden, sollte sich Großbritannien nicht mehr in der Lage sehen, die drei Staaten des Northern Tier Griechenland, die Türkei und Iran - mit notwendiger militärischer Ausrüstung zu versorgen. ${ }^{158}$ Nach dem Eintreffen der beiden diplomatischen Noten im State Department am 21. Februar 1947, die das Ende der britischen Unterstützung ankündigten, erklärte sich die TrumanAdministration folgerichtig bereit, die vormals britische Rolle sogleich zu übernehmen. ${ }^{159} \mathrm{Im}$ Frühjahr 1947 war der Cold War Consensus innerhalb der Administration soweit gereift, dass nunmehr ein Gang an die Öffentlichkeit nicht mehr nur denkbar sondern geboten erschien obgleich man wachsende sowjetische Konzessionsbereitschaft und ein merkliches Abklingen der Spannungen registriert hatte. ${ }^{160}$ In den folgenden Tagen wurde fieberhaft an einer Umsetzung dieser Entscheidung gearbeitet, die schließlich in die berühmte Rede Präsident

\footnotetext{
${ }^{156}$ Vgl. State \#813, 4.4.47; State \#221, 2.5.47; State \#487, 18.8.47, FRUS 47, V, S. 902-4, 909, 934-6; zur Rede Allens siehe Tehran \#874, 11.9.47, ebd., S. 951f.; vgl. auch Hess, Iranian Crisis, S. 145; KuniHOLM, Origins, S. 414; LyTle, Origins, S. 187; Goode, Neglect, S. 12; der britische Botschafter Le Rougetel wurde dagegen zuerst instruiert, den Iranern von einer Ablehnung des Ölabkommens mit den Sowjets abzuraten. Vgl. Bevin to Inverchapel, No. 8410, 19.8.47; Bevin to Le Rougetel, No. 658, 27.8.47, FOCP IV, B, 3, S. 250, 252; vgl. SHAW, Azerbaijan Crisis, S. 294f.; den Legalismus der Administration überzogen als durchtriebene US-Strategie mit dem Ziel der Beseitigung der Vormachtstellung Londons schildernd DAVIS, New Trusteeship, 59.

${ }^{157}$ Ein prinzipielles Offenlassen zukünftiger Verhandlungen mit der Sowjetunion über das nördliche Öl, von Ġawām gewünscht um die Reaktion Moskaus abzumildern, verweigerten die Abgeordneten. Doch wurde immerhin in Aussicht gestellt, zukünftig im Norden gefördertes Öl an die UdSSR zu verkaufen. Details zu den Mağles-Verhandlungen in Tehran \#1031, 23.10.47; Tehran \#1035, 23.10.47; FRUS 47, V, S. 969-72; vgl. RamaZani, Iran's Foreign Policy, S. 181-3; AzImI, Crisis, S. 174f.; KauZ, Politische Parteien, S. 283-6; LYTLE, Origins, S. 187ff.; Allen verteidigte die AIOC-Konzession gegenüber dem Schah mit Nachdruck. Vgl. Tehran \#770, 19.8.47, FRUS 47, V, S. $936 \mathrm{f}$.

${ }^{158}$ Vgl. SCHNABEL, History of the JCS: I, S. 58ff.; KuniHOLM, Truman Doctrine, S. 94ff.; vgl. die Einträge vom 12.9. und 6.11.46 in MiLlis, Forrestal Diaries, S. 209, $215 \mathrm{f}$.

${ }^{159}$ Text der britischen Noten in FRUS 47, V, S. 32-7.

${ }^{160}$ Siehe CIG, ORE 1/1, 6.1.47, CIA-FOIA, S. 2; auch intern gab es in der Truman-Administration Kritik am gewählten Zeitpunkt: ,There has been no overt action in the immediate past by the U.S.S.R. which serves as an adequate pretext for the 'All-out' speech."; zit. aus Elsey Memo to Clifford, 7.3.47, in: Documentary History of the Truman Presidency: 8, S. 72; siehe auch George M. Elsey OHI, 7.7.70, OH-HSTL, S. 352-9, $362 \mathrm{ff}$.
} 
Trumans vor beiden Häusern des Kongresses am 12. März 1947 mündete - bald als die TrumanDoktrin in die Geschichte eingehend. ${ }^{161}$

Trotz der Stabübergabe Londons an Washington, zumindest was die Verteidigung des östlichen Mittelmeers anging, darf die britische Initiative nicht als Abdankung von der Nahostregion fehlinterpretiert werden. Vielmehr war es die Absicht der Attlee-Regierung mittels partiellem Rückzug und amerikanischer Unterstützung Ressourcen für die Verteidigung eben dieser nahöstlichen Position freizusetzen, der die Funktion des zukünftigen Schwerpunkts einer britischen Weltmachtrolle, quasi das neue Indien, zugedacht war. ${ }^{162}$ In den an die Ankündigung des britischen Rückzugs aus Griechenland anschließenden Pentagon-Gesprächen vom OktoberNovember 1947 zeigten sich die Amerikaner durchaus aufgeschlossen gegenüber den imperialen Problemen Großbritanniens und insbesondere gegenüber der zentralen Frage der Revision des Anglo-Ägyptischen Vertrages von 1936. ${ }^{163}$ Im Kern eine Neuauflage der angloamerikanischen Nahostverhandlungen von 1944, führten die Pentagon-Gespräche zu einer Reihe von informellen Absprachen zwischen beiden Mächten mit Bezug auf die Nahostregion. Die fortgesetzte westliche Kontrolle über die Gesamtregion sei eine kriegsentscheidende Notwendigkeit, so die Amerikaner während der Verhandlungen, und die Eindämmung bzw. der Ausschluss sowjetischen Einflusses lebenswichtig. Somit schien die Einleitung eines umfassenden Hilfsprogramms zur Stabilisierung der Region geboten, und demgemäß auch eine konsequente Bestätigung der bestehenden britischen Position seitens der USA. ${ }^{164}$ Die USA sprachen sich für die Beibehaltung einer ,starken strategischen, politischen und ökonomischen Position“ Großbritanniens aus. Gleichzeitig betonte man aber, dass dies auf keinen Fall als Zugeständnis einer (exklusiven) britischen Einflusssphäre missverstanden werden dürfe: ,[...] it would not follow that we should become a sort of Middle Eastern junior partner of the British, nor that we should be placed in the position of more or less blindly following the British lead“. ${ }^{165}$ Das gemeinsame Abschlussdokument demonstrierte dennoch, wie vereinbar

${ }^{161}$ Die Literatur zur Entstehung der Truman-Doktrin ist kaum noch überschaubar. Konzise Zusammenfassungen des bürokratischen Prozesses bei Kuniholm, Truman Doctrine; LefFler, Preponderance, S. 142-6; vgl. Kuniholm, Origins, S. 420-3; Kennans klassische Kritik an der Rhetorik der Doktrin in KenNAN, Memoirs: I, S. 314ff., 321f.; für den Text der Rede selbst siehe Special Message, 12.3.47, PPP: Truman 1947, S. 176-80.

${ }_{162} \mathrm{Zu}$ dieser Räson vgl. REYNOLDS, Britannia Overruled, S. 158ff.; mit der Übernahme vormals britischer Verpflichtungen entlang des Northern Tier schien die Umsetzung der ehrgeizigen Ziele Bevins und des Foreign Office möglich: Die Etablierung einer reformierten, eher informellen britischen Vormachtstellung in den arabischen Kerngebieten der Nahostregion, basierend auf einer Zusammenarbeit mit bestehenden monarchischen Regimes und moderaten Nationalisten. Vgl. KInGSTON, Politics of Modernization; für die Strategiedebatten siehe COHEN, Fighting World War Three, S. 69-88; AldRICH/ZAMETICA, Rise and Decline.

${ }^{163}$ Zur Entstehungsgeschichte der Pentagon Talks siehe State Memo, o.D., FRUS 47, V, S. 488-96; vgl. LOUIS, Empire in the Middle East, S. 226-64; HAHN, United States, Great Britain, and Egypt; zum Hintergrund der Gespräche vgl. DAVIS, Anglo-American Middle East.

${ }^{164}$ Vgl. Hare Memo, 5.11.47, FRUS 47, V, S. 577; State Memo, o.D., ebd., S. 575; konkret wurde amerikanische Unterstützung zugesagt für die Beibehaltung britischer Stützpunkte bzw. britischer Nutzungs- und Zugangsrechte in Ägypten, für die Errichtung weiterer britischer Stützpunkte (und in der Folge faktische politische Kontrolle) in der Kyrenaika, der Bewahrung der britischen Stellung im Sudan, sowie der Etablierung einer modernisierten und verstärkten britischen Präsenz im Irak unter Einschluss der strategisch wichtigen Luftwaffenbasen in al-Habbānīya und aš-Ša'bīya. Vgl. LouIS, Empire in the Middle East, S. 322-31; KINGSTON, Politics of Modernization, S. 94122.

${ }^{165}$ General Statement by the American Group, o.D., FRUS 47, V, S. 583; Hare Memo, 5.11.47, ebd., S. 579; Raymond A. Hare, ein bekannter „Arabist“ im State Department und Mitte der 1960er Assistant Secretary of State for Near Eastern Affairs and South Asian Affairs, begründete in seiner unveröffentlichten Autobiographie die hohe 
amerikanische und britische Ziele hinsichtlich der Nahostregion im Herbst 1947 nunmehr in der Folge der perzipierten Bedrohung durch die sowjetische Macht erschienen. Somit waren die Resultate der Pentagon-Gespräche die vielleicht nachdrücklichste Bekräftigung des während des Zweiten Weltkriegs etablierten latenten anglo-amerikanischen Kondominiums, enthielten aber zugleich den Nukleus des sich in den folgenden zwanzig Jahren vollziehenden Zerfalls desselben.

Das in den anglo-amerikanischen Gesprächen angedachte umfangreiche Aufbau- und Modernisierungsprogram für den Nahen und Mittleren Osten kam allerdings nicht zustande. Die JCS und der neu gegründete Policy Planning Staff unter Kennan sprachen sich für eine zuvorderst auf Westeuropa gerichtete, vorwiegend ökonomische Stabilisierungspolitik aus, andere Weltregionen vernachlässigend. ${ }^{166}$ Angesichts der frühen Aufmerksamkeit für Griechenland und die Türkei war es erstaunlich, dass Iran, obwohl Schauplatz einer direkten und öffentlich ausgetragenen Konfrontation im noch jungen Kalten Krieg und seit 1946 als „vital“ bzw. „major interest" für die nationale Sicherheit der USA befunden, in diesen Jahren weitgehend ignoriert wurde. In einer Rangordnung in einer Studie des SWNCC-ad-hocKomitees vom April 1947 wurde Iran noch gemeinsam mit Italien als drittwichtigstes Land aus US-Sicht unmittelbar nach Griechenland und der Türkei genannt. ${ }^{167}$ Kurz darauf überging eine 16 Länder umfassende, nach strategischer Wichtigkeit geordnete Liste der JCS Iran dann aber völlig. Die JCS sprachen sich nunmehr gegen die Aufnahme von Hilfsleistungen an Iran aus, entgegen ihrer Einschätzung vom Oktober des vorhergehenden Jahres. Aus Sicht der USMilitärplaner waren die Staaten entlang der südlichen Peripherie der UdSSR eher eine Bürde als eine potentielle Verstärkung der eigenen Position. ${ }^{168}$ Dennoch bekräftigte der neu gegründete National Security Council (NSC) im Februar 1948 erneut die ,vitale“ Bedeutung des östlichen Mittelmeers und des Nahen und Mittleren Ostens für die Sicherheit der USA selbst und definierte die Bewahrung der Unabhängigkeit und Integrität der Türkei, Griechenlands, Irans und Italiens als unmittelbares Politikziel. ${ }^{169}$

Dies änderte jedoch nichts an der Überzeugung der US-Planer, dass eine Aufrüstung Irans wenig sinnvoll war. Selbst umfangreiche amerikanische Militärhilfe würde die iranischen Streitkräfte nicht in die Lage versetzen, etwas mehr als sporadischen Widerstand zu leisten bzw.

Geheimhaltung mit der Sorge vor ,[...] charges of an Anglo-American condominium“; Paul Hare, ,Tales of Arabia and Beyond', o.D., ,Folder 14', Box 1, Hare Papers, GUL.

${ }^{166}$ Vgl. GADDIS, Strategies, S. 55-65; LEFFLER, Preponderance, S. 148-51, 157-64.

${ }^{167}$ Report of the Special 'Ad Hoc' Committee of the SWNCC, 21.4.47, FRUS 47, III, S. 208, 206; bereits zuvor hatte eine anderes Komitee im State Department Iran als viertwichtigstes Empfängerland für zukünftige Militärhilfe eingestuft. Vgl. PCA M-37, 7.3.47, FRUS 47, I, S. 722-4.

168 Begründet wurde diese geänderte Einschätzung mit der Unfähigkeit Irans (und ebenso Iraks und SaudiArabiens) einen sowjetischen Angriff abzuwehren, außer bei direkter militärischer Unterstützung durch USStreitkräfte. Siehe JCS 1769/1, 29.4.47, encl. to JCS Memo, 12.5.47, ebd., S. 737f., 742; widersprüchlich aber dagegen die gleichzeitige Betonung der strategischen Bedeutung der Ölfelder. Vgl. PAINTER, Oil and Marshall Plan; zur „Energiekrise“" vgl. PALMER, Guardians of the Gulf, S. 42ff.; RosEnBERG, Problem of Oil, S. 55; ANDERSON, ARAMCO, S. $165 \mathrm{f}$.

${ }^{169}$ Vgl. NSC 5/2, 12.2.48, FRUS 48, IV, S. 46-51. 
wenig effektive Guerilla-ähnliche Operationen gegen sowjetische Invasoren durchzuführen. Dies führte zu Beschwerden seitens der Iraner, die Truman-Doktrin errichte nur zwei Drittel eines Damms gegen die sowjetische Bedrohung. Das verbliebene Drittel, eben Iran, sei aber schutzlos der Gefahr ausgesetzt. ${ }^{170}$ Somit sprachen 1947 vor allem militärstrategische Einschätzungen der Lage gegen eine Gleichbehandlung Irans mit der Türkei. ${ }^{171}$ Relativiert wurde diese Tendenz allerdings immer durch die Betonung der gegenseitigen Verflechtung der Sicherheitsinteressen an den verschiedenen Staaten des Northern Tier, was im Grunde unabhängig von militärischer Realisierbarkeit - die Aufgabe auch nur eines Bausteins der „Eindämmungskette“ strikt untersagte. Dean Acheson hatte bereits im Kontext der TrumanDoktrin gegenüber Kongressabgeordneten analog zur späteren Domino-Theorie argumentiert: Ähnlich wie ,[...] apples in a barrel infected by one rotten one, the corruption of Greece would infect Iran and all to the east." 172 Die amerikanische Sicherheitsgarantie für die Türkei und Griechenland galt somit de facto auch für Iran. ${ }^{173}$

Konkrete Umsetzungen der Sicherheitsgarantie für Iran blieben jedoch aus, abgesehen von der limitierten und ohnehin nur begrenzt iranische Sicherheitsinteressen tangierenden Etablierung einer dauerhaften Marinepräsenz der U.S. Navy im Persischen Golf im Januar 1948 in Bahrain, später unter der Bezeichnung Middle East Force (MEF) bekannt. ${ }^{174}$ Unmittelbar nach Ablehnung des Ölabkommens im Oktober 1947 hatten die Iraner, praktisch als Belohnung, eine Gleichstellung mit den Hauptadressaten der Truman-Doktrin erwartet - und wurden sogleich ein weiteres Mal enttäuscht. ${ }^{175}$ Vorerst musste sich Iran mit dem im Juni 1947 gewährten Kredit

\footnotetext{
${ }^{170}$ Siehe State \#434, 29.7.47, FRUS 47, V, S. 925ff., und ebd., S. $924 n 1$; ähnliche Überlegungen einer iranischen „Lücke“ im Eindämmungsgürtel finden sich in Joint Strategic Plans Committee 814/3, 11.12.47, DDRS: CK2349346257, S. 18; vgl. CIA, ORE 48, 20.10.47, CIA-FOIA, S. 4; vgl. JCS Memo [SANACC 358/8], 24.11.48, FRUS 48, IV, S. 191f.

${ }^{171}$ Während die Bedeutung der Ölfelder im Persischen Golf bereits im Oktober 1946 als „vital“ eingeschätzt wurde, bezeichnete man Iran nunmehr nur als ,,area of major strategic interest to the United States“; SWNCC Memo, 12.10.46, FRUS 46, VII, S. 530 \{Hervorheb. v. Verf.\}; vgl. PALMER, Guardians of the Gulf, S. $37 \mathrm{ff}$.

172 ACHeson, Present at the Creation, S. 219.

173 Vgl. Tehran \#506, 14.6.47; State \#337, 21.6.47, FRUS 47, V, S. 913f., 916ff.; allerdings sahen es die militärischen Planungen im Laufe des Jahres 1948 als unmöglich an, im Kriegsfall eine sowjetische Besetzung der Ölfelder am Golf zu verhindern - einige Notfallplanungen sahen sogar im Kriegsfall die Evakuierung Westeuropas sowie der gesamten Nahostregion, also auch von Kairo-Suez, vor, doch wurde dies bald wieder revidiert. Vgl. COHEN, Fighting World War Three, S. 20-3; vgl. CONDIT, History of the JCS: II, S. 153-8; ALDRICH/ZAMETICA, Rise and Decline, S. 254f.; man plante zugleich die vorsorgliche Zerstörung der Ölförderanlagen in der Golfregion, um einen Zuwachs der sowjetischen Kapazitäten im Falle einer drohenden Besetzung zu unterbinden bzw. zumindest hinauszuzögern. Siehe SANACC 398/1, 6.5.48, abgedr. in MEJCHER, Die Politik und das Öl: II, S. 43342; vgl. MemCon, 23.8.50, FRUS 50, V, S. 72f.; Truman unterzeichnete 1949 NSC 26/2, das die Umsetzung einer Zerstörung der Ölförderanlagen im Kriegsfall regelte. Siehe Memo [Summary of NSC Meeting], 7.1.49, DDRS: CK2349284840; vgl. auch SANACC 398/4, 25.5.48, ,FMACC Minutes', NEA/Records of the Military Adviser, 1945-1950, Box 4, RG 59, NACP; vgl. Bruce Memo, 7.4.52, FRUS 50-55: The Intelligence Community, S. 243ff.; vgl. REARDEN, History of the Office of the Secretary of Defense: I, S. 203-8; TELHAMI, The Stakes, S. 140ff.; Handschriftliche Notiz [Staff Meeting Minutes], 13.3.51, ,NSC 54 Series [...] ', NSC Files, 1947-1961, Coordinating Division, OASD/ISA, Box 8, RG 330, NACP; die Eisenhower-Administration verabschiedete im Januar 1954 die Folgestudie NSC 5401. Vgl. auch NSC Planning Board Report on NSC 176, 22.12.53, DDRS: CK2349473601; nach weiteren Beratungen mit den Briten wurden die Planungen auf sämtliche Ölförder- und Öltransportanlagen in der Levante und in Ägypten ausgedehnt. Vgl. OCB Progress Report NSC 5401, 22.6.56, ,President's Papers 1956 (7)', WHO, OSANSA, Special Assistant Ser., Presidential Subs., Box 3, DDEL; vgl. auch ed. note in FRUS 55-57, XII, S. 442; zu den Navy-Plänen vgl. RoSENBERG, Problem of Oil, S. 54-7.

${ }^{174}$ Vgl. ebd., S. 56-61; PALMER, Guardians of the Gulf, S. 45-51.

175 Vgl. Tehran \#1056, 30.10.47, FRUS 47, V, S. 974-6; Gawām hatte dies bereits im Juni angekündigt. Siehe Tehran $\# 579,28.6 .47$, ebd., S. $918 \mathrm{ff}$.
} 
über \$25 Millionen für den Einkauf amerikanischer Militärgüter zufrieden geben. ${ }^{176}$ Dabei spielten auf US-Seite auch Überlegungen eine Rolle, dass eine zu weitgehende Integration Irans in die entstehende militärische Eindämmungsstruktur politisch gefährlich sein könnte. John Jernegan, inzwischen zum ersten Leiter der neu geschaffenen Division of Greek, Turkish, and Iranian Affairs (GTI) innerhalb NEAs bestimmt, zweifelte offen, ob ,[...] Iran's safety can best be promoted by arraying her unequivocally and irrevocably in the Western camp in opposition to the Soviet Union. “177

In der Tat wurde die Position des State Departments von einer nicht geringen Zahl von Iranern geteilt. Nur unter großen Schwierigkeiten gelang im Februar 1948 die Ratifikation des amerikanischen Militärkredits durch den Mağles. ${ }^{178}$ Aufgrund der vielen Verzögerungen dauerte es schließlich bis zum Frühjahr 1949, bevor die ersten Lieferungen militärischer Güter in Iran eintrafen. Fragen der Aufrüstung, des US-Militärkredits und des Fortbestehens der amerikanischen Hilfsmissionen wurden dabei immer maßgeblich durch den weiterhin bestehenden Machtkonflikt zwischen Hof und Ministerpräsident beeinflusst. Aus Sicht derjenigen Teile des iranischen politischen Establishments, die eine Rückkehr zu den diktatorischen Regierungsformen unter Rezā Šāh zu verhindern trachteten, konnte eine zusätzliche Stärkung der weitgehend unter Kontrolle des Schahs stehenden Armee aber kaum als wünschenswert betrachtet werden. Ein erster wichtiger Sieg der Hofkreise und vor allem des neuen starken Mannes, Generalstabschef 'Ali Razmārā, der sowohl das Vertrauen des Monarchen genoss wie auch aufgrund seiner Rolle als Kommandeur der militärischen Operationen in Aserbaidschan eine gewisse Popularität erworben hatte, war die Beseitigung der autonomen Rolle der vom amerikanischen Berater Brigadegeneral Norman Schwarzkopf Senior maßgeblich seit 1942 aufgebauten Gendarmerie und ihre Eingliederung in die reguläre Armee im Sommer 1949. ${ }^{179}$ Aus amerikanischer Sicht war ohnehin die vormals zweitrangige Beratermission bei der iranischen Armee in den Vordergrund gerückt. Mit einem Abkommen im Oktober 1947 auf eine neue vertragliche Basis gestellt, wurde die erweiterte und aufgewertete American Military Mission With the Iranian Army, bald unter dem Akronym ARMISH geläufig, in der Folgezeit zu einem der wichtigsten Einflussinstrumente der USA in

\footnotetext{
${ }^{176}$ Das State Department verweigerte die Umwandlung des Darlehens in nicht rückzahlbare Direkthilfen. Vgl. State \#337, 21.6.47, ebd., S. 916ff.; vgl. ed. note in ebd., S. 916; vgl. JCS History Iran, S. 34f.; vgl. GASIOROWSKI, Client State, S. 52; GoODE, Neglect, S. 32ff.

177 Jernegan Letter, 9.12.47, FRUS 47, V, S. 993; vgl. FAWCETT, Iran and the Cold War, S. 139f.; für einen Überblick über die sich verändernden Einschätzungen der Rolle Irans in der amerikanischen strategischen Gesamtkonzeption siehe BYRNE, Road to Intervention, S. 201-26; zur Gründung der GTI siehe KUNIHOLM, Origins, S. 423.

178 Trotz einer am Ende klaren Mehrheit reduzierte das Parlament die Höhe der Kreditanfrage wieder auf \$10 Millionen und stellte darüber hinaus Bedingungen, die weitere Nachverhandlungen erforderten. Erst im Juli 1948 kamen diese zum Abschluss. Vgl. Tehran \#196, 18.2.48, FRUS 48, V, S. 110; vgl. GoodE, Neglect, S. 34f.

179 Formal eine Polizeitruppe und damit dem Innenminister unterstellt, hatte der Mağles den Ausbau der Gendarmerie lange Zeit unterstützt, den Modernisierungsbemühungen seitens der Armee dagegen fortwährend Widerstand geleistet. Zu Schwarzkopfs Arbeit vgl. RICKS, U.S. Military Missions, S. 170-3; zur Entlassung Schwarzkopfs aus seinen Verpflichtungen und zur Revision des Abkommens vom November 1943 vgl. GoODE, Neglect, S. 27ff.; RAMAZANI, Iran's Foreign Policy, S. 159f.; vgl. Tehran \#655, 15.5.49; State \#473, 24.5.49; State \#485, 27.5.49, FRUS 49, VI, S. 518f., 522f., 527; zu Razmārā vgl. GHODS, Razmara; Milani, Eminent Persians: I, S. 483-9.
} 
Iran. ${ }^{180}$ Im Rückblick aus dem Jahr 1956 wurde die ARMISH-Vereinbarung vom Oktober 1947 aus britischer Sicht als Schlüsselereignis interpretiert, das die amerikanische Monopolstellung im militärischen Bereich begründet und den Transfer der Vormachtstellung von Großbritannien auf die USA formalisiert habe. ${ }^{181}$

Inzwischen war auch der intensiv geführte Machtkampf zwischen Ministerpräsident und Schah zugunsten des letzteren entschieden worden. Zwar war es Ġawām und seiner HDI in der Tat gelungen, die Wahlen zum 15. Mağles mittels Wahlfälschungen, Einschüchterungen und mittels Kontrolle der Verwaltungen zu dominieren und sich im August 1947 mit 78 Stimmen der insgesamt 122 Stimmen erneut zum Ministerpräsidenten wählen zu lassen. Ohne die Unterstützung der linken Kräfte musste aber der Versuch, Iran durch eine heterogene Honoratiorenpartei wie die HDI zu kontrollieren, scheitern. ${ }^{182}$ Mit der Ablehnung des sowjetisch-iranischen Ölabkommens im Oktober 1947 hatte Ġawām aus Sicht des Hofs seine Schuldigkeit getan. Offenbar durch finanzielle und anderer Offerten seitens des Hofs inspiriert, trat die Hälfte der HDI-Deputierten zur Opposition über. Ġawāms Vertrauensvotum im Mağles scheiterte, offenbar minutiös von Ašraf, der Zwillingsschwester des Schahs, vorbereitet. ${ }^{183}$ Damit ging die zweijährige Amtszeit des wichtigsten Opponenten gegen die politischen Ambitionen des jungen Schahs zu Ende.

Bald wandelte sich die Vorgehensweise der Amerikaner vor Ort analog zur zunehmend rigoros antikommunistischen Politik in Washington selbst. Dem trotz seines Eingreifens vom Oktober 1946 in den internen Machtkampf meist vorsichtig, nuanciert und diplomatisch agierendem Allen war im Februar 1948 John Wiley als US-Botschafter in Teheran nachgefolgt. Wileys manichäische Weltsicht, und seine Entschlossenheit - geteilt vom ARMISH-Leiter Generalmajor Robert W. Grow - das vermeintliche sowjetische Vordringen im Nahen und Mittleren Osten mit allen Mitteln stoppen zu müssen, resultierten in einer Konzentration der US-Politik vor Ort zuvorderst auf diejenigen Maßnahmen, die den Widerstandswillen der Iraner zu stärken versprachen. ${ }^{184}$ Begünstigt wurde diese Haltung durch die zunehmende Militarisierung der Eindämmungspolitik. Gleichzeitig verstärkte die ansteigende Präsenz amerikanischer Militärberater und Geheimdienstoffiziere - bereits Anfang 1947 hatte eine

\footnotetext{
${ }_{180} \mathrm{Vgl}$. ed. note in FRUS 47, V, S. 966; der Text des in abgewandelter Form bis in die frühen 1970er Jahre verlängerten Abkommens in: AlEXANDER/NANES, United States and Iran, S. 155-61; vgl. RICKS, U.S. Military Missions, S. 173ff.; RAMAZANI, Iran's Foreign Policy, S. 160f.; MoTTER, Persian Corridor, S. $476 \mathrm{f}$.

${ }^{181}$ Vgl. Stevens to Lloyd, No. 139, 7.12.56, FO 371/120724, TNA:PRO.

182 Zu siehe vor allem KauZ, Politische Parteien, S. 251-63; ABRAHAMIAN, Two Revolutions, S. 242f.; AzIMI, Crisis, S. 170f.; vgl.CIA, ORE 65-48, 8.10.48, CIA-FOIA, S. 3.

${ }^{183}$ Vgl. AzImI, Crisis, S. $176 f f . ;$ KAuZ, Politische Parteien, S. 286-93; Goode, Neglect, S. 14; Ġāsem Ġani, ein dem Hof nahestehender Beobachter, beschrieb in seinem Tagebuch den ungewöhnlichem Einfluss Ašrafs, die Ernennungen bis hinunter zur Stufe der Staatssekretäre mitbestimmte. Vgl. GHANI, Diaries, S. 253; Einschätzungen zu den langfristigen Konsequenzen des Rücktritts bei CoTTAM, Iran and the United States, S. 85; LADJEVARDI, Origins of Support, S. $233 \mathrm{ff}$.

${ }^{184} \mathrm{Zu}$ Wiley vgl. GoodE, Neglect, S. 15; COTTAM, Iran and the United States, S. $85 \mathrm{ff}$;; Grows Nähe zum Hof und seine Bevorzugung einer Schah-Diktatur in Grow Memo, 9.5.48, ,TOP SECRET 1948`, Iran, Tehran Embassy, "TOP SECRET" File. 1946-49, RG 84, NACP; der abkommandierte Schwarzkopf hatte zuletzt an Washington appelliert, das Abgleiten in einen „Polizeistaat“" zu verhindern. Vgl. GooDE, Neglect, S. 27.
} 
Station der bald zur CIA zusammengeschlossenen Nachrichtendienste die entsprechenden Funktionen der Militärattachés und anderer mit ähnlichen Aufgaben betrauter Botschaftsangehöriger übernommen - die Tendenz hin zu einer verkürzenden Perspektive auf die inneren Entwicklungen Irans und einer einseitigen Betonung innerer Stabilität, zuvorderst durch eine Stärkung der Armee. So begrüßte eine Einschätzung der CIA vom Januar 1948 den Machtzuwachs von Hof und Armee, da nur er wirkungsvolleres Handeln gegen sowjetische Infiltrations- und Subversionsversuche verspreche. ${ }^{185}$

In diesem Kontext wandelte sich auch die US-Position gegenüber Wünschen Mohammad Rezās nach einer konstitutionellen Reform mit dem Ziel einer weiteren Stärkung seiner politischen Position. Anfangs abgelehnt von Idealisten im State Department wie GTI-Direktor John Jernegan als Schwächung des Parlamentarismus und der Etablierung des ,personal rule“ des Schahs in Iran, führte letztlich ein Ereignis im Februar 1949 zu einer Kehrtwende in der USPolitik. ${ }^{186}$ Am 4. Februar 1949 entging Mohammad Rezā nur knapp einem Anschlag auf sein Leben während einer Veranstaltung in der Teheraner Universität. Der Attentäter, als Photograph für eine extremistisch-islamische Zeitung getarnt, aber offenbar in Wirklichkeit der Tudeh nahestehend, wurde umgehend von der Entourage des Schahs überwältigt und erschossen. ${ }^{187}$ Sein durch das überstandene Attentat kurzzeitig gewachsenes Renommee nutzte Mohammad Rezā, um den Mağles zur Einberufung einer konstitutionellen Versammlung zu bewegen. Nur zwei bis drei Monate später waren zentrale Punkte seiner neuen konstitutionellen Konzeption umgesetzt, die nach Einschätzung der CIA in ihrer Gesamtheit ein weiteres Verschieben der Machtbalance zugunsten des Schahs bewirkte, u.a. das Recht zur Auflösung des Parlaments und die Einrichtung eines von Hof und Armee dominierten Senats als zweiter Kammer. ${ }^{188}$ Gemeinsam mit dem nach dem Attentat verfügten Verbot der Tudeh-Partei, der erneuten Ausrufung des Kriegsrechts, der Unterdrückung anderer oppositioneller Gruppierungen und Presseorgane und der bevorstehenden Wahlen zum 16. Mağles schien die Dominanz des Schahs im politischen System Irans vorerst besiegelt. Für viele Zeitgenossen stellte die konstitutionelle „Reform“ von 1949 und die mit ihr einhergehenden Maßnahmen nichts weniger als einen Staatsstreich dar, der die parlamentarisch-konstitutionellen

\footnotetext{
${ }^{185}$ Zur Gründung der CIA-Station in Teheran vgl. GASIOROwSKI, Client State, S. 54f.; vgl. CIA, Review of World Situation, 12.1.48, DDRS: CK2349367740, S. 5 .

${ }^{186}$ Vgl. Jernegan Memo, 4.12.47, FRUS 47, V, S. 991f.; der Schah informierte den US-Botschafter, er gedenke das amerikanische ,check and balance $\{s i c\}$ system“ einzuführen, warnte aber zugleich vor den damit einhergehenden Maßnahmen ,.[... ] which might be interpreted as 'dictatorial measures'“; Tehran \#467, 3.5.48, 891.00/5-348, CF 45-49.

${ }^{187}$ Vgl. Tehran \#119, 4.2.49, FRUS 49, VI, S. 478; die CIA erhielt mit Verspätung Informationen, die auf einen groß angelegten Umsturzversuch der Tudeh hinzudeuten schienen. Dennoch ging sie von einem,,act of individual terrorism rather than part of a widespread plot“" aus. Vgl. CIA Information Report, 21.2.49, CREST: \#RDP82*0020; CIA, ORE 65-49, 27.6.49, CIA-FOIA; uneinig über den Hintergrund ist die spätere Geschichtsschreibung. Vgl. LYTLE, Origins, S. 194; Goode, Neglect, S. 22; dagegen AzIMI, Crisis, S. 203; RuBIN, Good Intentions, S. 40; unentschlossen BILL, Eagle and Lion, S. 51; COTTAM, Iran and the United States, S. 86; ANSARI, Modern Iran, S. 104; GASIOROwSKi, Client State, S. 48; ABRAHAMIAN, Two Revolutions, S. 249f;; eine gemeinsame Verschwörung Razmārās und der Tudeh konstruiert KATOuZIAN, Struggle for Power, S. 69f.; der Schah selbst glaubte Jahre später an eine britische Verschwörung. Siehe den Eintrag vom 7.1.70 in ALAM, Diary, S. 122f.

${ }_{188}$ Zur konstitutionellen Versammlung siehe Tehran \#A-84, 4.3.49, FRUS 49, VI, S. 486; die Einschätzung der CIA in CIA, ORE 65-49, 27.6.49, CIA-FOIA, S. 3f.
} 
Grundlagen des Verfassungssystems weiter aushöhlte. ${ }^{189}$ Ex-Premier Ġawām kritisierte das Vorgehen des Schahs denn auch scharf in zwei öffentlichen Briefen aus seinem europäischen Exil.

Der Versuch des Hofs, die Regierungsgeschäfte nun unmittelbar zu führen, scheiterte jedoch an den Realitäten Irans. Im Anschluss an die von ihm mit großem Eifer betriebene Verfassungsreform hatte Mohammad Rezā die Gelegenheit, zum zentralen Träger der von den USA gewünschten, effizienten Zentralregierung zu werden, rasch verspielt: „The Shah, an earnest young man full of good intentions, cannot make up his mind whether he should reign or rule, and consequently does neither. [...] His indecision is monumental and his moral courage debatable."190 Das Auftreten des jungen Monarchen während seines ersten Staatsbesuchs im November 1949 in den Vereinigten Staaten trug zur Beschädigung seiner Reputation bei, da er in seinen Gesprächen mit amerikanischen Offiziellen fortwährend die sowjetische Bedrohung und die dringende Notwendigkeit sofortiger und großzügiger Militärhilfe für Iran in den Vordergrund stellte, eine Ausweitung der Truman-Doktrin auf Iran und eine Sicherheitsgarantie forderte, die dringlicheren wirtschaftlichen Probleme des Landes und die unzureichenden Verwaltungsstrukturen und die gängige Korruption aber nur am Rande erwähnte. ${ }^{191}$ Hier wurde bereits die durchaus als Obsession zu qualifizierende Priorisierung militärischer Belange durch Mohammad Rezā sichtbar, die maßgeblich die bilateralen Beziehungen bis in die 1970er beeinflussen sollte, insbesondere die fast schon pathologische Vorliebe des Schahs für die modernste Waffentechnologie. Neben seinen Plänen zum Erwerb strahlgetriebener Kampfflugzeuge für die iranische Luftwaffe verlangte er nun auch zusätzlich 100 mittlere M-4 Sherman sowie 100 leichte M-24 Panzer, Warnungen der ARMISH-Mission in den Wind schlagend. Botschafter Wiley zufolge bewegten sich die militärischen Ambitionen des Schahs „strictly in never never land.“192 Angesichts des von ihm erkannten gewaltigen Bedarfs an Militärhilfe konnte die tatsächliche US-Unterstützung für Mohammad Rezā nur unzureichend ausfallen. Zwar war Iran in das parallel zu den Verhandlungen über den Nordatlantikakt konzipierte globale Militärhilfeprogramm integriert worden. ${ }^{193}$ Statt auf Darlehensbasis erhielt Iran nunmehr militärische Güter als nicht rückzahlbare Zuwendungen, eine alte Forderung der Iraner erfüllend, doch blieb der Lieferumfang weit unter den Erwartungen. Als sogenanntes Title III-Empfängerland erhielt Iran nur symbolische Unterstützung (,token' aid) - die letztlich

\footnotetext{
${ }^{189}$ Apologetisch behandelt bei LeNCZOwSKI, Second Pahlavi Kingship, S. 436ff.; der CIA zufolge war der Schah nun der, greatest single influence in the government“; CIA, ORE 90-49, 9.11.49, CIA-FOIA; allgemein zum Kurswechsel zugunsten diktatorischer Bestrebungen vgl. SCHMITZ, Right-Wing Dictatorships, 1921-1965, S. 141168 .

${ }_{190}^{168}$ State Paper, UM D-97 ,The Present Crisis in Iran', o.D. [ca. 19.4.50], FRUS 50, V, S. 509-18, hier S. 512.

191 Vgl. ACHESON, Present at the Creation, S. 502; GOODE, Neglect, S. 57; MCGHEE, Envoy, S. 69; in einer Vorwegnahme der die bilateralen Beziehungen in den nächsten Jahrzehnten immer wieder belastenden Debatten insistierte Mohammad Rezā auf eine Aufstockung der Armee von der bestehenden Sollstärke von 132.000 Mann auf 180.000. Vgl. Acheson Memo, 18.11.49; MemCons, 18.11.49, FRUS 49, VI, S. 572-80.

${ }_{192}$ Tehran \#807, 14.6.49, 891.001Pahlavi, Reza Shah/6-1449, CF 45-49; MemCon, 18.11.49, ,MAP Miscellaneous, 1949', NEA/Records of the Military Adviser, 1945-1950, Box 1, RG 59, NACP; vgl. FRUS 49, VI, S. $529 n 1$.

${ }^{193}$ Vgl. LeFFLER, Preponderance, S. 285f.; Robertson Memo, 26.7.49, ,Iran - MAP', NEA/Records of the Military Adviser, 1945-1950, Box 1, RG 59, NACP.
} 
resultierende Militärhilfe für das Etatjahr 1950 belief sich nur auf enttäuschende \$11.7 Millionen. ${ }^{194}$

Das wachsende Engagement der USA in Iran und insbesondere der amerikanischen ,Men on the Spot" belastete auch bald das Verhältnis zu den Briten, allein schon aufgrund der Stellung der AIOC und ihres weitreichenden Einflusses auf den Mağles weiterhin die präponderante Macht in Iran. Es war vor allem die Sorge vor einem britischen Eindringen in das eigene Beratungsmonopol bei den iranischen Sicherheitskräften, welche die Truman-Administration im März 1948 zu massivem Druck auf die Regierung in Teheran bewegte, Forderungen nach einer Revision der der ARMISH-Vereinbarung aufzugeben. Zentral war dabei der Wunsch nach Streichung des Artikels 24, der die iranische Regierung für die Dauer der Gültigkeit des Vertrags verpflichtete, keine Berater aus anderen Staaten für den Dienst in der iranischen Armee anzuwerben. Unter Druck gesetzt mit der Drohung eines unilateralen Rückzuges der US-Mission und möglichen Konsequenzen hinsichtlich des Militärkredits, gaben Razmārā und der Schah ihre Forderung nach Revision der ARMISH-Vereinbarung auf. ${ }^{195}$ Botschafter Wiley sah den britischen Verbündeten auch als treibende Kraft hinter den megalomanen Aufrüstungsideen Mohammad Rezās im Anschluss an seinen ersten Staatsbesuch in London im Sommer 1948. Hier hatte sich ebenfalls die fast schon obsessive Beschäftigung des jungen Herrschers mit dem Ausbau der iranischen Luftwaffe - ungeachtet der ,astronomischen Kosten“ - gezeigt. ${ }^{196}$ Die Regierung in London reagierte allerdings sehr zurückhaltend auf die Wünsche des Schahs und koordinierte - ganz im Geiste der Pentagon-Gespräche von 1947 ihr Vorgehen mit den USA. ${ }^{197}$

Innerhalb des anglo-amerikanischen Kondominiums im Nahen und Mittleren Osten strebte das überlegene Machtpotential der USA schrittweise nach Dominanz, eine Tendenz, die auch in Iran in den späten 1940ern zu beobachten war. ${ }^{198}$ Symptomatisch war der rasante Ausbau des

\footnotetext{
${ }^{194}$ Vgl. CONDIT, History of the JCS: II, S. 426-36; JCS History Iran, S. 35ff.; der US-Kongress bewilligte für die Title II-Länder Griechenland und die Türkei gemeinsam über \$211 Millionen. Die mithilfe des Militärkredits von 1947 zu stark reduzierten Preisen erworbenen Güter hatten einen tatsächlichen Gesamtwert von \$54 Millionen, somit die Militärhilfe für 1950 erheblich übertreffend. Siehe DOD Memo, 1.2.49, DDRS: CK2349394402; , Mutual Defense Assistance Agreement between the United States of America and Iran', 23.5.50, DNSA: IR00215.

${ }^{195}$ Vgl. State \#310, 9.4.48, FRUS 48, V, S. 136f.; vgl. ebd., S. 146 n4; vgl. GoODE, Neglect, S. 29f.; die Iraner forderten 1957 und 1958 erneut eine Streichung von Artikel 24. Siehe Tehran \#A-123, 19.11.57, 788.5/10-2957, CF 55-59; Ashford Memo, 7.11.57, ,Iran Armish-MAAG Mission 1957‘, Lot 60 D 533, Subject Files Relating to Iran, 1951-1958, OiCIA/GTI, Box 9; Sturm Memo, 15.10.58, ,[Iran] Status of Forces [1958] 3-A', Box 10, ebd.; Russell to Lloyd, No. 131, 11.11.57, FO 371/126909, TNA:PRO.

${ }^{196}$ Angedacht war die Einrichtung einer parallelen britischen Beratermission für die Luftwaffe und die Ausstattung letzterer mit hochmodernen britischen de Havilland Vampire-Düsenjägern. Vgl. London \#3549, 5.8.48, FRUS 48, V, S. 170f.; 176 n1; , astronomisch“" in Tehran \#1041, 3.9.48, ebd., S. 176f.; Tehran \#1037, 2.9.48, 891.20/9-248, CF $45-49$.

${ }^{197}$ Auf lokaler Ebene führte die Affäre allerdings zu einigen Spannungen. Vgl. Tehran \#549, 20.5.48; Wiley Letter, 21.5.48, ,TOP SECRET 1948“, Iran, Tehran Embassy, "TOP SECRET" File. 1946-49, RG 84, NACP; die anglophobe Haltung Grows war einer der Gründe für seine baldige Abberufung. Vgl. GoodE, Neglect, S. 31, $119 \mathrm{f}$. $n 19$; die britischen Chiefs of Staff entschieden, maximal sechs - statt der vom Schah erhofften 200 - Vampires an Iran zu liefern, um die Option einer zukünftigen engeren Zusammenarbeit mit der iranischen Luftwaffe offenzuhalten.

${ }^{198}$ Die Einschätzung von Kauz, wonach die USA bereits mit der Intervention vom Oktober 1946 , die bestimmende ausländische Macht für Iran“ geworden seien, geht dennoch zu weit. So KAUZ, Politische Parteien, S. 220.
} 
pro-amerikanischen Netzwerks: Nicht nur der Hof, sondern auch einige ehemalige britische Parteigänger wandten sich an die US-Botschaft auf der Suche nach Unterstützung, den schleichenden Einflussverlust Großbritanniens in Iran dokumentierend. Im kommerziellen Bereich zeigten sich zunehmend Rivalitäten und Eifersüchteleien zwischen den angloamerikanischen Mächten, so z.B. im Bereich des zivilen Luftfahrtwesens, wenngleich eine Konkurrenz im zentralen Feld der Ölförderung ostentativ vermieden wurde. ${ }^{199}$ Problematisch aus Sicht Londons war aber sicherlich der bald dominierende US-Einfluss in der Wirtschaftsplanung. Im Einklang mit den Pentagon-Gesprächen vom Herbst 1947 waren einige Beispielprojekte zugunsten wirtschaftlichen Wachstums und Modernisierung konzipiert worden, die man mit Unterstützung der Internationalen Bank für Wiederaufbau und Entwicklung (International Bank for Reconstruction and Development/IBRD) umzusetzen hoffte. Zur Unterstützung des Antrags beauftragten die Iraner ein amerikanisches Konsortium, die Morrison-Knudsen Corporation, mit der Ausarbeitung eines nationalen Wirtschaftsplans, vorgelegt im August 1947, der umfangreiche Entwicklungsmaßnahmen in sämtlichen Wirtschaftsbereichen vorsah und letztlich in einen ambitionierten Siebenjahresplan mündete. ${ }^{200}$ Im Kontext der Wirtschaftsplanung erfolgte der gesellschaftliche Aufstieg einer Reihe von iranischen Persönlichkeiten aus dem Umfeld des pro-amerikanischen Netzwerkes, häufig zum Nachteil britischer kommerzieller Interessen, wie z.B. der die Planungsaktivitäten der 1950er Jahre maßgeblich prägende Abu 1-Hasan Ebtehāğ, nun Direktor der Nationalbank. ${ }^{201}$ Zugleich begann nun die Zeit seines amerikanischen Vertrauten Max Weston Thornburg, international operierender Ölunternehmer und ehemals Petroleum Advisor im State Department. Ein weiteres amerikanisches Konsortium, die Overseas Consultants, Inc. (OCI), überarbeitete den bestehenden Siebenjahresplan, der schließlich im Februar 1949 vom Mağles in Gesetzesform verabschiedet wurde. Für die Zukunft der iranischen Entwicklung war dabei von besonderer Bedeutung, dass mit dem Gesetz eine von Regierung und Parlament weitgehend unabhängige und autonome Planungsbehörde geschaffen wurde, alsbald wichtiger zusätzlicher Einflusspunkt der USA mit temporär erheblicher Machtfülle, gerade in fiskalischer Hinsicht. In der Praxis agierte die Behörde als eine Art Schattenregierung. ${ }^{202}$

\footnotetext{
${ }^{199}$ Die CIA zeigte fortwährend ein erhebliches Interesse an der Zukunft der zivilen Luftfahrt und an den Iranian Airways. Vgl. CIG Memo, 19.3.47, DDRS: CK2349162755; eine Quelle aus dem Jahr 1957 aus dem State Department referenzierte etwas ominös das amerikanische „deep interest“ am Erfolg der Fluglinie. Vgl. Williams Memo, 10.10.57, ,Iran Airways 1957‘, Lot 60 D 533, Subject Files Relating to Iran, 1951-1958, OiCIA/GTI, Box 9.

${ }^{200}$ Ministerpräsident Ġawām hatte bereits im Oktober 1946 zur Finanzierung seiner Reformideen einen Kreditantrag über die fantastisch anmutende Summe von \$250 Millionen bei der Bank gestellt. Vgl. LOONEY, Economic Cycles, S. 83-94; der Siebenjahresplan hatte eine Größenordnung von \$500 Millionen, in etwa 14 iranischen Jahresbudgets entsprechend. Vgl. CIA, ORE 65-48, 8.10.48, CIA-FOIA, S. 5; vgl. KINGSTON, Politics of Modernization, S. 71.

${ }^{201}$ Ebtehāğ setzte durch, dass die Imperial Bank of Iran mit Ablauf ihrer 1889 gewährten Konzession im Januar 1949 einen großen Teil ihrer vormals herausgehobenen Stellung einbüßte. Vgl. BosTOCK/JONES, Planning and Power, S. 72-80; vgl. JONES, Banking and Oil, S. 3-33.

${ }^{202}$ Vgl. CIA, ORE 65-48, 8.10.48, CIA-FOIA, S. 5; GoOdE, Neglect, S. 40-4; Bostock/JONES, Planning and Power, S. 93-100; zu Thornburgs Rolle grundlegend QAIMMAQAMI, Catalyst of Nationalization, S. 7; BALDWIN, Planning and Development, S. 24-31; BAYNE, Persian Kingship, S. 144-9.
} 
Gerade der Hof unterstützte anfangs die Autonomie der Planorganisation und den Einfluss der OCI - Thornburg selbst residierte als neuer Vizepräsident der OCI bis 1951 in Teheran, zumal sich so die Budgetkontrolle des Mağles bequem unterlaufen ließ. Von Anbeginn an war die Arbeit der Planorganisation starken Versuchen politischer Einflussnahme ausgesetzt, was ihre Arbeit erheblich beeinträchtigte. ${ }^{203}$ Die Stellung der OCI - wenngleich formell eine privatwirtschaftliche Initiative ${ }^{204}$ - verstärkte die Wahrnehmung amerikanischen Einflusses auf Regierungsgeschäfte des Landes, zumal viele Iraner das Konsortium, nicht ganz zu Unrecht, als Organ der Politik der Truman-Administration wahrnahmen. Aus britischer Sicht gefährlich mussten die vielen Hoffnungen erscheinen, welche die Aktivitäten der Planorganisation und der Siebenjahresplan geweckt hatten. Es war absehbar, dass sich - sollten die erhofften Kredite ausbleiben - das Augenmerk rasch auf die eigenen nationalen Ressourcen richten würde, um ein Entwicklungsprogramm zu finanzieren, auch und gerade mit Blick auf die von der AIOC jährlich gezahlten Öltantiemen. ${ }^{205}$

Genau diese Entwicklung traf dann auch ein. Weder wurde die erhoffte US-Wirtschaftshilfe in großem Ausmaß gewährt noch stimmte die Weltbank dem Kreditwunsch zu, trotz detaillierter Vorarbeiten der OCI. ${ }^{206}$ In der Folge litt das Ansehen der USA in Iran beträchtlich. ${ }^{207}$ Die größten Auswirkungen aber hatte das Scheitern der Wirtschaftsplanung, wie in London befürchtet, auf die britisch-iranischen Beziehungen. Die bereits seit Ende 1947 laufenden informellen Revisionsverhandlungen über die Konzession zwischen AIOC und iranischer Regierung standen alsbald unter dem Schatten des durch Initiierung des Siebenjahresplans entstandenen Finanzbedarfs. In diesem Kontext führten die Aktivitäten des ehemaligen „Ölmanns“ Thornburg und der OCI zu erheblichen Verstimmungen mit London. Der von Thornburg betriebene Aufbau einer indigenen iranischen Ölindustrie in denjenigen Teilen des Landes, die nicht unter Konzession der AIOC standen, zielte letztlich auf die Verringerung der Abhängigkeit von ausländischer Expertise und ließ auf britischer Seite Zweifel wachsen, ob der Verbündete nicht doch nach vollständiger Verdrängung des eigenen Einflusses trachtete. ${ }^{208}$

\footnotetext{
203 Vgl. Bostock/Jones, Planning and Power, S. 104f.; Kingston, Politics of Modernization, S. 83ff.; RamaZAnI, Iran's Foreign Policy, S. 162ff.; die technokratische Ausrichtung der OCI-Pläne kritisiert KEDDIE, Modern Iran [2003], S. $121 \mathrm{ff}$.

${ }^{204}$ Die direkte Verbindung OCIs zur amerikanischen Intelligence Community wird nachdrücklich suggeriert von PISANI, CIA and Marshall Plan, S. 122; vgl. HerSH, The Old Boys, S. 330; überzogen bei DorRIL, MI6, S. 566; Interesse bestand jedoch am Ausbau der bestehenden Kontakte zu den neuen politischen Eliten in Iran, die sich insbesondere im Umfeld der Planorganisation fanden. So ist es sicherlich kein Zufall, dass Ebtehāğ sowohl den späteren CIA-Direktor Dulles wie auch den Organisator des Coups von 1953, Kermit Roosevelt, persönlich kannte. Siehe Bostock/Jones, Planning and Power, S. 107; Roosevelt, Arabs, Oil and History, S. 210.

${ }^{205}$ Vgl. QAimmaQAmi, Catalyst of Nationalization, S. 8f., 13; Tehran \#576, 29.4.49, FRUS 49, VI, S. 514ff.

206 Vgl. BALDWIN, Planning and Development, S. 25f.; für die verschiedenen Anfragen an die Weltbank siehe Bostock/Jones, Planning and Power, S. 100f.; Rougetel to Attlee, No. 289, 8.8.49, FOCP IV, B, 7, S. 188f.; die grundsätzliche State Department-Position in State \#477, 25.5.49, FRUS 49, VI, S. 523ff.

${ }^{207}$ Vgl. State Paper, o.D. [21.4.50], FRUS 50, V, S. 509-18, hier 511; Ebtehāğ plädierte nun für eine Finanzierung des Plans ausschließlich unter Heranziehung eigener finanzieller Ressourcen und lehnte eine weitere Anfrage an die Weltbank ab, was zu einem Konflikt mit dem Schah führte. Vgl. BosTock/Jones, Planning and Power, S. 101; GoODE, Neglect, S. 44, 123f. $n 15$; zu amerikanischen Propagandaanstrengungen gegenüber Iran in dieser Phase vgl. KISATSKY, Voice of America and Iran.

${ }^{208}$ Für Wiley hatte der Aufbau einer eigenen nationalen Ölindustrie ,[...] all the hazardous qualities of roulette.“; Tehran \#708, 25.6.48, 891.6363/6-2448, CF 45-49.
} 
Wieder in der Rückschau aus dem Jahr 1956 zeigte man sich in London überzeugt, dass , ,[..] the nationalisation of the Iranian oil industry was stimulated and encouraged by Americans in the service of the Iranians who were not in any sense officials of the U.S. Government (notably Mr. Thornberg $\{s i c\}$ ).“209 Die Quellenlage spricht dagegen recht eindeutig gegen diese These - weder das State Department noch die amerikanischen Öl-Majors hatten zu diesem Zeitpunkt ein Interesse an einer Infragestellung der britischen Monopolstellung in der Ölförderung in Iran. $^{210}$

US-Botschafter Wiley unterschätzte die in den AIOC-Verhandlungen lauernden Gefahren einer Eskalation und nationalen Krise, da er weiterhin die Hauptgefahr für die innere Stabilität, analog zu seinem durchaus als wahnhaft einzuschätzenden Antisowjetismus, von Norden kommend sah - ein sowjetischer Einmarsch war für Wiley nur eine Frage der Zeit. Gemeinsam mit seinem - bald berüchtigten - Mitarbeiter Gerald F. P. Dooher betrieb Wiley einen antikommunistischen Kreuzzug in Iran, der zu erneuten Spannungen mit Moskau und zur Polarisierung der iranischen Gesellschaft beitrug. ${ }^{211}$ Die Einschätzungen amerikanischer Planer und Nachrichtenoffiziere widersprachen aber dem Alarmismus Wileys. ${ }^{212}$ NSC 54, das erste zentrale Planungsdokument der Truman-Administration zu Iran, verabschiedet vom NSC am 4. August 1949, bekräftigte weiterhin die Bedeutung Irans als fortgesetztes Ziel sowjetischer Expansion, führte aber zugleich aus, dass in nächster Zeit nicht mit einer militärischen Intervention $\mathrm{zu}$ rechnen sei. ${ }^{213}$ Bedrohlicher seien sowjetische Subversionsoperationen in Iran, wenngleich der Einfluss Moskaus weitgehend zurückgedrängt worden war - so war die pro-sowjetische Tudeh durch die Repressionen seit 1946 geschwächt

\footnotetext{
209 Stevens to Lloyd, No. 139, 7.12.56, FO 371/120724, TNA:PRO; vgl. QAimMAQAmI, Catalyst of Nationalization, S. 1f., $2 n 1$, 9; den Vorwurf einer subtilen, gegen das AIOC-Monopol gerichteten Unterminierungsstrategie unterstützend DAVIS, New Trusteeship, S. 59; WATT, Succeeding John Bull, S. 126f.; die Unterminierung der britischen Nahostposition als Leitmotiv in KELLY, Arabia, the Gulf and the West; aus neokorporatistischer theoretischer Perspektive zu ähnlichem Ergebnis kommend VITALIS, America's Kingdom; überzeugender die These von James Goode, die amerikanische Diplomatie habe Iran zwischen 1947 und 1950 vernachlässigt und damit der anschließenden Ölkrise mit ihren Verwerfungen erst den Weg bereitet. Siehe GOODE, Neglect, S. 23; Dean Acheson schob die Verantwortung später dem Versagen der US-Vertreter vor Ort zu. Vgl. ACHESON, Present at the Creation, S. 499-502.

210 Nach dem Scheitern der zwischenstaatlichen Versuche eines anglo-amerikanischen Erdölausgleichs hatten Absprachen zwischen den großen Ölkonzernen und der AIOC eine neue Struktur des Welterdölmarkts etabliert, welche für die Majors von großem Vorteil war. Vgl. STOFF, Oil, War, and American Security, S. 200-8; BLAIR, Control of Oil, S. 130-9; Yergin, The Prize, S. 409-30; BAMBERG, History of BP: II, S. 334ff.; vgl. McGhee Memo, 3.12.46, FRUS 46, VII, S. 40-3.

${ }^{211}$ Siehe Wiley Letter, 29.3.49, FRUS 49, VI, S. 496f.; das Zitat in Satterthwaite Memo, 3.5.49, ebd., S. 517 ; Vgl. John H. Stutesman OHI, 22.6.88, FAOH; Evan M. Wilson OHI, 18.7.75, OH-HSTL, S. 61f.; vgl. GoODE, Neglect, S. 10f.; so sprach sich Wiley dafür aus, den sowjetisch-iranischen Freundschaftsvertrag von 1921 öffentlich aufzukündigen, da die Sowjets dessen Artikel V und VI in ihren diplomatischen Noten wiederholt als Druckmittel benutzt hatten. Artikel V des Vertrags verpflichtete die Vertragsparteien, keinerlei gegen den Anderen gerichtete feindselige Handlungen auf dem eigenen Territorium zuzulassen. Artikel VI gestand Russland im Falle der Nutzung persischen Territoriums als Basis für militärisch Operationen ,,[...] the right to advance its troops into Persian territory in order to take the necessary military action in self defense" zu; Moscow Treaty Between the Russian Socialist Federated Soviet Republic and Persia, 26.2.21, in: DMYTRYSHYN/COX, Soviet Union and the Middle East, S. 260-71, hier 263; vgl. Tehran \#772, 5.7.48; Istanbul \#206, 15.7.48, FRUS 48, V, S. 154f., 160f.; das State Department lehnte das Ansinnen als unnötig provokativ ab.

${ }^{212}$ Vgl. CIA, ORE 58-48, 30.7.48, CIA-FOIA, S. 7, 10.

${ }^{213}$ Vgl. NSC 54, 21.7.49, FRUS 49, VI, S. 545-51.
} 
und zudem internen Spannungen ausgesetzt. ${ }^{214}$ Erfolgreicher waren sowjetische Penetrationsversuche gerichtet auf die iranische Armee, wie später das 1954 entdeckte TudehNetzwerk in den Streitkräften demonstrierte. Die bereits 1944 begründete, sogenannte „Militärorganisation“ (Sāzemān-e Nezāmi-je Hezb-e Tude-je Irān) bzw. die „Offiziersorganisation“ (Sāzemān-e Afsarān), die zum Zeitpunkt ihrer Zerschlagung fast 500 Offiziere umfasste, wobei das größte Wachstum erst in der Mosaddeg-Periode zu verzeichnen war, diente offenbar zuvorderst der Nachrichtenbeschaffung und weniger der tatsächlichen Umsturzvorbereitung. ${ }^{215}$ Radio Moskaus Sendungen in Farsi und der von Baku aus operierende „Freie Aserbaidschanische Sender“, der auch Sendungen in Azeri und Kurdisch offerierte, konzentrierten sich auf die zahlreichen wirtschaftlichen und sozialen Probleme in Iran. Gegen diese ideologische Offensive startete der US-Propagandasender Voice of America im März 1949 seine eigenes Radioprogramm in Farsi. ${ }^{216}$

Bereits zuvor hatten die USA im Anschluss an die Einleitung verschärfter politischer Kriegführung infolge von NSC 10/2 im Juni 1948 eine großangelegte CIA-Operation in Iran eingeleitet. Die Operation unter dem Codenamen TPBEDAMN, das Präfix TP dabei das gängige CIA-interne Länderkürzel für Iran, mit einem Etat zwischen einer halben und einer Million US-Dollar - aus einem globalen Gesamtbudget für verdeckte Operationen von etwa \$82 Millionen - zielte vorrangig auf Erzeugen antikommunistischer Einstellungen und die Förderung von gegen die Tudeh gerichteten Gruppierungen und Parteien. ‘Ali Ğalāli und Fārug Kajwāni - namentlich bekannt seit der Veröffentlichung der internen Geschichte des Coups von 1953 durch die New York Times im Jahr 2000 - bauten nach ihrer Anwerbung 1951 in Iran ein Subagentennetz von ca. hundert Personen auf, eine Art amerikanisches Pendant zum bereits erwähnten, für die Briten arbeitenden Rašidijān-Netzwerk. TPBEDAMN-Operationen umfassten Aktionen wie das Platzieren antikommunistischer Zeitungsartikel und Karikaturen, das Verteilen ebensolcher Flugblätter, die Verbreitung gefälschter Tudeh-Schriften zum Zweck der Desavouierung der iranischen Linken, das Organisieren von Demonstrationen bis hin körperlichen Angriffen auf pro-sowjetische Demonstranten und Büros der Tudeh und sogenannte ,schwarze“ Operationen wie Attacken auf religiöse Symbole und Moscheen, für die dann die Kommunisten verantwortlich gemacht wurden. ${ }^{217}$ Parallel zu den

\footnotetext{
${ }^{214}$ NSC 54 führte explizit aus, dass die ,Tudeh Party [...] does not have the capability of overthrowing the regime from within at this time.“; siehe ebd., 549; vgl. Summary of NSC Meeting, 4.8.49, DDRS: CK2349284671; die Gesamtmitgliederzahl der Tudeh wurde Anfang 1949 auf nur etwa 25.000 geschätzt. Vgl. CIA, ORE 23-49, 18.7.49, CIA-FOIA; Embassy Report, , The Nucleus of the Tudeh Party', 1.1.51, DNSA: IR00229.

${ }^{215}$ Für iranische Studien zur Militärorganisation siehe XOSROU-PANĀH, Sāzemān-e Afsarān-e; vgl. ZABIH, The Left, S. 9, 12ff.; auf nach der Zerschlagung seitens der Regierung veröffentlichten Informationen basiert die Analyse von MIYATA, Tudeh Military Network; die CIA verwendete die zutage getretenen Informationen für eine Fallstudie über kommunistische Penetration von Streitkräften. Vgl. CIA, , The Officer's Organization of the Tudeh Party“, Januar 1955, CREST: \#RDP78*005-9; vgl. auch D. T. West Minute, 12.9.58, FO 371/133006, TNA:PRO. ${ }^{216}$ Vgl. KISATSKY, Voice of America and Iran; VAUGHAN, Failure of Propaganda, S. 36ff.; vgl. RoOSEVELT, For Lust of Knowing, S. 300-5; zur Rolle der sowjetischen Propaganda und Kulturdiplomatie vgl. PICKETT, Soviet Civilization; MOSSAKI/RAVANDI-FADAI, Guarded Courtship.

${ }^{217}$ Zur Rolle der „,verdeckten“" politischen Kriegführung gegen die Sowjets und NSC 10/2 siehe u.a. HIXSON, Parting the Curtain, S. 1-27; DEL PERO, Role of Covert Operations; CORKE, Bridging the Gap; dies., US Covert Operations, S. 58-63; Details zu TPBEDAMN in erster Linie bei GASIOROWSKI, TPBEDAMN Operation; ders., 1953 Coup d'Etat, S. 268ff.; ders., Coup Against Mosaddeq, S. 235ff.; Ğalāli und Kajwāni wurden anschließend
} 
antikommunistischen Operationen lief der weitere Ausbau des pro-amerikanischen Netzwerks, klandestin wie offen. Die zu dieser Zeit anberaumten engen Beziehungen zu einigen der weitgehend autonomen Stämme in Iran - insbesondere zur Stammeskonföderation der Gašs̆gāe $i$ - durch amerikanische Geheimdienstoffiziere wie dem erwähnten Gerry Dooher oder dem späteren Organisators des 1953-er Coups, Kermit «Kim» Roosevelt, waren wohl eher der Abenteuerlust dieser Akteure geschuldet sowie dem Wunsch, die Hochzeiten eines Kiplingschen „Great Game“ in Asien wenigstens in Auszügen selbst zu erleben. ${ }^{218}$

Die übertriebene Aufmerksamkeit für die, ohnehin nur sehr limitierte, Bedrohung seitens der Sowjetunion und ihrer Parteigänger in Iran verleitete die US-Vertreter vor Ort dazu, den heraufziehenden innenpolitischen Sturm zu übersehen. Die vonseiten der USA nach anfänglicher Skepsis als reformförderlich gepriesene Etablierung des Schahs als bestimmende Macht im konstitutionellen Aufbau des Landes trug entgegen der Erwartungen zu einer Destabilisierung der Lage bei. Enttäuscht vom amerikanischen Desinteresse, gab Mohammad Rezā seine bisherige Unterstützung für die von den USA befürworteten umgreifenden Reformen auf. Planorganisation und Siebenjahresplan stagnierten ab dem Herbst 1949. Die Zentralisierung politischer Macht im Hof führte nicht zu größerer Effektivität, sondern zum Aufstieg von Günstlingen wie dem korrupten 'Ali Mansur, der im März 1950 das Ministerpräsidentenamt übernahm. „Reform-minded and progressive Iranians“, viele aus dem Kreis des pro-amerikanischen Netzwerks, zogen sich enttäuscht aus Politik und Regierungsbürokratie zurück. ${ }^{219}$ Die CIA registrierte nun auf einmal Ressentiments gegen die US-Repräsentanten vor Ort, die, so die Kritik, ,[...] are attempting to assume a pervasive influence in internal affairs, of the sort traditionally associated with the British Embassy in Tehran“, ohne zugleich Bereitschaft zu zeigen, dem Land spürbare Unterstützung zuteil werden zu lassen. 220

Auf den sich abzeichnenden amerikanischen Einflussverlust im Frühjahr 1950 reagierte die Truman-Administration mit einer politischen Kehrtwende, angetrieben von George C.

\footnotetext{
unter den Codenamen NERREN und CILLEY geführt. Zur Verheimlichung ihrer Identität gegenüber MI6 im Vorfeld des Coups siehe CIA [Donald N. Wilber], Clandestine Service History, S. 7f.; Beispiele bei WILBER, Adventures, S. 191.

218 Vorgeblicher Hauptzweck des Aufbaus enger Kontakte zu den Ġašḡài war die Organisation von „Stay Behind"-Aktivitäten im Falle einer sowjetischen Besetzung Irans. Vgl. GASIOROWSKI, stay-behind Operation; ders., TPBEDAMN Operation, S. 8f.; Foster Memo, 20.5.52, Iran Collection, National Security Archive; grundlegend zum „Mind-Set“ der frühen CIA-Akteure jetzt WILFORD, America's Great Game; zu Kim Roosevelt vgl. ebd., S. 3-16; MEYER/BRYSAC, Kingmakers, S. 322-47; zwar machten Stammesangehörige immerhin etwa ein Viertel der Gesamtbevölkerung von insgesamt etwa 14 Millionen aus, ihre politische Bedeutung nahm aber für jeden halbwegs informierten Beobachter augenfällig - rapide ab. Zur zeitgenössischen Überschätzung ihrer Bedeutung vgl. RooseVELT, Arabs, Oil and History, S. 199-206; 1948 übernahm Roosevelt die Leitung der Middle East Division im OPC. Vgl. Hersh, Old Boys, S. 331; RoOsevelt, For Lust of Knowing, S. 298f., COPELAND, Game of Nations, S. 47-60; siehe auch ders., The Game Player, S. 111, 131.

${ }^{219}$ Zur Berufung Mansurs vgl. Tehran \#520, 23.3.50, FRUS 50, V, S. 490f.; Zitat aus State Paper, o.D. [21.4.50], ebd., S. 512; vgl. AZIMI, Crisis, S. 218-25; HEISS, Empire and Nationhood, S. $22 \mathrm{f}$.; dies führte auch zu Belastungen im Verhältnis zwischen Amerikanern und Mitgliedern des Netzwerks wie z.B. Ebtehāğg. Eine Instruktion des State Department vom Mai 1950 sprach abwertend von der ökonomischen und finanziellen Kontrolle Irans durch die „Ebtehaj-Mansur-Naficy family group“; State \#594, 22.5.50, 788.5-MAP/5-2250, CF 50-54.

${ }^{220}$ CIA, ORE 90-49, 9.11.49, CIA-FOIA, S. 6.
} 
McGhee, ehemals Coordinator des Hilfsprogramms für die Türkei und Griechenland und nach einer Umorganisation innerhalb des State Department - seit Juni 1949 der erste Assistant Secretary of State for Near Eastern and African Affairs (ab Oktober: Near Eastern, South Asian, and African Affairs) und neue Leiter von NEA ${ }^{221}$. Noch Ende 1949 war die Situation in Iran als erstaunlich stabil eingeschätzt worden - nur wenige Monate später war plötzlich von „The Present Crisis in Iran“ die Rede. ${ }^{222}$ Angesichts der gravierenden wirtschaftlichen Probleme und dem Legitimitätsverlust der herrschenden Klassen hielt man nun einen Aufstand der Bevölkerung, ja sogar einen erfolgreichen Putsch der Tudeh, für denkbar, die noch in NSC 54 vom Juli 1949 zu findenden Grundannahmen revidierend. McGhee plädierte daher nun zugunsten einer Wende in der US-Politik und zugunsten umfassender Wirtschaftshilfe für den bedrohten Iran. ${ }^{223}$

Der überraschende wie präzedenzlose Alarmismus, der sich im Frühjahr 1950 in den Analysen und Berichten von State Department und NSC wiederfand, war allerdings nur bedingt durch Entwicklungen innerhalb Irans ausgelöst worden. Der Richtungswechsel lässt sich besser verstehen, zieht man die breitere Transformation der amerikanischen Außenpolitik Anfang der 1950er Jahre in die Analyse mit ein. Im Anschluss an Trumans Entscheidung vom 31. Januar 1950 zugunsten des Baus der Wasserstoffbombe - in Reaktion auf den Verlust des atomaren Monopols der USA und den kommunistischen Sieg im chinesischen Bürgerkrieg - wurde die Formulierung einer umfassenden nationalen Sicherheitsstrategie in Auftrag gegeben. Eine vom Nachfolger Kennans als Direktor des Policy Planning Staff, Paul H. Nitze, geleitete Arbeitsgruppe formulierte im Anschluss die Studie NSC 68, im April 1950 dem NSC vorgelegt. In religiös-manichäischer Terminologie warnte NSC 68 vor den Folgen einer weiteren Ausdehnung des sowjetischen Imperiums, die nicht nur das Ende der amerikanischen Republik bedeuten würde, sondern auch den Untergang der Zivilisation an sich. ${ }^{224}$ Im Kontext des unerwarteten Ausbruchs des Koreakriegs zwischenzeitlich als geradezu prophetisch angesehen, wurde die spätere Version NSC 68/4 im Dezember 1950 von Truman gebilligt und in der Folge einige der grundsätzlichen Empfehlungen zum Ausbau der militärischen Kapazitäten

\footnotetext{
${ }^{221}$ Loy Henderson war während der Gründungsphase Israels im Kontext zionistischer Kritik an der Haltung von NEA als Direktor abgelöst worden. McGhee übernahm am 28.6.49. Das bisherige Office of Near Eastern and African Affairs (NEA) wurde nun durch das Bureau of Near Eastern, South Asian, and African Affairs (NEA) ersetzt, weiterhin unter McGhee. NEA untergeordnet war weiterhin das Office of Greek, Turkish, and Iranian Affairs (GTI) (vormals Division) unter Jernegan. Siehe ed. notes in FRUS 49, VI, S. 433f., 1418; George C. McGhee OHI, 11.6.75, OH-HSTL, S. 41ff.; vgl. MCGHEE, On the Frontline, S. 47-51.

${ }^{222}$ Positiv und optimistisch noch CIA, ORE 90-49, 9.11.49, CIA-FOIA, S. 1; so der Titel des State Paper, o.D. [21.4.50], FRUS 50, V, S. 509-18; zur Entstehung vgl. Woodbridge Memo, 3.4.50, ,3.300 General, May 1941 through April 1950‘, Lot 54 D 363, Iranian Files 1947-50, NEA/GTI, Box 36; vgl. CIA 3-50, 15.3.50, DDRS: CK2349376133, S. 5.

${ }^{223}$ Eine angedachte Revision von NSC 54 kam nicht zum Abschluss. Siehe FRUS 50, V, S. 520 n6; vgl. McGhee Memo, 25.4.50, ebd., S. 521-526; Einschätzungen zu McGhees Wirken bei GooDE, United States and Iran, S. 27; LOUIS, Empire in the Middle East, S. 596f.; William M. Rountree OHI, 20.9.89, OH-HSTL, S. 18; Henry Allen Holmes OHI, 9.3.99, FAOH, o.S.; McGhee fand aber Unterstützung für seine Ideen in der akademischen Welt. Siehe z.B. Young, Between Russia and Reform.

${ }_{224}$ Vgl. Rusk Memo, 18.1.50; Truman Directive to Acheson, 31.1.50, FRUS 50, I, S. 138f.; 141f.; LEFFLER, Preponderance, S. 359; aus der umfangreichen Literatur zu NSC 68 siehe vor allem vgl. HoGAN, Cross of Iron, S. 291-312; NEWMAN, NSC 68; JOHNSON, Improbable Dangers, S. 72-8, 115f.; REARDEN, History of the Office of the Secretary of Defense: I, S. 521-35; der Text in NSC 68, 7.4.50, 14.4.50, FRUS 50, I, S. 234-92.
} 
implementiert. ${ }^{225}$ Die ausufernde Rhetorik diente aber wohl eher dem Zweck, innere bürokratische Widerstände gegen die anberaumte großflächige Mobilisierung der amerikanischen Kapazitäten zu überwinden, - ,[...] to bludgeon the mass mind of 'top government'“, wie Acheson später in seinen Memoiren präzisierte. ${ }^{226}$ Die Grundideen Nitzes hinter NSC 68 und den Nachfolgestudien NSC 114 und NSC 135/3 wurden im Kern aber nie umgesetzt, wie er selbst enttäuscht am Ende von Trumans Amtszeit konstatierte. ${ }^{227}$ Als Konsequenz blieb die Grand Strategy der USA auch im Anschluss an NSC 68 im Kern eine Eindämmungsstrategie.

Allerdings schuf die Debatte rund um NSC 68 ein neues Momentum im Bereich der politischen Kriegführung. In der Folge schuf die Truman-Administration im April 1951 den Psychological Strategy Board (PSB) als zentrales Koordinationsorgan für die Planung und Umsetzung der psychologischen und politischen Kriegführung und verdeckter Operationen und definierte die Zielsetzung solcherlei Aktionen im Oktober 1951 mit Verabschiedung der Studie NSC 10/5. ${ }^{228}$ Ein vom PSB im November 1952 verabschiedetes umfassendes strategisches Konzept (PSB D31) zur unkonventionellen Kriegführung im Kalten Krieg präzisierte diese Planungen. ${ }^{229}$ Während der Amtszeit Trumans wurden insgesamt 81 Geheimoperationen autorisiert. ${ }^{230}$ Obwohl die USA an der Eindämmungskonzeption festhielten, hatten die strategischen Debatten von 1950-2 somit gerade für die Staaten der Peripherie und insbesondere für Iran weitreichende Folgen, da diese letztlich zu einer Intensivierung verdeckter Operationen diesseits des Eisernen Vorhangs führten. Vieles spricht dafür, hier den Ausgangspunkt für die in der Zukunft so folgenreiche Schwerpunktsetzung auf verdeckte Operationen gerade in der sogenannten Dritten Welt zu sehen. ${ }^{231}$ NSC 10/5 hatte als zweitwichtigstes Aufgabengebiet für die CIA direkt nach der Subversion des Ostblocks das Ziel definiert, die Orientierung der Regierungen der „Freien

\footnotetext{
${ }^{225}$ NSC Report to Truman, NSC 68/4, 14.12.50, FRUS 50, I, S. 467-74; zu den verschiedenen Entwürfen von NSC 68 vgl. NEWMAN, NSC 68, S. 80ff.; vgl. GADDIS, Strategies, S. 82; vgl. auch KenNAN, Memoirs: I, S. 497-500; NiTZE, Hiroshima to Glasnost, S. 93-100; der US-Verteidigungshaushalt verdreifachte sich in der Folgezeit.

${ }^{226}$ ACHESON, Present at the Creation, S. 374.

${ }^{227}$ Bereits Mitte 1951 - von der historischen Forschung unverständlicherweise weitgehend ignoriert - war der strategische Kerngedanke Nitzes bereits zu den Akten gelegt worden. Nitzes ursprüngliches Ziel war der Aufbau eines präponderanten militärischen Machtpotentials gewesen, um die Sowjetunion quasi zur politischen Aufgabe zu zwingen. Dies ist der eigentliche performative Widerspruch in der Wirkungsgeschichte der Studie. Vgl. Memo, 12.1.53, FRUS 50, I, S. 202-5, insbesondere 205; vgl. auch Executive Secretary Report, NSC 135/3, 25.9.52, FRUS 52-54, II, S. 142-156.

${ }^{228}$ Siehe ed. note in FRUS 50-55: The Intelligence Community, S. 120f.; siehe auch bereits NSC Report, NSC 10/5, 23.10.51, ebd., S. 206ff.; zu Entstehung und Aufgabenbereich des PSB vgl. HIXSON, Parting the Curtain, S. 17-20; trotz der Befreiungsrhetorik muss ähnlich wie im Fall der militärischen Präponderanzstrategie konstatiert werden, dass auch die Ideen eines Roll-Back bzw. einer Liberation mit Bezug auf die sowjetische Sphäre nicht einmal annähernd umgesetzt wurden. Die Gruppe der „Determined Interventionists“ im Umkreis von Frank Wisner, dem Leiter des für die Ausführung verdeckter Operationen in erster Linie zuständigen OPC, wurde im August 1952 durch die Eingliederung in das neue Directorate of Plans der CIA quasi domestiziert. Siehe CIA, Office of Policy Coordination 1948-1952, o.D., CIA-FOIA, S. 24; vgl. FRUS 50-55: The Intelligence Community, S. 338 n2; RUDGERS, Origins of Covert Action, S. 258f.; CoRKE, Bridging the Gap, S. 55-8; dies., US Covert Operations, S. 119-37.

${ }^{229}$ PSB Paper, PSB D-31, 26.11.52, FRUS 50-55: The Intelligence Community, S. 375-381, hier 377; vgl. CORKE, Bridging the Gap, S. 56-9.

${ }^{230}$ Vgl. CIA, ,Coordination and Policy Approval of Covert Operations‘, 23.2.67, CIA-FOIA.

${ }^{231}$ Ein PSB-Dokument vom Februar 1952 PSB setzte Iran auf Platz Eins der Liste derjenigen Staaten ,,in which covert operations are now desirable to forestall critical situations“, gefolgt von Ägypten, Burma, Indochina, Indonesien und Panama. Vgl. PSB Memo, 4.2.52, DDRS: CK2349307236.
} 
Welt" auf die USA sowie ihren Widerstandswillen gegen die kommunistische Gefahr zu stärken. ${ }^{232}$ PSB D-31 nannte explizit Iran als einen der Staaten, in welchen „,covert manipulation of key elements“ anti-sowjetische Stabilität und Westorientiertheit garantieren sollte. ${ }^{233}$ Interne Kritiker warnten vor den Folgen dieser vermeintlich gebotenen „Stabilisierungspolitik“. Diese würde mittelfristig ,[...] guarantee the eventual loss of the cold war through the proliferation and subsidization of unstable little tyrants. “ 234

Aus Sicht amerikanischer Interessen im Nahen und Mittleren Osten stand aber zuerst einmal, ähnlich wie im Falle Ägyptens, die Frage der eigenen Positionierung im eskalierenden Konflikt zwischen den imperialen Interessen Großbritanniens und der an Stärke gewinnenden Nationalbewegung in Iran im Vordergrund. Die US-Politik seit dem Zweiten Weltkrieg hatte, den rapiden sozialen Wandel in den nahöstlichen Gesellschaften vorausahnend, den Aufbau enger und konstruktiver Beziehungen zu den sich in Wartestellung befindlichen neuen Eliten als Schlüsselziel verfolgt, wie z.B. im iranischen Beispiel die Identifizierung der Mitglieder des pro-amerikanischen Netzwerks als vermeintliche technokratische und uneingeschränkt prowestliche Zukunftselite. Angesichts der verbreiteten nationalistischen und antiimperialistischen Einstellungen innerhalb dieser neuen Eliten drohte nun aber die Anbindung der US-Politik an die des britischen Verbündeten eben diese Langzeitperspektive zu gefährden und einen Schwenk zugunsten neutralistischer oder sogar pro-sowjetischer Positionen auszulösen. ${ }^{235}$ Paul Nitze gab im April 1952 das vorherrschende Gefühl innerhalb des State Department wieder, als er seine Befürchtung äußerte, man laufe durch den Einsatz amerikanischen Prestiges zugunsten der Aufrechterhaltung der britischen Stellung Gefahr ,[...] of becoming involved in their general decline in the Middle East without being able effectively to halt it. “236 Die Amerikaner versuchten sowohl in Ägypten wie auch in Iran einen Ausgleich zwischen regionalen Nationalisten und der britischen Imperialmacht zu vermitteln, hielten aber zugleich London vor allzu aggressiven militärischen Lösungsansätzen für das „Nationalismus““Problem ab: „What we could do in 1882 would not be acceptable to world opinion in 1952.،237

\footnotetext{
${ }^{232}$ Vgl. NSC 10/5, 23.10.51, FRUS 50-55: The Intelligence Community, S. 206ff.; NSC 10/5 definierte als dritten Aufgabenbereich den Aufbau von Stay Behind-Netzwerken in strategisch wichtigen Gebieten. Bis 1955 existierte bezüglich des Nahen und Mittleren Osten nur für Iran ein Notfallplan für unkonventionelle Kriegführung, offenbar ein Residuum der bereits genannten frühen Pläne, gestützt auf Guerillaoperationen mit Unterstützung der Stämme. Anfang 1956 hatte die CIA einen Notfallplan für fünf Staaten der Region, darunter Iran, fertiggestellt. Vgl. auch OPC Paper, ,CIA/OPC Strategic War Plan', 4.5.51, ebd., S. 121-30; CIA, ,Unconventional Warfare Planning in Europe", o.D. [ca. 1956], CREST: \#RDP88*003-6.

${ }^{233}$ PSB D-31, 26.11.52, FRUS 50-55: The Intelligence Community, S. 378, 380; wie bereits oben erwähnt, war bereits 1948 eine CIA-Operation in Iran (TPBEDAMN) angelaufen mit dem Ziel, kommunistischen Einfluss zurückzudrängen. Der Entwurf einer NSC-Studie im "heißen Sommer“ von 1950 forderte ein sofortiges gemeinsames anglo-amerikanisches Programm für ,[...] aggressive action to forestall Soviet covert moves in Iran."; JCS Memo, 14.8.50, DDRS: CK2349305599.

${ }^{234}$ Schaub Memo, 8.5.50, FRUS 50, I, S. 302.

${ }^{235}$ Grundlegend zur frühen amerikanischen Reaktion auf den Neutralismus in der Dritten Welt ist BRANDS, Specter of Neutralism.

${ }^{236}$ MemCon, 24.4.52, FRUS 52-54, IX, S. 220.

${ }^{237}$ State \#2923, 14.12.51, FRUS 51, V, S. 439; in der Golfregion waren die anglo-amerikanischen Gegensätze allerdings schärfer ausgeprägt und führten zu einer Art Stellvertreterkrieg unter Heranziehen lokaler Klienten. Gerade die in der Regel mit dem Namen einer umstrittene Oase als Buraimi-Frage titulierten Auseinandersetzungen auf der Arabischen Halbinsel wurden gerade von britischen Historikern in der Folgezeit immer wieder als Beleg für die fortgesetzte amerikanische Penetrationspolitik in dem Raum, angeblich auf
} 
Eine ähnliche Haltung vertraten die Vereinigten Staaten hinsichtlich der britischen Position in Iran - wobei hier aufgrund des bereits vorhandenen Einflusses in den militärischen und wirtschaftlichen Sphären erhebliche amerikanische Interessen präsent waren. Das drohende Scheitern der Verhandlungen zwischen der iranischen Regierung und der AIOC über ein neues Ölabkommen gefährdete aber zunehmend das zentrale amerikanische Politikziel gegenüber Iran: die Sicherung der inneren Stabilität. Dem in geheimen Verhandlungen zustande gekommenen Supplemental Agreement vom Juli 1949 (nach den Verhandlungsführern auch als Gass-Golšāeijān-Abkommen bezeichnet) hatte der 15. Mağles die Ratifizierung verweigert, da es nur sehr begrenzte Zugeständnisse seitens der AIOC konzedierte. ${ }^{238}$ Amerikanische Ö1Majors informierten die Administration, die von den Iranern gewünschten Revisionen seien „reasonable“ und die Annahme der Forderungen müsse eigentlich auch aus Sicht der AIOC als eine ,sound commercial proposition“ angesehen werden müsse. ${ }^{239}$ Im September 1950 merkte ein NEA-Mitarbeiter an, „[...] Persian Gulf oil operations have been and continue to be exceptionally profitable from a commercial standpoint, particularly AIOC operations. “240 Eine spätere Berechnung der CIA zur Verteilung der Profite aus der iranischen Ölindustrie kam zu dem Schluss, dass ,[...] British profits and other income to non-Iranians currently siphon off 70 to 80 percent of the gross receipts. “241

Hauptaugenmerk der amerikanischen Politik aber war zuerst einmal die Umsetzung des von McGhee im Frühling 1950 initiierten umfassenden Hilfsprogramms für Iran. Die sogenannte Grady-Mission wurde gebildet, eine Wirtschaftsmission zur Feststellung der sinnvollsten Einsatzgebiete für einen umfangreichen Kredit der Export-Import-Bank, unter Leitung von Henry F. Grady, ehemals Botschafter in Griechenland und Indien und zudem ein enger

Übernahme der britischen Ölkonzessionen gerichtet, angeführt. So z.B. WATT, Succeeding John Bull, S. 126f.; Kelly, Arabia, the Gulf and the West, S. 69ff.; BALFour-PAul, End of Empire, S. 110-7; vgl. HarT, Security Partnership, S. 56-62; NEWSOM, Imperial Mantle, S. 87-93; vgl. FRUS 50, III, S. 981 n5; für eine vereinzelte Stimme, die die britische Position im Golf gänzlich in Frage stellte, siehe z.B. Byroade Letter, 20.2.53, ,SaudiArabia - Boundaries - Buraimi, Jan-Jun '53', , Lot 61 D 260, Subject Files Relating to the Arabian Peninsula, 1952-1960, Box 19; für die Ausnahme der bereits im Frühjahr 1950 mündlich ausgesprochenen Beistandsgarantie für Saudi-Arabien vgl. MemCon, 19.3.50, FRUS 50, V, S. 1131-45.

238 Die Verhandlungsleiter waren das Aufsichtsratsmitglied der AIOC, Neville Gass, und der iranische Finanzminister der Sā'ed-Regierung, 'Abbās-Goli Golšā'ijān. Die zentralen iranischen Forderungen fünfzigprozentige Profitbeteiligung, Offenlegung der Geschäftsbücher und iranisches Personal in höheren Führungsebenen - waren nicht erfüllt worden. Zu den Unzulänglichkeiten der Vereinbarung vgl. ELLWELLSutTon, Persian Oil, S. 164-75; Martschukat, Antiimperialismus, S. 66-73; BILl, Eagle and Lion, S. 61ff.; RamaZAni, Iran's Foreign Policy, S. 185ff.; Lytle, Origins, S. 196f.; Goode, Neglect, S 46-51; RuBIN, Good Intentions, S. 43f.; Elm, Oil, Power, and Principle, S. 48-64; HeIss, Empire and Nationhood, S. 12ff.; sehr kritisch, aber die Chronologie der Ereignisse falsch wiedergebend KATOUZIAN, Struggle for Power, S. 66ff.; eher neutraldeskriptiv BAMBERG, History of BP: II, S. 387-98; offenkundig rechnete man in London nach dem politische Ende Ġawāms und seiner HDI mit einer Rückkehr vieler pro-britischer Abgeordneter in den 16. Mağles und einer anschließenden reibungslosen Ratifizierung des Supplemental Agreement. Vgl. Gasiorowski, Coup Against Mosaddeq, S. $332 n 17$.

${ }^{239}$ Funkhouser Memo, 18.9.50, DDRS: CK2349344231; vgl. auch BILL, Eagle and Lion, S. 72.

240 Funkhouser Memo, 14.9.50, FRUS 50, V, S. 97 \{Hervorheb. i. Orig.\}; tatsächlich stand hinter der Kompromisslosigkeit der AIOC die britische Regierung. Vgl. BAMBERG, History of BP: II, S. $387 \mathrm{f}$.

${ }^{241}$ Vgl. Nutter Note, 22.8.51, CREST: \#RDP79*023-8; der iranische Botschafter in den USA, Allāhjār Sāleh, Mitbegründer der reformistisch-progressiven Iran-Partei (hezb-e Irān), Teil der Nationalen Front, informierte Ende 1951 den UN-Sicherheitsrat, die AIOC habe im Vorjahr £200 Millionen Gewinn erzielt, davon aber nur $£ 16$ Millionen an Iran als Tantiemen gezahlt. Tatsächlich habe das Unternehmen in den letzten 50 jahren insgesamt nur $£ 114$ Millionen an das Förderland gezahlt. Vgl. BILL, Politics of Intervention, S. 262f. 
Vertrauter McGhees. Zugleich wurde Grady zum Nachfolger Wileys als Botschafter in Teheran bestimmt und ein direkteres Eingreifen in die iranische Politikformulierung - eine „policy of more direct advice to the Shah concerning Iranian administrative, political and economic matters" - anvisiert. ${ }^{242}$ Ausgelöst von der Entmachtung der hauptsächlichen Vertreter des pro-amerikanischen Netzwerks, des Stagnierens des Siebenjahresplanes, der ostentativen Infragestellung der pro-westlichen Orientierung durch den Schah und dessen defacto-Aufkündigung des Reformprogramms war die Situation in Iran zugleich ein herbeigesehnter Steigbügel für McGhees breitere Ambitionen in der Nahostregion. ${ }^{243}$ Aus britischer Sicht unterminierten die Versprechungen der Grady-Mission wie auch das Entgegenkommen der ARAMCO gegenüber saudischen Forderungen nach einer 50:50Profitteilung die britische Verhandlungsposition gegenüber den Iranern. ${ }^{244}$ Die Amerikaner wiederum kritisierten den britischen Mangel an Flexibilität. ${ }^{245}$ Die Destabilisierungspolitik des britischen Verbündeten in einem Land, das die USA als wahrscheinlichstes Ziel sowjetischer Politik in der Nahostregion ausgemacht hatten, verstörte das „official mind“ in Washington sichtbar und verstärkte bereits spürbare Tendenzen, die Überlegenheit britischer Expertise in dieser Weltregion in Frage zu stellen. „Never had so few lost so much so stupidly and so fast“, so lautete Außenminister Achesons späteres Diktum über die britische Politik. ${ }^{246}$

Amerikanische Bemühungen für eine Stärkung Irans konterkarierten britische Bemühungen, die eigene Position in der Ölfrage durchzusetzen. Der nunmehr unverhohlene Interventionismus seitens der USA war zuerst auf die Installierung eines „amerikanischen“ Premierministers gerichtet, der das Abdriften des Landes in eine neutralistische Position verhindern und zugleich eine entschlossene Umsetzung eines neuen Reformprogramms garantieren sollte. Die Wahl fiel auf den Generalstabschef 'Ali Razmārā, ernannt am 26. Juni 1950, der als effektiver Organisator im Militärischen hervorgetreten war und sich darüber hinaus den Ruf eines unbestechlichen Patrioten erworben hatte. ${ }^{247}$ Die Rückkehr zum Konzept

${ }^{242}$ Vgl. Memo for the File, o.D., FRUS 50, V, S. 518-21; McGhee Memo, 25.4.50, ebd., S. 524; GTI Paper, 28.12.50, ebd., S. 258; Tehran \#851, 12.10.50, ' 'G' Letters', Lot 53 D 468, Office Files of McGhee, Box 2; vgl. GoOde, Neglect, S. 63ff.; MARsh, Cold War Oil, S. 42; LOUIS, Empire in the Middle East, S. 653f. ${ }^{243}$ Vgl. McGhee Memo, 25.4.50, FRUS 50, V, S. 523.

${ }^{244}$ Vgl. MCGHEe, Envoy, S. 320-5; GoOdE, Neglect, S.86; vgl. ANDERSON, ARAMCO, S. 184-97; PAINTER, Oil and the American Century, S. 165-71; State Department Paper, September 1950, FRUS 50, V, S. 76-96.

${ }^{245}$ Scharf kritisch Rountree Memo, 20.12.50, ebd., S. 634f.; Grady verurteilte das britische Verhalten als Versuch, die amerikanischen Bemühungen um eine Stärkung Irans zu sabotieren, ,[...] in order to preserve its dubious supremacy and control here" und empfahl sogar, mit London zu brechen. Tehran \#998, 31.10.50, ebd., S. 613; Jahre später debattierte man über die Rolle Gradys innerhalb des britischen Foreign Office: „Grady was hostile to us and encouraged Iranian nationalistic and anti-British feeling."; D. Wright Minute, 18.12.56, in Stevens to Lloyd, No. 139, 7.12.56, FO 371/120724, TNA:PRO; siehe auch MARSH, Special Relationship; MARTSCHUKAT, Antiimperialismus, S. 84-98; LOUIS, Empire in the Middle East, S. 642-51; HEISS, Empire and Nationhood, S. 1538.

${ }^{246}$ ACHESON, Present at the Creation, S. 503; vgl. Greenhill Letter, 23.8.51, BDEE B, 4, II, S. 209ff.; Grady beschuldigte später in einem Brief an Truman vom November 1952 Acheson, maßgeblich für das Scheitern der US-Politik in Iran verantwortlich zu sein. Abgedr. in: GRADY, Memoirs, S. 199f.; siehe auch ebd., S. 184.

${ }^{247} \mathrm{Vgl}$. Bill, Eagle and Lion, S. 52f.; QAimmaQAmi, Catalyst of Nationalization, S. 16ff.; GoOdE, Neglect, S. 68ff.; KatouZIAN, Struggle for Power, S. 79ff.; ANSARI, Modern Iran, S. 110f.; AzIMI, Crisis, S. 226-9; LYTLE, Origins, S. 199; geschichtsverfälschend RuBIN, Good Intentions, S. 47; dagegen die Einschätzung des damaligen CIA-Mitarbeiters Cottam als ,,the one serious indication before 1952 of direct U.S. involvement in Iranian political affairs at the working level.“; COTTAM, Iran and the United States, S. 87-90; siehe auch den Eintrag vom 16.2.51, in GHANI, Diaries, S. 374ff.; zu Razmārās Werdegang vgl. GHODS, Razmara, S. 22f. 
eines starken Ministerpräsidenten als treibende Kraft für Reform und Stabilisierung des Landes war gleichbedeutend mit der Aufgabe der bisherigen Strategie, beginnend mit Allens Intervention gegen Ġawām im Oktober 1946, die auf die Lenkung und politische Dominanz des Hofs und auf wenig durchsetzungsfähige bzw. vom Hof abhängige Ministerpräsidenten Ebrāhim Hakimi, 'Abdo 1-Hosejn Hažir, Mohammad Sā'ed und 'Ali Mansur - gesetzt hatte. Mohammad Rezā war nicht ganz zu Unrecht beunruhigt, wurden Razmārā doch Ambitionen zur Errichtung einer Militärdiktatur nachgesagt. ${ }^{248}$

In der Zwischenzeit waren grundsätzliche Verschiebungen im politischen System Irans aufgetreten, die auch begannen, die konstitutionellen Streitigkeiten, die Frage der Hilfsprogramme und des Siebenjahresplans bzw. die nach der außenpolitischen Orientierung des Landes zu transzendieren. Ausgehend von Protesten gegen die sich wieder einmal abzeichnenden Wahlmanipulationen hatte sich während der Wahlen zum 16. Mağles um die Führungsfigur Mohammad Mosaddeg eine Gruppierung gebildet, die schrittweise zur wichtigsten Opposition in Iran aufstieg. Im Oktober 1949 als Nationale Front (ğebhe-je melli) konstituiert - ein heterogener wie loser Zusammenschluss reformerisch-demokratischer bzw. liberaler, links-sozialistischer und konservativ-islamischer, mit dem Basar verbundener Gruppierungen und Individuen, darunter auch einige Veteranen von Ġawāms HDI konzentrierten sich ihre Forderungen auf das Zurückdrängen der Machtansprüche von Hof und Militär, die Verwirklichung bürgerlicher Freiheiten und auf soziale Reformen im Innern sowie auf eine nationalistisch-neutralistische bzw. antiimperialistische Ausrichtung nach außen. Mosaddeg wurde 1882 in eine der bekanntesten aristokratischen Familien Irans geboren und war mit Ġawām verwandt. Er war mehrfacher Mağles-Abgeordneter und hatte sich als unbestechlicher Administrator in den Provinzen weite Popularität und den Ruf eines liberalen Demokraten und kompromisslosen Nationalisten erworben. Zentral für seine Weltanschauung war die Ablehnung der traditionellen außenpolitischen Strategie des ,positiven Gleichgewichts“ (mowāzane-je mosbat). Dieser stellte er seine Strategie des „negativen Gleichgewichts“ (mowāzane-je manfi) entgegen, die auf der Durchsetzung völliger Unabhängigkeit und Neutralität gegenüber den Blöcken sowie der Ablehnung bzw. Aufhebung sämtlicher Konzessionen anderer Mächte in Iran beruhte, mit dem Ziel, externe Einmischung für immer zu beenden. ${ }^{249}$ Acht Abgeordnete der Nationen Front, darunter Mosaddeg selbst, fanden sich schließlich in einem größtenteils von royalistischen Abgeordneten dominierten 16. Mağles mit insgesamt 131 Abgeordneten wieder. In zeitgenössischen amerikanischen

\footnotetext{
${ }^{248}$ Für Razmārās Programm vgl. Tehran \#970, 26.5.50, FRUS 50, V, S. 558f.; MemCon, 25.3.50, ,3.020 General 1950‘, Lot 54 D 363, Iranian Files 1947-50, NEA/GTI, Box 36; Cottam bezeichnete die Förderung Razmārās später explizit als amerikanische Entscheidung zugunsten einer Militärdiktatur. Vgl. CoTTAM, Iran and the United States, S. 89; vgl. auch MCGHEE, Envoy, S. 75f.; bei QAIMMAQAMI, Catalyst of Nationalization, S. 17, erscheinen die Übernahmepläne Razmārās als Quasi-Staatstreich.

${ }^{249}$ Zur Entstehung der Nationalen Front vgl. ABRAHAMIAN, Two Revolutions, S. 251-61; BILL, Eagle and Lion, S. 68-72; CotTam, Nationalism in Iran, S. 259-73; ders., Nationalism; Siavoshi, Liberal Nationalism, S. 49-85; ForAn, Fragile Resistance, S. 283-94; KATOUZIAN, Struggle for Power, S. 71-7; zum politischen Werdegang Mosaddeġs vgl. ebd., S. 1-38; AzIMI, Political Career; ANSARI, Modern Iran, S. 106f.; DIBA, Mossadegh, S. 1495; MusADDIQ, Memoirs, S. 124-256.
} 
Dokumenten anfangs als ,so-called 'opposition'“ abgekanzelt, entwickelten die Abgeordneten der Nationalen Front, getragen von einer anschwellenden außerparlamentarischen Nationalbewegung, einen weit über ihre numerische Stärke hinausgehenden Einfluss. Eine neu geschaffene Ölkommission des Mağles, unter dem Vorsitz Mosaddeġs selbst, stand bald unter dem Einfluss der Front. ${ }^{250}$

Ministerpräsident Razmārā reagierte auf den wachsenden innenpolitischen Druck mit einer durchaus populären - Entspannungsoffensive gegenüber der UdSSR, im Grunde die alte Strategie Ġawāms aufgreifend, was auf US-Seite wenig überraschend mit einigem Entsetzen registriert wurde. ${ }^{251}$ Statt wie erwartet amerikanischen Einfluss zu stärken, beseitigte Razmārā den verbliebenen Einfluss des pro-amerikanischen Netzwerks - selbst der langgediente Direktor der Nationalbank, Abu 1-Hasan Ebtehāğ, musste nun seinen Posten räumen. Der Vertrag mit dem OCI-Konsortium wurde aufgekündigt. ${ }^{252}$ Die Lage in Iran spitzte sich nun rasch zu. Das Supplemental Agreement war bereits im November 1950 von der Ölkommission des Mağles endgültig abgelehnt worden. ${ }^{253}$ Die zunehmend aufgeladene Atmosphäre in Teheran entlud sich schließlich in einem erfolgreichen Attentat auf den Ministerpräsidenten am 7. März 1950 während eines Moscheebesuchs. Der Attentäter war ein Mitglied der islamistischen Terrorgruppe Fedāe ijān-e Eslām, die wohl zu Recht in dem Verdacht stand, Auftragsmorde für andere politische Gruppierungen auszuführen. Nicht wenige Verdachtsmomente deuteten dabei auf eine Involvierung des Hofs hin. Sechs Jahre später gestand der damalige Hofminister Manučehr Eg̉bāl gegenüber einem amerikanischen Offiziellen, die Ermordung sei ,with the full knowledge of the Shah, if not on his direct order“ erfolgt. $^{254}$ In der aufgepeitschten, nationalistischen Stimmung nach dem Anschlag war es unmöglich für die konservativen Kräfte, die Kontrolle über die Situation zu bewahren. Eine Übergangsregierung unter dem „elder statesman“ Hosejn 'Alā stand bereits unter dem bestimmenden Einfluss der Nationalen Front. Begleitet von öffentlichen Demonstrationen folgte der Mağles schließlich am 15. März der Empfehlung der Ölkommission und votierte

${ }^{250}$ „So-called Opposition“ in McGhee Memo, 7.7.50, FRUS 50, V, S. 565.

251 Im Sommer 1950 begonnene Verhandlungen über ein Handelsabkommen mit der UdSSR wurden bereits im November zum Abschluss gebracht. Vgl. CIA, Intel Memo No. 332, 20.9.50, CIA-FOIA; CIA, M-15, Februar 1951, CREST: \#RDP79*003-4; vgl. GOODE, Neglect, S. 80f.; zur von Razmārā verfügten Einstellung der Radioprogramme von BBC und Voice of America vgl. State \#873, 20.11.50, FRUS 50, V, S. 615f.; vgl. KISATSKY, Voice of America and Iran, S. 172f.; auch GHODS, Razmara, S. 25; AZIMI, Crisis, S. 226-45.

${ }^{252}$ Vgl. Goode, Neglect, S. 79ff.; Bostock/Jones, Planning and Power, S. 104ff.; QAimmaQAmi, Catalyst of Nationalization, S. 25f.; KATOUZIAN, Struggle for Power, S. 80f.; im Anschluss an Razmārās Ermordung gab auch Thornburg auf und verließ das Land im April 1951 auf Drängen Gradys.

${ }^{253}$ Vgl. HEISS, Empire and Nationhood, S. 36-53; MARTSCHUKAT, Antiimperialismus, S. 98-102; BAMBERG, History of BP: II, S. 404ff., 414f.; RAMAZANi, Iran's Foreign Policy, S. 190-7; GoODE, Neglect, S. 84-90; LoUIS, Empire in the Middle East, S. 647-57; MARSH, Cold War Oil, S. 50-61.

${ }^{254}$ Die Fedāijān waren 1946 (andere Quellen sprechen von 1945) im Anschluss an die Ermordung des säkularistischen Historikers und Reformers Ahmad Kasrawi gegründet worden und verübten in der Folgezeit zahlreiche Anschläge - u.a. waren sie für die Ermordung des früheren Ministerpräsidenten Hažir verantwortlich. In der Folgezeit gerieten sie unter den Einfluss von Ājatollāh Kāšāni. Vgl. Tehran Despatch \#20, 7.7.51, 788.00/7751, CF 50-54; zu den Fedāe ij ān vgl. TAGHAvi, Islamic Reformism, S. 115-8; sowie ders., Islamic Hard-liners; BEHDAD, Fada'ian-e Eslam; umfangreiche Informationen zum Attentat bei KATOUZIAN, Struggle for Power, S. 83f., der plausible Argumente für eine Beteiligung des Hofs vorbringt. Für den Hofminister vgl. CIA Intel Report 2035-72, Mai 1972, FRUS 69-76, E-4, doc. 180; vgl. die Schilderung Mohammad Rezās in BAYNE, Persian Kingship, S. 152-6. 
einstimmig zugunsten der prinzipiellen Nationalisierung der iranischen Ölindustrie, gefolgt vom Senat fünf Tage darauf. Im folgenden Monat votierten beide Kammern für ein Gesetz, das diese Grundsatzentscheidung implementieren sollte. Widerwillig musste der Schah am 29. April 1951 Mosaddeġs Kandidatur für das Amt des Ministerpräsidenten akzeptieren. Zwei Tage darauf unterzeichnete der Schah resignierend das Umsetzungsgesetz. Die anglo-iranische Ölkrise war nun nicht mehr aufzuhalten. ${ }^{255}$

Der Verlauf der anglo-iranischen Ölkrise und das gewaltsame Ende der Regierung Mosaddeg ist in einer ganzen Reihe von Einzelstudien untersucht worden und kann hier nicht im Detail ausgeführt werden. Grob zusammengefasst, spitzte sich die Situation vom Mai 1951 bis zum Staatsstreich vom August 1953 schrittweise krisenhaft zu, die vielfältigen sozio-ökonomischen wie politischen Probleme und Widersprüche der iranischen Gesellschaft genauso widerspiegelnd wie die diffizile bis unauflösbare Stellung Irans in den unterschiedlichen strategischen Konzeptionen der beiden anglo-amerikanischen Mächte, aber auch der Sowjetunion. Außen- und innenpolitische Analyseebene interagierten in dieser Zeit fortwährend, und ohne Berücksichtigung ihrer Interdependenz ist keine für sich alleine verständlich. Der eigentliche Auslöser der Krise in Iran, der Ölkonflikt, blieb ungelöst, was gleichermaßen auf die fehlende Bereitschaft Mosaddeġs wie der britischen Regierungen der Zeit zurückzuführen ist, ihre jeweiligen Kernpositionen aufzugeben. Die AIOC war eine Art „Staat im Staate“ innerhalb Irans, mit eigener Infrastruktur, Schulen und Hospitälern für die 4.500 britischen Expats und der größten Raffinerie der Welt - der britische Staat erwirtschaftete mittels Beteiligung und Steuern umgerechnet etwa \$400 Millionen im Jahr zusätzlich zur Verfügbarkeit verbilligten Öls. ${ }^{256}$ Britisches Entgegenkommen während den Ölverhandlungen mit der Mosaddeg-Regierung war immer nur taktischer Natur und meistens dem Kalkül geschuldet, gegenüber den Amerikanern nicht als die Partei zu erscheinen, die einen Kompromiss und damit eine Beilegung der Krise verhinderte. Tatsächlich aber gab es keinerlei Bereitschaft auf britischer Seite, die tatsächliche operative Kontrolle über die Ölförderung in Iran abzugeben - man war sich in London sicher, dass es wie in der Vergangenheit möglich sein würde, mit einer anderen, weniger nationalistisch gesinnten und weniger prinzipientreuen und unbestechlichen Regierung eine für die britischen kommerziellen wie imperialen Interessen weitaus erträglichere Vereinbarung einzugehen. Die britische Politik arbeitete daher fortwährend auf den Sturz der Regierung Mosaddeg hin. Mosaddeġs politischer Aufstieg dagegen war eng mit der Ölfrage verknüpft gewesen. Die von nahezu allen politisch bewussten Iranern geteilte Gegnerschaft zur übermächtigen Stellung der AIOC im Wirtschaftsleben des

${ }^{255}$ Zum Nationalisierungsbeschluss vgl. RamaZAni, Iran's Foreign Policy, S. 194-7; GoodE, Neglect, S. 91f.; HeIss, Empire and Nationhood, S. 54-64; ELM, Oil, Power, and Principle, S. 81-93; MuSADDIQ, Memoirs, S. 2647 ; in der Literatur findet sich häufig die fehlerhafte Angabe des 2. Mai als Termin der Verkündung des Gesetzes. Vgl. ed. note, FRUS 52-54, X, 44; Mosaddeġs Ernennung verhinderte die vonseiten des Schahs gemeinsam mit den Briten zu dieser Zeit geplante Amtsübernahme des erzkonservativen Sejjed Zijāe ad-Din Tabātabā'i mit dem Ziel der Einführung einer Auflösung des Mağles, also einer de-facto-Diktatur gelenkt vom Hof und einer nötigenfalls gewaltsamen Durchsetzung eines Ölkompromisses. Vgl. AzIMI, Unseating Mosaddeq, S. 44-9; LouIS, Britain and the Overthrow, S. 139ff.

${ }^{256}$ Vgl. PAINTER, Oil and the American Century, S. 174. 
Landes und der de facto-Kontrolle iranischer Politik durch das Unternehmen im Zusammenspiel mit der britischen Regierung, war entscheidend für den Zusammenhalt der eigentlich sehr heterogenen Nationalen Front. Diese Einigkeit ermöglichte zugleich Fortschritte hinsichtlich der Ziele der Bewegung jenseits der Frage der Nationalisierung, die auf eine Transformation des politischen Systems im Sinne liberaler und demokratischer Ideen abzielten. Eine krisenhafte Zuspitzung der Ölfrage war somit für beide Antagonisten potentiell von Vorteil: Großbritannien erhoffte sich den Sturz der missliebigen Regierung, Mosaddeg die Durchsetzung seiner Maximalposition in der Frage der Nationalisierung und infolgedessen seine eigene politische Dominanz im Zuge einer konsequenten Parlamentarisierung und Demokratisierung Irans. ${ }^{257}$

Diese Ausgangslage hilft, die komplizierten wie ergebnislosen Verhandlungen vom Mai 1951 bis zum August $1953 \mathrm{zu}$ verstehen. Verhandlungsversuche unmittelbar nach der Wahl Mosaddegis scheiterten allein schon an dessen rascher Umsetzung des Implementierungsgesetzes für den Nationalisierungsbeschluss des Mağles. Mit der umgehenden Übernahme der AIOC-Ölinstallationen durch die neu gegründete National Iranian Oil Company (NIOC/Šerkat-e melli-je naft-e Irān) und der britischen Reaktion darauf, der Evakuierung des nicht-iranischen AIOC-Personals und der daraus resultierenden Einstellung sämtlicher Ölexporte und der Schließung der Raffinerie in Ābādān, waren die Fronten rasch geklärt. ${ }^{258}$ Britischer Einfluss in der internationalen Ölwelt vereitelte bis auf wenige Ausnahmen iranische Versuche, in der Ölförderung und -verarbeitung erfahrene Experten aus anderen Ländern anzuwerben. Die Unterstützung des britischen Ölboykotts durch die USA und die amerikanischen Konzerne machten es Iran zudem unmöglich, die eigenen Exporte aufrechtzuerhalten, was angesichts der Bedeutung der Öltantiemen für die Staatsausgaben zu erheblichen Einnahmeverlusten und einer wirtschaftlichen und in der Folge politischen Destabilisierung führte. ${ }^{259}$ Während die Truman-Administration den britischen Wirtschaftskrieg gegen Iran somit unterstützte, stellte sie sich andererseits unumwunden gegen zwischenzeitlich erwogenen Pläne Großbritanniens, den Konflikt militärisch durch die Besetzung der Ölfelder zu „lösen“, wohl zu Recht eine sowjetische Gegenreaktion basierend auf dem sowjetisch-iranischen Freundschaftsvertrages von 1921 befürchtend. ${ }^{260}$ Zudem überzeugten die Amerikaner Ende Mai 1951 London von der Notwendigkeit, zumindest das

\footnotetext{
${ }^{257} \mathrm{Vgl}$. LAdJEVARDI, Constitutional Government; eher die ultra-nationalistischen und anti-liberalen Aspekte der Bewegung betont RAMAZANI, Intellectual Trends.

${ }^{258}$ Im Juni 1951 fanden die Iraner bei der Durchsuchung von AIOC-Büros bzw. im Haus des Repräsentanten belastende Dokumente, die illegale Aktivitäten der Firma in Iran und die großflächige Bestechung iranischer Offizieller, Abgeordneter und Journalisten belegten. Ähnlich wie später die 1979 in der US-Botschaft erbeuteten Dokumente wurde auch dieser Fund innenpolitisch instrumentalisiert. Vgl. KATOUZIAN, Struggle for Power, S. 115, 280 n4; KinZer, Shah's Men, S. 96f.; kritisch ABrahamian, The Coup, S. 121.

${ }_{259} \mathrm{Zu}$ den Hintergründen des Ölboykotts und seinen Auswirkungen auf Iran vgl. HeISs, International Boycott; Elm, Oil, Power, and Principle, S. 144-54; zu Auswirkungen der Ölkrise auf andere regionale Konzessionen vgl. State Department, OIR Report No. 5563, 28.6.51, DDRS: CK2349401149.

${ }^{260} \mathrm{Zu}$ britischen Überlegungen militärisch zu intervenieren, siehe LOUIS, Empire in the Middle East, S. 672-6, 686-9; MARSH, Cold War Oil, S. 63-7, 75-8; vgl. FRUS 52-54, X, S. 56 n4; Cabinet Conclusions, 12.7.51; Cabinet Conclusions, 27.9.51, BDEE A, 2, I, S. 87-90, 93-6; erstaunlich aufgeschlossen gegenüber einer britischen Intervention war George Kennan. Siehe den Eintrag vom 23.1.52, in: Costigliola, Kennan Diaries, S. 305-8.
} 
souveräne Recht auf Nationalisierung anzuerkennen und (verspätet) auch eine 50:50Profitteilung $\mathrm{zu}$ akzeptieren. Die verschiedenen unter amerikanischer Vermittlung abgehaltenen Verhandlungsrunden zwischen britischer Regierung und den Iranern waren aber allesamt erfolglos, da man in London nicht bereit war, die eigentlich Kernfrage der operativen Kontrolle der Ölindustrie ernsthaft zu diskutieren, wiederum das sine qua non aus Sicht des iranischen Premiers. Akzeptabel wäre maximal „the flavor or façade of nationalization“, so eine interne britische Einschätzung, ,while retaining the substance of control.“ Die Iraner lägen also, so die ehrliche interne Einschätzung, nicht ganz falsch mit ihren Beschwerden ,that our proposals are, in fact, merely dressing up AIOC control in other clothing. “261 Im Anschluss an den Abbruch der diplomatischen Beziehungen zu Großbritannien durch Mosaddeg im Oktober 1952 - in erster Linie eine Reaktion auf die fortwährenden verdeckten Operationen des MI6 mit dem Ziel des Sturzes der iranischen Regierung - war eine verhandlungsbasierte Lösung des Streits über die Nationalisierung der Ölindustrie de facto vom Tisch. ${ }^{262}$

Im Rahmen dieser Studie von größerem Interesse als der eigentliche Verlauf des angloiranischen Ölkonflikts und der innenpolitischen Krisen in Iran in dieser Zeit ist die Haltung der beiden US-Administrationen und die spätere Interpretation der US-Politik durch die historische Forschung. Jenseits des amerikanischen Vorgehens in Detailfragen interessiert zuerst einmal die Formulierung der eigenen Iranpolitik im Kontext der allgemeinen Grand Strategy der USA. Die oben bereits behandelte, erste NSC-Studie zu Iran, NSC 54 vom August 1949, war inzwischen aufgrund der Zuspitzung der Ölkrise überholt. Die Formulierungsphase der neuen Studie erstreckte sich von Mitte 1950 bis zum Frühjahr 1951, also von der Grundsatzentscheidung zugunsten verstärkter Intervention über den gravierenden Einflussverlust der USA in Iran bis hin zum Ausbruch der Ölkrise. Das Endergebnis der Beratungen, NSC 107, am 21. März 1951 und damit noch vor dem Amtsantritt Mosaddeg̀s,

\footnotetext{
${ }^{261}$ Zit. aus Ervand ABRAHAMIAN, 1953 Coup in Iran, S. 191; ausführlich zur Kernfrage des Konflikts vgl. ders., The Coup, S. 81-8; ähnlich MARTSCHUKAT, Antiimperialismus, S. 139, 175-7; vgl. YeRGIN, The Prize, S. 456-70; apologetisch dagegen LOUIS, Britain and the Overthrow, S. 148f.; sämtliche auch von London mitgetragenen Kompromissvorschläge zur Regelung der Nationalisierungsfrage zielten im Kern auf fortgesetzte Kontrolle und Leitung der eigentlichen Öloperationen wie Exploration, Förderung, Ausnutzung und Vertrieb durch die AIOC oder eine von ihr dominierte Gesellschaft. Das traf gleichermaßen auf die direkten Verhandlungen mit der AIOC im Juni 1951, auf die sogenannten Stokes-Mosaddeg-Verhandlungen im Sommer 1951 unter direkter Vermittlung des amerikanischen Sonderemissärs Averell Harriman, auf die Bemühungen der Weltbank für eine Interimsvereinbarung bis zum März 1952 wie auch auf die sogenannten Truman-Churchill Proposals im Sommer und Herbst 1952 zu. Aus dieser Haltung erklärt sich auch im November 1951 die britische Ablehnung des am Rande der UNO-Sicherheitsratssitzungen über den Ölkonflikt ausgehandelten McGhee-MosaddegKompromisses. Zu diesem vgl. BILL, Eagle and Lion, S. 76f.; für Beispiele für die Konsistenz der britischen Position und die Frage der tatsächlichen Kontrolle vgl. MemCon, 18.4.51; Tehran \#340, 24.7.51; Tehran \#675, 19.8.51; State \#1740, 28.9.51; Paris \#2743, 9.11.51; MemCon, 9.1.52; Tehran \#3377, 5.3.52; MemCon, 24.6.52; State \#1019, 13.8.52, FRUS 52-54, X, S. 37-42, insbes. 40; 109-114, insbes. 110; 140ff.; 180-3; 272ff.; 311-320, hier 318 [, The basic British thinking upon the oil question is that they must keep their hands on all or most of Persia's oil."']; 365f.; 400-3; 439-42; vgl. Makins to Eden, No. 207, 9.3.53, FO 416/106, TNA:PRO; die amerikanische Seite war allerdings durchaus bereit, in der Frage der Kontrolle gewisse Zugeständnisse zu machen, da man die von den Briten erwartete vollständige Restauration der AIOC in operative Kontrolle der iranischen Ölindustrie angesichts der jüngeren Entwicklungen für unrealistisch hielt. Vgl. State \#2704, 5.11.51, FRUS 5254, X, S. 258ff.; Nitze Notes, 13.5.80; MemCon, 7.5.80, ,Iran, [...] negotiations, 1951-53', Box 121, Nitze Papers, LOC.

${ }^{262}$ Vgl. Gasiorowski, U.S. Foreign Policy, S. 58f.; LouIs, Britain and the Overthrow, S. 150f.; HeISS, Empire and Nationhood, S. 148-51; RAMAZANI, Iran's Foreign Policy, S. 225-31.
} 
vom NSC verabschiedet, paraphrasierte die Konzeption der „Permanenten Intervention“, den Kernbestand der amerikanischen Iranpolitik bis in die 1960er Jahre hinein. In der historischen Forschung hat NSC 107, wenn überhaupt, in erster Linie als dokumentarische Bestätigung für die Belastungen der ,special relationship“ aufgrund divergierender Interessen und Einschätzungen in der Ölfrage Beachtung gefunden, vor allem aufgrund einer Passage, die zu verstärktem Druck auf den britischen Verbündeten mahnte. ${ }^{263}$ Somit wurde die NSC-Studie historiographisch gerne als Beleg für die angeblich im Grundsatz äquidistante Haltung der Truman-Administration in der Ölkrise herangeführt, exemplifiziert in den zahlreichen Mediationsversuchen. Einerseits wurde die unilaterale Expropriation durch Iran - aber nicht das Prinzip der Nationalisierung an sich - abgelehnt, was sich in der US-Unterstützung für den britischen Ölboykott gegen Iran äußerte. Andererseits stellten sich die USA gegen britische Pläne, eine Lösung des Konflikts durch eine militärische Intervention in Ābādān zu erzwingen. Erst - dies der zentrale chronologische Aspekt dieser dominanten Interpretation - als sich die Einsicht durchgesetzt hatte, dass eine Verhandlungslösung angesichts der Standpunkte der beiden Parteien nicht zu erwarten war, und angesichts der Destabilisierung der politischen Lage in Iran, habe man sich - genauer: die neue republikanische Administration - zu einem Eingreifen entschlossen, letztlich im CIA-MI6-Staatsstreich vom August 1953 resultierend. Repräsentativ für diese Sichtweise ist Malcolm Byrnes Feststellung, wonach die „,...] Truman administration continued to press doggedly for an oil agreement they thought would be equitable to both Great Britain and Iran, rather than consider overt intervention.“264

Dieser augenscheinlichen Neutralität der USA widerspricht der vollständige Text von NSC 107, der von der früheren Forschung allerdings ignoriert wurde bzw. lange Zeit nicht zugänglich war. Dieser enthält Verweise auf ,special political operations“, unter Umständen in Kooperation mit Großbritannien, für bestimmte Szenarien, zuvorderst ein drohender „Verlust“ Irans für die „Freie Welt“. ${ }^{265}$ Expliziter als das Hauptdokument erläuterte eine

${ }^{263}$ Die Passage im Wortlaut: „Press the United Kingdom to effect an early and equitable settlement of the AngloIranian Oil Company dispute."; NSC 107: ,Draft Statement of Policy“, 14.3.51, FRUS 52-54, X, S. $21 \mathrm{ff.,} \mathrm{hier} \mathrm{22;}$ NSC 107 wurde vom NSC am 21. März verabschiedet und anschließend von Truman am 24.3. gebilligt. Siehe ed. note in ebd., S. $23 \mathrm{f}$.

${ }^{264}$ BYRne, Road to Intervention, S. 215 f.; ähnlich Gasiorowski, U.S. Foreign Policy, S. 55; Marsh, Special Relationship, S. 537f.; BILL, Eagle and Lion, S. 75f.; COTTAM, Iran and the United States, S. 98f.; noch weiter gehend RUBIN, Good Intentions, S. 57f.; repräsentativ für die vorherrschende Meinung in der (amerikanischen) Geschichtsforschung KUNIHOLM, Triumphs and Tribulations, S. 330-4; die Forschung wurde maßgeblich beeinflusst durch William Roger Louis' Standardwerk mit seiner starken Betonung anglo-amerikanischer Differenzen und insbesondere von Dean Achesons Darstellung in seinen Memoiren mit einer sympathisierenden Darstellung Mosaddeġs. Vgl. ACHESON, Present at the Creation, S. 503ff.; ähnlich MCGHEE, Envoy, S. 328-42, $388-404$

${ }^{265}$ Hier bereits der spätere Sprachgebrauch von NSC 10/5 vom Oktober 1951. Vgl. oben S. 96, Anm. 232; die 1989 für die Veröffentlichung in Band X der FRUS 52-54 deklassifizierte Version der Studie enthielt mehrere Auslassungen, die den eigentlichen Inhalt von NSC 107 entscheidend verfälschten, doch hat die bisherige Forschung dieser Tatsache nicht Rechnung getragen. Die in dieser NSC 107-Version „geschwärzten“ Passagen wurden erst mit der Veröffentlichung des neuen FRUS-Bandes zu Iran im Jahr 2017 offiziell deklassifiziert. Eine vollständige Fassung der Studie fand sich bereits zuvor in den sogenannten „Disaster Files“ in der Eisenhower Library in Abilene, KS. Siehe NSC 107, 14.3.51, , Iran (1)‘, WHO, NSCS, Disaster File Ser., Box 65, DDEL; die ausgelassenen Passagen in FRUS (S. 22) lauten wie folgt: „4. In the event an Iranian Government, despite the foregoing United States measures, should take steps leading toward communist control in Iran and capitulation to the USSR, the United States should be prepared to undertake special political operations to reverse the trend and to effect Iranian alignment with the free world.“ sowie „5. [...] b. Conduct of special political operations by the 
zugehörige NSC Staff Study die Einnahme einer ,,attitude of neutrality“ Irans im Kalten Krieg als eines der Szenarien, welches die Einleitung verdeckter Operationen notwendig machen würde. Hier ging es wohlgemerkt nicht um die Reaktion auf eine tatsächliche kommunistische Machtübernahme in Teheran oder die Installierung einer Marionettenregierung, sondern einzig - und im Dokument expliziert - auf einen möglichen iranischen Politikwechsel zugunsten einer Verständigung mit dem nördlichen Nachbarn wie z.B. die Gewährung einer Ölkonzession nach Muster der Vereinbarung von 1946. Eine Rückkehr Irans zur traditionellen neutralen Haltung war für die Verfasser der Studie somit inakzeptabel. Daher empfahl NSC 107 bei Eintreten dieses Szenarios eine unmittelbare „counter-action“ zu einer solchen Entwicklung: ,[...] in conjunction with the United Kingdom and with little risk in proportion to the possible gain, take positive steps, including covert measures, to support pro-Western elements and effect Iran's alignment with the free world." ${ }^{266}$

Somit war bereits im März 1951 mit der Verabschiedung von NSC 107 eine direkte Intervention mittels verdeckter geheimdienstlicher Operationen zur Verhinderung einer neutralistischen außenpolitischen Positionierung Irans im Kalten Krieg von den höchsten Entscheidungsorganen der Administration grundsätzlich sanktioniert worden. Die Einmischung des ehemaligen US-Botschafters Allen vom Oktober 1946, ad hoc und im Alleingang umgesetzt, war somit viereinhalb Jahre später endgültig zur Richtlinie amerikanischer Iranpolitik geworden. Von dieser Grundsatzentscheidung führt aus Sicht des Verfassers der vorliegenden Studie eine direkte Verbindung zum von der CIA organisierten Staatsstreich gegen die Regierung Mosaddeg. Die in NSC 107 angedachten Maßnahmen wurden kurz darauf tatsächlich implementiert, wie ein Progress Report über die Umsetzung der Studie vom Mai 1951 belegt. $^{267}$ Hier ist der Ausgangspunkt für die von der historischen Forschung bisweilen zwar wahrgenommenen Aktivitäten des bestehenden CIA-Agentennetzes TPBEDAMN vor Ort - das angesichts der Krise zudem personell verstärkt worden war -, die nun jenseits der ursprünglich antikommunistischen Zielsetzung der Operation darüber hinaus darauf abzielten, die politische Basis der Regierung Mosaddeg zu untergraben und die Nationale Front auseinanderzudividieren. ${ }^{268}$ Somit handelte es sich hier nicht, wie von Mark

United States and the United Kingdom.“; vgl. nun auch NSC 107 Draft Statement, 14.3.51, FRUS 52-54, Retrospective Volume: Iran, S. 23-35.

${ }^{266}$ NSC Staff Study (NSC 107), , The Position of the United States With Respect to Iran', o.D., S. 15, 9f. \{Hervorheb. v. Verf.\}; an demselben Ort in DDEL - siehe vorherig. Anm.; wieder mit Auslassungen in FRUS 5254, X, S. 11-21; in diesem Sinne auch die Instruktion des State Departments an Grady Anfang Mai, wonach im Falle der Gefährdung der Sicherheitslage in Iran , extraordinary political measures might be required in effort $\{$ to; R.P. prevent loss of Iran to the free world."; zudem wurde dem US-Botschafter aufgetragen, den Schah über diese Sichtweise und über die Präferenz zugunsten seiner fortgesetzten politischen Dominanz zu informieren, somit explizit Unterstützung für eine Entlassung Mosaddeġs signalisierend. Vgl. State \#2067, 10.5.51, ebd., S. 50; zum Widerstand der JCS gegen NSC 107 vgl. JCS History Iran, S. 19f.; JCS Memo, 20.3.51, , 107 Position of [...]', NSC Files, 1947-1961, Coordinating Division, OASD/ISA, Box 16, RG 330, NACP.

${ }^{267}$ Der Bericht meldete lapidar, dass die anvisierten „special political measures“ nun eingeleitet worden seien, ohne dies im Detail weiter auszuführen Vgl. Progress Report on NSC 107, 2.5.51, „Iran (1)“, WHO, NSCS, Disaster File Ser., Box 65, DDEL; vgl. auch CIA, SE-6, 22.5.51, CIA-FOIA, S. 7.

${ }^{268}$ Die CIA hatte bereits im Juni 1951 die Ausarbeitung eines „strategic psychological plan“ für Iran als eine von fünf dringlichsten Aufgaben für den eben gegründeten PSB vorgeschlagen. Vgl. Allen Dulles Memo, 1.6.51, DDRS: CK2349304184; der CIA-Repräsentant im PSB schlug einen Monat später konkrete Planungen ,to pull Iran towards the West" vor und empfahl Notfallmaßnahmen für den Fall eines kommunistischen Umsturzes oder 
Gasiorowski angenommen, um „Rogue Elephant“-Operationen seitens der CIA oder untergeordneter Stellen, sondern um die Umsetzung der von höchsten Stellen sanktionierten Politik. $^{269}$

Kurz darauf wurde diese - zuvor noch improvisierte - amerikanische Haltung in einer weiteren Überarbeitung der NSC-Studie konkretisiert. NSC 107/2, am 27. Juni 1951 vom NSC verabschiedet und formal bis November 1952 in Kraft, legte die grundsätzliche US-Position für das Gros der verbliebenen Amtszeit der Truman-Administration fest. NSC 107/2 ging in der Formulierung des zentralen amerikanischen Politikziels über die Vorgängerstudie noch hinaus und definierte dieses als Verhinderung kommunistischer Kontrolle über Iran im Sinne der Eindämmung und als Bewahrung einer unabhängigen und souveränen Nation ,firmly aligned with the free world“. Eine enge Anbindung an die „Freie Welt“ aber, also eine positive Definition einer bestimmten außenpolitischen Orientierung dauerhaft $\mathrm{zu}$ garantieren, implizierte angesichts der innenpolitischen Situation in Iran eine permanente Bereitschaft, in den inneren Angelegenheiten des Landes zu intervenieren. So plädierte die neue Studie auch für die Fortsetzung der ,special political operations“ zur Unterstützung der pro-westlichen Orientierung. Explizit war nun auch nicht mehr von der Stärkung der iranischen Regierung, kontrolliert von den Nationalisten, sondern von der Stärkung der Führungsrolle des Schahs die Rede. ${ }^{270}$ Entgegen der in der späteren Historiographie dominierenden Ölfrage war die drohende neutralistische Orientierung Mosaddeġs aus Sicht Washingtons das eigentliche Hauptproblem. ${ }^{271}$

Geheimdienstliche Aktivitäten - über deren Details aufgrund der weiterhin gesperrten CIADokumente nur bruchstückhafte Informationen verfügbar sind - und Washingtons Beteiligung am britischen Ölboykott gegen Iran gemeinsam mit einer Aussetzung der zuvor zugesagten finanziellen Unterstützungsleistungen wie dem Kredit der Export-Import-Bank hatten allesamt das Ziel, die politische Basis der Nationalen Front entscheidend zu schwächen und mittelfristig den Sturz der Regierung zu ermöglichen. Allerdings - einer der hauptsächlichen Streitpunkte zwischen London und Washington - sollte ein überstürztes Vorgehen gegen Mosaddeg mit den

\footnotetext{
,a pronounced shift by the present regime towards the Soviet Union“"vorzubereiten, die spätere Begründung für den CIA-Coup gegen Mosaddeg vorwegnehmend. Vgl. CIA Representative Memo to PSB Staff, 23.7.51, DDRS: CK2349318269; vgl. auch Sargeant Memo, 24.5.51, FRUS 50-55: The Intelligence Community, S. 149-52.

${ }^{269}$ Vgl. GASIOROWSKI, 1953 Coup, S. 267; ders., TPBEDAMN Operation, S. 13ff.; zur Aufstockung der CIAStation vgl. GoODE, Neglect, S. 94.

${ }_{270}$ Vgl. NSC 107/2, 27.6.51, FRUS 52-54, X, S. 71-6, hier 74, 73; die FRUS-Version enthält wieder mehrere Auslassungen. Eine Version ohne Auslassungen in JCS Memo to Lovett, 15.4.52, ,Iran (2)“, WHO, NSCS, Disaster File Ser., Box 65, DDEL; nun auch in FRUS 52-54, Retrospective Volume: Iran, S. 106-10; die Rolle des Schahs stark betonend NSC Staff Study (NSC 107/1), 20.6.51, ,Annex to NSC 107/1', Policy Papers, Box 14, RG 273, NACP, S. 3; zur internen Debatte vgl. JCS History Iran, S. $21 \mathrm{ff}$; der US-Vermittler Harriman war offenbar über die Strategie im Bilde. Vgl. London \#1090, 28.8.51, FRUS 52-54, X, S. $150 \mathrm{ff}$.

${ }^{271}$ Grady war instruiert worden, beim Schah auf die sofortige Entlassung Mosaddeg su drängen, sollte dieser wie befürchtet die Tätigkeit der amerikanischen Militärmission beenden, den Verteidigungsetat drastisch kürzen oder das Verbot der Tudeh-Partei aufheben. Vgl. State \#2067, 10.5.51, FRUS 52-54, X, S. 50f.; die amerikanische Position zusammengefasst in Berry Memo, 8.1.52, ebd., S. 305-11; vgl. State \#656, 26.9.51, ebd., S. 169f.; Tehran \#2329, 26.12.51, ebd., S. 298ff.; zur neutralistischen Tendenz Mosaddeġs vgl. Tehran \#2199, 14.12.51, ebd., S. 291-5; vgl. CIA, NIE-6, 5.4.51, CIA-FOIA.
} 
daraus womöglich resultierenden unberechenbaren Folgen vermieden werden. ${ }^{272}$ Die USPolitik nahm dabei eine vorübergehende Destabilisierung Irans in Kauf, da diese als notwendig für eine Schwächung der nationalistischen Regierung betrachtet wurde. Nach deren Sturz rechnete man mit einer raschen Wiederherstellung der pro-westlichen Ordnung durch Hof und traditionelle Eliten. ${ }^{273}$ Die von außen als flatterhaft erscheinende US-Politik im Anschluss ergab sich, da sich die Grundannahmen der beiden NSC 107er-Studien als falsch erweisen sollten. Die Mosaddeg-Regierung und die iranische Nationalbewegung erwiesen sich als widerstandsfähiger und langlebiger als angenommen - die interne Kritik am Kurs der Administration nahm in der Folge zu, gerade vonseiten des US-Militärs. ${ }^{274}$ Bereits im Spätherbst 1951 erkannte man auf amerikanischer Seite, dass die Stärkung der Institution der Monarchie als Bollwerk pro-westlichen - und gerade pro-amerikanischen Einflusses angesichts der Mobilisierung breiter Schichten der iranischen Bevölkerung infolge der nationalistischen Aufwallung durch die Ölkrise nicht umsetzbar war. Zugleich wuchs die amerikanische Frustration über die mangelnde Konzessionsbereitschaft der Briten. Acheson mutmaßte, London wäre eher bereit einen kommunistischen Iran als eine Aufgabe der eigenen Position in dem Land zu akzeptieren. ${ }^{275}$

Spätestens mit dem gescheiterten Versuch vom Juli 1952, den aus dem Exil zurückgekehrten Ġawām als Ministerpräsidenten durchzusetzen, wurde offenbar, dass eine verfassungskonforme Beseitigung Mosaddeġs aufgrund der Stärke der nationalistischen Bewegung in Iran nicht gelingen würde. Ende Juli informierte man London, dass man angesichts der nun geringen Wahrscheinlichkeit, dass der Schah bzw. die traditionelle Elite

\footnotetext{
${ }^{272}$ Während die Forschungsliteratur die Bedeutung der NSC-Studien 107 und 107/2 weitgehend übersieht, gibt sich Melvyn Leffler überzeugt, ,[...] that numerous covert operations were hatched during the summer of 1951."; LEFFLER, Preponderance, S. 424; anglo-amerikanische Differenzen ergaben sich aus Uneinigkeit über den günstigsten Zeitpunkt eines Vorgehens gegen Mosaddeg, nicht aber aus irgendwelchen Differenzen hinsichtlich der grundsätzlichen Notwendigkeit seines Sturzes. In Einschätzungen des State Department bzw. der CIA waren die Bezeichnungen ,,indigenous fanaticism“ oder „reactionary ultra-nationalist element“ gängig, wann immer über die Nationale Front berichtet wurde. Mosaddeg selbst wurde in US-Quellen meist als unberechenbarer Populist und Demagoge beschrieben, wenn ihm auch zuweilen patriotische Gesinnung und liberale Prinzipien attestiert wurden. ,Indigenous fanaticism“ findet sich in NSC 107/2, ,ultra-nationalists“ z.B. in CIA, NIE-6, 5.4.51, CIAFOIA; auch Mosaddeġs Beschreibung als ,impractical visionary and poor administrator“, aber gleichzeitig als ,astute politician“" in CIA, SE-6, 22.5.51, CIA-FOIA, S. 3; derselbe Bericht erwähnt auch Mosaddeg்s demokratische Überzeugungen. Positiv die Darstellung Mosaddeġs in CIA History Staff, The Battle for Iran, S. 26f., B-2f.; vgl. dagegen NITZE, Memoir, S. 131; zur Darstellung in der Presse und in der öffentlichen Meinung vgl. Goode, United States and Iran, S. 68f.; Dorman/Farhang, U.S. Press and Iran, S. 31-62; vgl. auch Roberts, Radio Propaganda; SREBERnY/TorfeH, Persian Service, S. 49-74.

${ }^{273}$ Akzeptabel war diese Strategie, da man intern die Wahrscheinlichkeit einer kommunistischen Machtübernahme als gering einschätzte. NSC 107/2 hatte eine solche als „distinct possibility“ bewertet - in internen Memoranden der CIA vom Sommer 1951 wurde ein Erfolg der Tudeh aber als „,extremely unlikely“ eingeschätzt. Vgl. JHL [Identität ungeklärt] Memo, SPP No. 26, 21.8.51, CREST: \#RDP79*031-9.

${ }^{274}$ Vgl. Tehran \#1478, 22.10.51, FRUS 52-54, X, S. 237, 238; eine Einschätzung des Office of Intelligence Research (OIR) vom November konstatierte explizit das Scheitern der bisherigen, auf den Hof konzentrierten Strategie. Vgl. State OIR Report No. 5716, 23.11.51, DDRS: CK2349401210; ähnlich CIA, NIE-46, 4.2.52, CIAFOIA; [Name unkenntlich] Memo [CIA], 12.10.51, CIA-FOIA; zur internen Kritik vgl. PoOLE, History of the $J C S$ : $I V$, S. 185f.; JCS History Iran, S. 24ff.; vgl. JCS Memo, 10.10.51, FRUS 52-54, X, S. 220ff.; für Spannungen zwischen London und Washington aufgrund des offensichtlichen Scheiterns der Destabilisierungspolitik siehe auch State \#1624, 7.2.52, FRUS 52-54, X, S. 346f.; Rountree Memo, 11.1.52, FRUS 52-54, VI, S. 821-31.

${ }_{275}^{27}$ Vgl. State \#2837, 9.11.51; Paris \#2808, 10.11.51, FRUS 52-54, X, S. 275-8, 278-81; Loy Henderson kabelte Anfang 1952 aus Teheran, dass sich angesichts der Haltung Londons nun für die USA die Frage stelle, , [...] whether it can afford much longer to defer to British leadership in this area."; Tehran \#2480, 5.1.52, ebd., S. 304; vgl. HEISS, Empire and Nationhood, S. 113-8.
} 
ihren politischen Einfluss zurückerlangen würden, nun gezwungen sei, die bestehende Regierung in Iran zu unterstützen, um den vollständigen Verlust des Landes für den Westen abzuwenden. ${ }^{276}$ Eine neue Studie zur Iranpolitik, NSC 136/1 vom 20. November 1952, gab die Westorientierung als zweites primäres Ziel amerikanischer Politik neben der Verhinderung einer kommunistischen Machtübernahme vorerst auf. Um einen weiteren Zerfall der Regierungsautorität und einen möglichen Coup der Tudeh bzw. ihre Penetration der Regierungsbürokratie abzuwenden, stellte die NSC-Studie nun Haushaltszuschüsse an Iran zur Stabilisierung der Finanzen sowie Unterstützung für den Aufbau einer eigenen Ölindustrie und für den Verkauf des geförderten Öls in Aussicht, zwar weiterhin unter Rücksichtnahme auf „legitime Interessen“ Großbritanniens, aber explizit ein Veto Londons gegen die als notwendig empfundenen Maßnahmen ausschließend. ${ }^{277}$ Angesichts der zu diesem Zeitpunkt bereits feststehenden Amtsübernahme durch den Wahlsieger Eisenhower war den Beteiligten allerdings bewusst, dass es die Aufgabe der kommenden republikanischen Administration sein würde, diesen Beschluss und einen daraus potentiell resultierenden Bruch mit dem wichtigsten globalen Verbündeten Großbritannien umzusetzen. Spätere historiographische Deutungen einer äquidistanten US-Haltung während der Ölkrise und eines Sympathisierens mit der iranischen Nationalbewegung beziehen sich nicht zuletzt auf die in NSC 136/1 enthaltenen Politikempfehlungen, wenngleich diese offenkundig nur eine taktische Anpassung einer seit fast zwei Jahren gegensätzlich ausgerichteten Iranpolitik der Truman-Administration darstellte. ${ }^{278}$

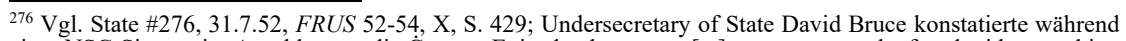
einer NSC-Sitzung im Anschluss an die Gawām-Episode, dass man ,[...] now appear to be faced with something that contradicts a main tenet of NSC 107/2 since the Shah demonstrated that he did not have the power to support Qavam.“; vgl. Memo for the President [121 ${ }^{\text {st }}$ NSC Meeting], 6.8.52, ebd., S. 431; innerhalb des State Department gab es Stimmen, die nun eine Aufhebung des Ölboykotts forderten, zumal nach Ansicht der eigenen Juristen die Rechtsposition der AIOC ,[...] might well not stand up in the courts."; Byroade Memo, 14.9.52, ,Iran U.S. Position [1952]", Lot 60 D 533, Subject Files Relating to Iran, 1951-1958, OiCIA/GTI, Box 9; zu Gawāms ComebackVersuch vgl. KAuZ, Politische Parteien, S. 294-307; AZIMI, Unseating Mosaddeq, S. 51-4; KATOUZIAN, Struggle for Power, S. 121-5; unglaubwürdig das Dementi einer britischen Beteiligung in FALLE, My Lucky Life, S. 79; obskur der Eintrag vom 13.8.52 in: BERLE/JACOBS, From the Papers of Adolf A. Berle, S. 607: „, The United States seems to have decided that it has no troops to spare and cannot use force. It will, therefore, make monkey-business with the southern tribes-a ghastly program for a great power."; Berle Jr. war inzwischen in leitender Funktion beim Twentieth Century Fund tätig.

277 Vgl. ,NSC 136/1: The Present Situation in Iran', 20.11.52, FRUS 52-54, X, S. 529-34; zur Abfassungsgeschichte siehe ed. note, ebd., S. 528f.; Version ohne Auslassungen in ,Iran (3) ${ }^{6}$, WHO, NSCS, Disaster File Ser., Box 65, DDEL; auch in NSArch EBBook No. 126; doc. 1; nun auch in FRUS 52-54, Retrospective Volume: Iran, S. 422-5; vgl. JCS History Iran, S. 27-31; die hier vertretene These über die frühe US-Politik bestätigt auch ein Brief des Secretary of Defense Lovett an David Bruce vom August 1952. Die Unterstützung der britischen „economic and financial pressure doctrine“ sei ein Fehler gewesen: „The British policy of economic squeeze, which has been pursued with our tacit support since the withdrawal from Abadan, cannot be said to have succeeded [...] it has conspicuously failed to force an oil settlement or to set events toward the emergence of a moderate government in Iran with which a settlement satisfactory to the United Kingdom would be possible.“; stattdessen empfahl er eine Kehrtwende: ,, [...] it must be discarded in favor of a policy of action to prevent Iran from falling to communism. Such a policy would involve a willingness, if necessary, to displace British influence and responsibility in Iran as has occurred in Greece, Turkey, and Saudi Arabia, which, it is recognized, might carry risks of damaging our close relations with Britain."; Lovett Letter to Bruce, 16.8.52, Iran Collection, National Security Archive; der letzte Satz auch zitiert in LEFFLER, Preponderance, S. 483; noch expliziter war offenbar ein Schreiben Lovetts vom 24.10.52. Vgl. FRUS 52-54, X., S. $510 n 2$.

${ }^{278}$ Den Forschungskonsens zusammenfassend GASIOROWSKI, Coup Against Mosaddeq, S. 229f.; für BYRNE, Road to Intervention, S. 217, stellt erst NSC 136/1 die Einleitung aggressiverer Maßnahmen seitens der Administration dar und diese seien nie gegen die nationalistische Regierung gerichtet gewesen - tatsächlich aber stellt die Direktive m.E. die Rückkehr zu einer Stabilisierungspolitik in Revision zu den beiden 107er-Direktiven des NSC dar. Das genaue Gegenteil behauptet LoUIS, Dilemmas, S. 242.
} 
Festzustellen ist, dass die sich in der Mehrzahl der vorliegenden Studien zu findende Behauptung einer äquidistanten Haltung der USA, zumindest der Truman-Administration, zwischen den beiden Streitparteien Iran und Großbritannien, angesichts der Quellenlage nicht aufrechterhalten lässt. Zwar gab es innerhalb der US-Regierung durchaus einzelne Personen, die mit dem iranischen Standpunkt sympathisierten ${ }^{279}$, doch darf dies nicht davon ablenken, dass sich die Truman-Administration von Beginn an auf eine Strategie festlegte, die bewusst auf ein finanzielles „Aushungern“ der nationalistischen Regierung in Teheran abzielte, um entweder ein Einlenken Mosaddeġs in den Ölverhandlungen oder, offenkundig die bevorzugte Lösung, die Abberufung bzw. den Sturz seiner Regierung zu erreichen. Die in nahezu allen vorliegenden Studien wiederholte Interpretation, erst der Amtsantritt einer ideologisch feindseligen und interventionistisch gesinnten Eisenhower-Administration in Kombination mit der krisenhaften Zuspitzung der innenpolitischen Lage in Iran und einer unmittelbar drohenden Machtübernahme der Tudeh habe die Entscheidung zum Einsatz einer verdeckten US-geführten Operation gegen die Nationalisten ermöglicht, ist mit der Quellenlage nicht vereinbar.

Bei allen Unterschieden in Weltanschauung und politischen Zielsetzungen zwischen der demokratischen und republikanischen Administration muss daher die grundsätzliche Kontinuität der US-Politik bezüglich Iran betont werden. Wie oben ausgeführt, hatte die Truman-Administration bereits nach 1950 die doktrinären und institutionellen Grundlagen für verdeckte Operationen und psychologische Kriegsführung gelegt und im Anschluss diese Maßnahmen in der Nahostregion wie auch in Iran implementiert. ${ }^{280}$ Eine neu formulierte Grand Strategy für die Nahostregion vom April 1952 sprach denn auch explizit vom Einsatz sämtlicher amerikanischer Einflussmittel ,to support or develop those leadership groups in the area which offer the greatest prospect of establishing political stability oriented toward the free world.“281 Eine begleitende NSC Staff Study ging noch weiter und sprach unmissverständlich

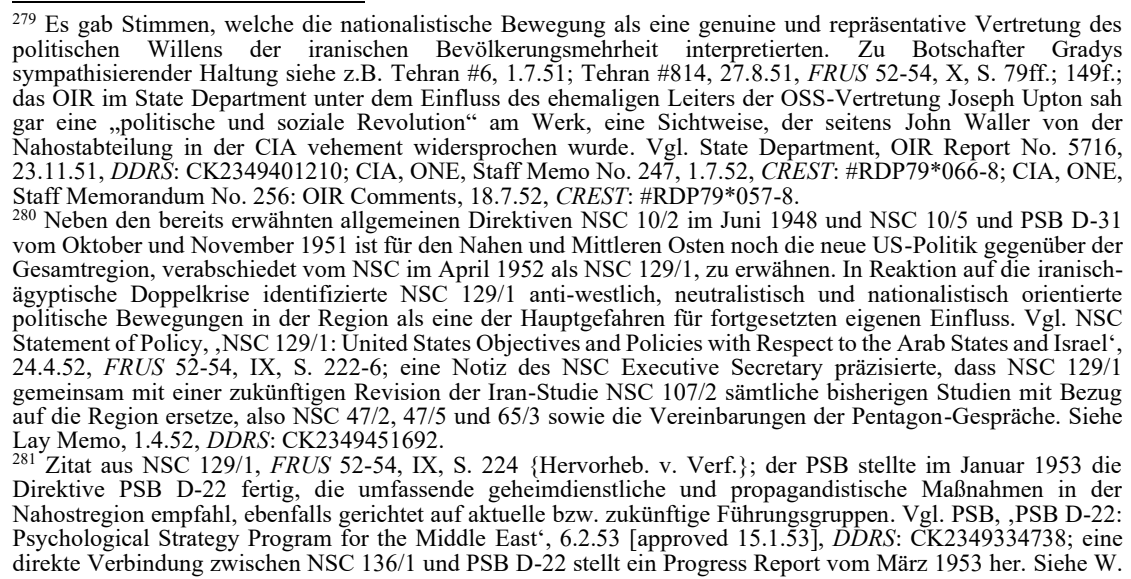


von dem Ziel ,[...] to encourage the emergence of competent leaders, relatively well-disposed toward the West, through programs designed for this purpose, including, where possible, $a$ conscious, though perhaps covert, effort to cultivate and aid such potential leaders, even when they are not in power. “282 Die Truman-Administration hatte sich somit endgültig im April 1952 - in Iran bereits ab März $1951^{283}$ - auf eine Strategie gegenüber den nahöstlichen Staaten und Gesellschaften festgelegt, die im Kern auf die Manipulation der politischen Prozesse und die Steuerung der politischen Eliten setzte. Die Bereitschaft, aktiv an den wirtschaftlichen und politischen Modernisierungs- und Reformprozessen in der Region mitzuwirken bzw. sogar bestimmten, häufig mit den jeweiligen amtierenden Regierungen konkurrierenden Personengruppen Unterstützung zukommen zu lassen, implizierte die Einleitung einer permanenten Interventionspolitik.

Im Februar oder März 1953, im Anschluss an das Scheitern des letzten amerikanischen Vermittlungsversuchs in der Ölfrage ${ }^{284}$, hatte sich die neue republikanische Administration in Washington im Grundsatz auf die Annahme eines britischen Vorschlags zu einer gemeinsamen Operation mit dem Ziel des Sturzes Mosaddeġs geeinigt. ${ }^{285}$ Die neue Administration sei in ihrer Haltung in der Ölkrise „,much more robust“ als ihr Vorgänger, registrierte man zufrieden in London. ${ }^{286}$ Nach einer Reihe von geheimen Treffen stand Mitte Juni 1953 ein ausgeklügelter Plan für einen Coup d'état gegen die Regierung Mosaddeg, der gemeinsam seitens CIA und MI6 in die Tat umgesetzt werden sollte, unter Leitung des bereits erwähnten Kermit «Kim»

B. Smith Memo, 11./20.3.53, in: NSArch EBBook No. 126, doc. 2; vgl. auch McGhee Memo, 31.10.51, ,General Top Secret', Lot 53 D 468, Office Files of McGhee, Box 11.

${ }_{282}$ NSC Staff Study (NSC 129/1), 24.4.52, , Near East (4)', WHO, NSCS, Disaster File Ser., Box 64, DDEL, S. 22 \{Hervorheb. v. Verf.\}; die JCS sprachen sich explizit für Hilfsprogramme und psychologische und andere Maßnahmen anstelle militärischer Beistandsverpflichtungen aus. Vgl. JCS Memo, 15.4.52, ,Near East (3)', ebd.; zur zunehmenden Involvierung der CIA in die Formulierung der Nahostpolitik siehe bereits Dulles Memo, 1.5.51, FRUS 51, V, S. 112f.; die Rekrutierung zukünftiger Führungseliten gelang jedoch kaum, nicht einmal in Iran mit seiner starken US-Präsenz. Dort hatte man Kontakte zu eher technokratisch und konservativ gesinnten Mitgliedern des pro-amerikanischen Netzwerks wie Prinz 'Abdorrezāa, Tag̀i Nasr oder Abu l-Hasan Ebtehāă. Die frühe Präsenz im militärischen Bereich ermöglichte Kontakte zu Offizieren aus dem Umfeld der ARMISH-Mission wie z.B. 'Abbās Farzānegān, ein späterer Hauptorganisator des Coups gegen Mosaddeg̀. Vgl. GASIOROWSKI, Coup Against Mosaddeq, S. 241; die zwischen 1950 und 1952 in den USA ausgebildeten 314 iranischen Offiziere spielten offenbar eine bedeutende Rolle für den Erfolg des Militärcoups vom August 1953. Vgl. SHANNON, Losing Hearts and Minds, S. 18f.; RICKS, U.S. Military Missions, S. 181f.; ähnlich eine Einschätzung vom Herbst 1954: „Without these missions we would probably have lost Iran during the critical days of last August."; Working Draft OCB Progress Report on NSC 5402, 28.9.54, ,OCB 091. Iran (File \#1) (9)', WHO, NSCS, OCB Central File Ser., Box 43, DDEL; die CIA beschwerte sich dagegen intern über den unzureichenden Informationsstand von G-2 über das iranische Offizierskorps. Vgl. CIA [Donald N. Wilber], Clandestine Service History, Appendix E, S. 7f.

${ }_{283}$ Eine Fußnote in NSC 129/1 referenzierte explizit eine separat stattfindende Revision von NSC 107/2 bezüglich Irans, die analoge Anwendung der neuen Politikausrichtung auch auf Iran signalisierend. Siehe FRUS 52-54, IX, S. 222, Anm. unten.

${ }^{284}$ Die USA hatten nach dem Abbruch der diplomatischen Beziehungen zwischen Teheran und London die Verhandlungsführung mit Mosaddeg direkt übernommen und entlang der Vorgaben in NSC 136/1 im Dezember 1952 einen weiteren Vorschlag unterbreitet. Nach eine Reihe von Modifikationen im Sinne Irans lehnte Mosaddeg dennoch im Februar 1953 das Gesamtpaket ab. Vgl. ausführlich MARTSCHUKAT, Antiimperialismus, S. 256-78; HEISS, Empire and Nationhood, S. 150-71; FO Intel No. 45, 21.2.53, FOCP V, B, 5, S. 155.

${ }_{285}$ Ein MI-6-Team hatte bereits im November 1952 in Washington einen gemeinsam organisierten Staatsstreich gegen Mosaddeg vorgeschlagen. Das State Department reagierte dilatorisch angesichts des anstehenden Wechsels im Weißen Haus, wohingegen die CIA, insbesondere der designierte zukünftige DCI Allen Dulles, Zustimmung signalisierte. Vgl. CIA [Donald N. Wilber], Clandestine Service History, S. 1; vgl. NSArch EBBook No. 601; WoOdHOUSE, Something Ventured, S. 117f.; RoOSEVElT, Countercoup, S. 119-24; FALLE, My Lucky Life, S. 83f.; die informelle Zustimmung der Eisenhower-Administration erfolgte noch Anfang Februar, die offizielle Autorisierung an die CIA im März 1953. Vgl. GASIOROWSKI, Coup Against Mosaddeq, S. 232, $331 n 12$.

${ }^{286}$ Zit. aus LOUIS, Dilemmas, S. 249. 
Roosevelt, ein Enkel Theodore Roosevelts, und zu dieser Zeit Leiter der CIA-Operationen im Nahen und Mittleren Osten. Angedacht war eine umfassende Schwächung der nationalistischen Regierung durch ,psychologische und politische Operationen“ unter Einsatz der verschiedenen „Assets“ beider Mächte vor Ort, zuvorderst das von der CIA geführte TPBEDAMN-Netzwerk und das für die Briten arbeitende Rašidijān-Netzwerk. Im Zuge der durch die verdeckten Aktionen angefachten politischen Krise in Teheran sollte dann Schah Mohammad Rezā überzeugt werden, Premier Mosaddeg zu entlassen und an seiner Stelle den von Washington und London bevorzugten Kandidaten, den pensionierten General und ExInnenminister Fazlollāh Zāhedi, zu ernennen. Teil dieses „quasi-konstitutionellen“ Machtwechsels war die Organisation eines Vertrauensentzugs für Mosaddeg durch den Mağles, befördert mittels Bestechung von Abgeordneten und Einschüchterung durch eine zu organisierende Großdemonstration aus dem konservativen Umfeld von Basar und Geistlichkeit. Ein parallel organisiertes Netzwerk monarchistischer Offiziere würde den Staatsstreich absichern und nötigenfalls militärisch die Macht ergreifen. ${ }^{287}$

Bedeutend für die in dieser Studie vorgestellte Interpretation, die in dieser Hinsicht wesentlich von nahezu allen übrigen Arbeiten über den Coup abweicht, war die Kontinuität zwischen dem Umsturzplan und den oben geschilderten „special political operations“ im Kontext der beiden NSC 107-Studien. Wie bereits seit dem Nationalisierungsbeschluss erhofft und auch von amerikanischer Seite aktiv, wenngleich verdeckt, gefördert - die letztlich gescheiterte Durchsetzung einer Ministerpräsidentenschaft Ahmad Ġawāms im Juli 1952 kann als ein erster Höhepunkt dieser Strategie betrachtet werden -, zielte auch der anfängliche Coup-Plan von CIA und MI6 auf eine oberflächlich verfassungskonforme Entfernung Mosaddeġs aus dem Amt. Die USA hatten bereits im Mai 1952 großzügige finanzielle Unterstützung für eine genehmere Nachfolgeregierung zugesagt. ${ }^{288}$ Formal war die Entlassung und Berufung des Premiers Teil der monarchischen Prärogative. Allerdings war allen Akteuren bewusst, dass eine Entmachtung Mosaddeġs nur bei gleichzeitiger gewaltsamer Unterdrückung der Nationalen Front wie auch der Tudeh erreicht werden konnte. ${ }^{289}$ Mit dem Scheitern des Umsturzversuchs vom Juli 1952 - de facto ein versuchter Staatsstreich - und der anschließenden Notstandsermächtigung Mosaddeġs war eine gewaltfreie wie

\footnotetext{
${ }^{287}$ Details zu den Coup-Planungen in CIA [Donald N. Wilber], Clandestine Service History, S. 5-15; der endgültig mit dem SIS erarbeitete Plan in voller Länge in ebd., Appendix B; „Quasi-legal method to be tried first“; ebd., Appendix A, S. 3; vgl. Gasiorowski, Coup Against Mosaddeq, S. 233-42; ABrahamian, The Coup, S. 170-83; RAHNEMA, Behind the Coup, S. 60-78; zu Zāhedi vgl. Milani, Eminent Persians: I, S. 495-505.

${ }^{288} \mathrm{Im}$ April 1952 forderte Henderson das State Department zu Vorbereitungen eines US-Hilfspakets an ,[...] to encourage a new regime to settle the oil controversy and to pursue policies generally oriented in a pro-Western direction."; FRUS 52-54, X, S. 383 n3; das State Department sagte kurz darauf im Falle eines ,replacement of Mosadeq by dependable successor" Soforthilfe zwischen \$115-145 Millionen zu. Mosaddeg hingegen war zuvor fast jede wirtschaftliche Unterstützung verweigert worden. Vgl. State \#2742, 30.5.52, ebd., S. 386-9; Memo for File, 24.7.52, ,Iran', Box 341, Harriman Papers, LOC; ABRAHAMIAN, The Coup, S. 135-47, ist zuzustimmen, die vorherige Forschung habe allzu leichtfertig die Rolle der USA in der Krise von 1952 übergangen.

${ }^{289}$ So explizit z.B. der Schah im Juni 1952. Siehe Tehran \#4837, 13.6.52, FRUS 52-54, X, S. 400; Beispiele für Drängen auf eine Entlassung Mosaddeġs z.B. in eben dieser Unterhaltung vonseiten Hendersons, sogar verklausuliert einen Staatsstreich erwähnend. Siehe ebd., S. 397f.; die Notwendigkeit einer Entlassung bereits angedeutet in State \#1274, 21.12.51, ebd., S. 295-8; ähnlich in Tehran \#4609, 28.5.52; Tehran \#4736, 6.6.52, ebd., S. 384ff., 389-92; zur Frage der Legalität des späteren Staatsstreichs vgl. RAHNEMA, Behind the Coup, S. $270-88$.
} 
verfassungskonforme Regierungsänderung in weite Ferne gerückt. ${ }^{290}$ Loy Henderson, seit September 1951 US-Botschafter in Teheran, und sein britischer Kollege George Middleton berichteten beide übereinstimmend, dass nunmehr allein ein Coup des Militärs einen Machtwechsel herbeiführen könne. ${ }^{291}$ Wie oben geschildert, gab die Truman-Administration im November 1952 mit NSC 136/1 aus wachsender Angst vor einem Anstieg kommunistischen Einflusses in Iran die bislang verfolgte Destabilisierungspolitik formal auf - allerdings scheinen die geheimdienstlichen Operationen gegen die Nationale Front gerade in dieser Zeit intensiviert worden zu sein, ein Widerspruch, der wohl erst nach Freigabe der CIA-Akten zu klären ist. ${ }^{292}$

Der anglo-amerikanische Coup-Plan, von britischer Seite mit der wenig subtilen Bezeichnung „Operation BOOT“ versehen, von amerikanischer Seite „TPAJAX“ genannt, eine Zusammensetzung aus dem für Iran verwandten Länderkürzel „TP“, sich beziehend auf die „Tudeh Party“ und einem bekannten Reinigungsmittel, somit also die Säuberung Irans vom Kommunismus zum Ziel setzend, wurde unmittelbar in die Tat umgesetzt ${ }^{293}$. Eine groß angelegte Propagandakampagne gegen die nationalistische Regierung wurde eingeleitet, Mosaddeg als Parteigänger Moskaus und der Tudeh sowie als anti-islamisch diffamiert. Neben dem konservativ eingestellten Basar spielte der politisierte Teil des schiitischen Klerus, ansonsten in der großen Mehrheit traditionell-quietistisch eingestellt und weitgehend desinteressiert an der Tagespolitik, in der Kampagne eine Schlüsselrolle, insbesondere der zuvor wichtigste religiöse Verbündete Mosaddeg̀s, Ājatollāh Kāšāni, der sich bereits Monate zuvor von der Regierung abgewandt und, wie eine Reihe anderer religiöser Führer auch, Bestechungsgeld von den Coup-Planern angenommen hatte. ${ }^{294}$ Offenbar hatte man auch Kontakte zur islamistischen Terrorgruppe Fedā ijān-e Eslām aufgebaut, die nun öffentlich mit Angriffen auf nationalistische Führungsfiguren drohte. ${ }^{295}$ Die von Donald Wilber konzipierte

\footnotetext{
${ }^{290}$ Mosaddeg reagierte auf den Umsturzversuch mit Maßnahmen gegen den Hof. So versuchte er die Verbindungen des Schahs zum Militär zu kappen und die zivile Oberaufsicht durchzusetzen und übernahm nun selbst das Ressort des Kriegsministers, diese Bezeichnung sogleich in Verteidigungsminister abändernd. Er reduzierte das Militärbudget um $15 \%$, setzte Komitees zur Untersuchung früherer Waffeneinkäufe ein und pensionierte in den darauffolgenden Monaten über 400 höhere Offiziere. Er reduzierte das Finanzbudget des Hofs, übertrug die kaiserlichen Ländereien dem Staat, und erzwang die Ausreise der konspirierenden Tāğ-o-1-Moluk, der Mutter Mohammad Rezās, und seiner Zwillingsschwester Ašraf. Der Rumpf-Mağles übertrug Mosaddeġ darüber hinaus außerordentliche Vollmachten für sechs Monate und akzeptiere die Auflösung des einseitig pro-monarchischen Senats. Vgl. ABRAHAMIAN, The Coup, S. 143-7; vgl. State \#585, 26.7.52, FRUS 52-54, X, S. $415 \mathrm{f}$.

${ }_{291}$ Hier wurde bereits Fazlollāh Zāhedi als möglicher Anführer eines Coups genannt. Zu diesem Zeitpunkt empfahlen Henderson und Middleton ihren Regierungen, einen Militärcoup weder,,to encourage or support“. Vgl. Tehran \#481, 31.7.52, ebd., S. 427f.

${ }^{292}$ Zur Intensivierung vgl. GASIOROWSKI, TPBEDAMN Operation, S. 13ff.

${ }^{293}$ Vgl. ders., Coup Against Mosaddeq, S. 331 n12; Churchill segnete die Operation am 1.7., Eisenhower am 11.7. ab. Vgl. CIA [Donald N. Wilber], Clandestine Service History, S. 18; die vorbereitende Destabilisierungskampagne begann aber bereits im Frühling 1953.

${ }^{294}$ Für eine Einschätzung der Rolle von Ājatollāh Kāšāni vgl. AKHAVI, Role of the Clergy; RICHARD, Ayatollah Kashani; YAZDI, Clerical Behavior, S. 289-302; Belege für die Bestechlichkeit Kāšānis, seiner Söhne und anderer Kleriker bei ABRAHAMIAN, The Coup, S. 136, 154ff.; ein CIA-Dokument spricht explizit von Kāšānis ,record of venality“; ONE/CIA Memo, 1.3.53, FRUS 52-54, X, S. 689ff.; hier geschwärzt, aber verfügbar in DDRS: CK3100705159; über die Motive hinter der Auslassung in FRUS kann man nur spekulieren. Die geheime CIAGeschichte des Coups erwähnt einen von Kāšānis Söhnen als direkten Beteiligten. Vgl. CIA [Donald N. Wilber], Clandestine Service History, S. 71.

${ }^{295}$ Vgl. GASIOROWSKI, Coup Against Mosaddeq, S. 237ff.; 242-6; ders., TPBEDAMN Operation, S. 15ff.; CIA [Donald N. Wilber], Clandestine Service History, Appendix B, S. 21; für britische Involvierung mit den Fedā ijān vgl. ABRAhamian, The Coup, S. 152f.; im Februar 1952 hatten die Fedāejiān bereits einen Anschlag auf Außenminister Hosejn Fātemi verübt, den dieser schwer verletzt überlebt hatte.
} 
CIA-Propagandakampagne konzentrierte sich unter anderem darauf, Mosaddeg und andere nationalistische Führungsfiguren als homosexuell $\mathrm{zu}$ diffamieren bzw. als heimliche Konvertiten zu Christen-, Juden- oder Bahaitum darzustellen, offenbar hoffend, sie so zur Zielscheibe islamistisch motivierter Mordanschläge zu machen. Obskur bleibt weiterhin die anglo-amerikanische Rolle in der Entführung und Ermordung des Mosaddeg-loyalen Polizeichefs Mahmud Afs̃artus im April 1953, zugleich Anführer der „Nationalistischen Offiziere“, einer geheimen Gruppierung innerhalb der Streitkräfte. ${ }^{296}$ Angesichts seiner Position und seiner nationalistischen Gesinnung war Afšartus der zentrale Gegenspieler des seitens MI6 und CIA im Aufbau befindlichen militärischen Netzwerkes in Unterstützung des geplanten Staatsstreichs. Die Tat war offenbar als Auftakt einer Serie gezielter Attentate gegen die wichtigsten Persönlichkeiten in der nationalistischen Führung gedacht gewesen und somit Teil eines geplanten „Enthauptungsschlages“ gegen die Mosaddeg-Regierung. Britische Beteiligung bzw. Mitwisserschaft ist zumindest in Teilen belegt, eine zumindest indirekte Beteiligung der CIA zudem wahrscheinlich. Einige Jahre später gestand der Hofminister gegenüber einem amerikanischen Gast auch eine direkte Beteiligung des Schahs an dem Mordkomplott. ${ }^{297}$

Schwieriger gestaltete sich die Inszenierung eines Misstrauensvotums durch den 17. Mağles, der ohnehin nur noch ein Rumpf-Parlament darstellte. Offenkundig informiert über die Absichten der Opposition, erzwang Mosaddeg die Auflösung des Mağles, die er im Anschluss von $99 \%$ des Wahlvolkes in einem demokratisch zweifelhaften Referendum Anfang August 1953 sanktionieren ließ. ${ }^{298}$ Kermit Roosevelt, seit Mitte Juli verdeckt in Iran operierend, suspendierte daher diejenigen Teile des Planes, die auf eine quasi-legale Absetzung Mosaddeg durch den Mağles abgezielt hatten. Somit rückten die militärischen Bestandteile des geplanten Staatsstreiches in den Vordergrund - der CIA-Experte für paramilitärische Operationen George Carroll organisierte mit Unterstützung Zāhedis und vor allem mithilfe des von der CIA angeworbenen 'Abbās Farzānegān, Oberst und ehemals Militärattaché der iranischen Botschaft

\footnotetext{
${ }^{296} \mathrm{Zu}$ den „Nationalistischen Offizieren“ und zur Ermordung von Afs̃artus vgl. KATOUZIAN, Struggle for Power, 130ff., 183ff.; RAHNEMA, Behind the Coup, S. 40-4; GASIOROWSKI, Coup Against Mosaddeq, S. 334 n30; AZIMI, Unseating Mosaddeq, S. 82f.; vgl. auch die Version in LouIS, Britain and the Overthrow, S. 314f. $n 170$; eine in der FRUS-Version des Dokuments ausgelassene Stelle einer CIA-Einschätzung vom März enthält einen ominösen Verweis auf die ,elimination of Mossadeq by assassination or otherwise“; ONE/CIA Memo, 1.3.53, FRUS 52-54, X, S. 689ff.; hier geschwärzt, aber in DDRS: CK3100705159.

${ }^{297}$ Die Beteiligung des ehemaligen Mosaddeg-Unterstützers Mozaffar Bag̀āèi, Zāhedis und der Rašidijān-Brüder scheint gesichert, was eine britische Verbindung sehr wahrscheinlich macht. Wilber erwähnt den Mord in seiner internen Geschichte mit keinem Wort trotz seiner zentralen Bedeutung für den Aufbau des Netzwerkes. Zur wahrscheinlichen Beteiligung der CIA vgl. auch HEISS, Empire and Nationhood, S. 177; zu Manučehr Eg̉bāls Geständnis vgl. CIA Intel Report 2035-72, Mai 1972, FRUS 69-76, E-4, doc. 180; Eg̉bāl zufolge war er selbst Kontaktmann zwischen Hof und den Mördern von Afšartus gewesen.

${ }^{298}$ Die Nationale Front stellte 30 der 79 Abgeordneten des bis Anfang 1952 gewählten Mağles. Mosaddeg hatte die Wahlen nach Besetzung von $60 \%$ der Sitze suspendiert, vorgeblich in Reaktion auf fortwährende Wahlmanipulationen des Hofs und konservativer Kräfte. Für Überlegungen Kim Roosevelts, den Mağles noch vor der Auflösung für die eigenen Zwecke zu nutzen, vgl. K. Roosevelt Memo, 15.7.53, NSArch EBBook No. 435, doc. 6; vgl. ABRAHAMIAN, The Coup, S. 169f., der ungefähr ein Drittel der Abgeordneten auf dem ,payroll“ von CIA und MI6 vermutet. GASIOROWSKI, Coup Against Mosaddeq, S. 244, hält sogar die Hälfte für denkbar. Die CIA [Donald N. Wilber], Clandestine Service History, Appendix A, S. 4, erwähnt die Einschätzung der SIS, dass ,[...] 20 deputies now not controlled must be purchased.“; der Zusammenhang scheint Kontrolle über 33 andere Abgeordnete zu suggerieren.
} 
in Washington, ein Putschisten-Netzwerk innerhalb der Streitkräfte. ${ }^{299}$ Trotz großer Bedenken der Coup-Planer bezüglich der Standfestigkeit des Monarchen, bemühte man sich intensiv um die Unterstützung Mohammad Rezās, um wenigstens oberflächlich den Eindruck verfassungskonformen Handelns zu erwecken. Nach langwierigen wie ermüdenden Gesprächen und erst infolge vonseiten CIA und MI6 inspirierter Sondermissionen seiner Zwillingsschwester Ašraf und des ehemaligen Leiters der Gendarmeriemission, Norman Schwarzkopf Senior, willigte der Schah schließlich am 12. August 1953 ein, Dekrete zur Entlassung Mosaddeġs und zur Ernennung Zāhedis als dessen Nachfolger zu unterzeichnen. ${ }^{300}$

Der ursprüngliche Plan für den Staatsstreich scheiterte zuvorderst am militärischen Netzwerk, das die ihm zugedachten Aufgaben im Rahmen des Coups nicht umzusetzen imstande war. Die vorgewarnte nationalistische Regierung vereitelte die militärische Okkupation strategischer Punkte in Teheran durch die Putschisten, verlegte loyale Truppenverbände in die Hauptstadt, entwaffnete die Leibgarde des Schahs und besetzte das Armeehauptquartier. Die Putschisten wurden verhaftet oder tauchten unter, der panische Mohammad Rezā floh über Bagdad nach Rom. Angesichts der späteren historischen Bedeutung des US-Botschaftsgeländes ist erwähnenswert, dass sowohl Farzānegān wie auch andere Putschisten dort vorübergehend Unterschlupf fanden, die Unverletzlichkeit der diplomatischen Mission missbrauchend. ${ }^{301} \mathrm{Am}$ 16. August schien nicht allein der Staatsstreich gescheitert, sondern auch die Monarchie in Iran am Ende - das CIA-Hauptquartier forderte Roosevelt am folgenden Tag zum Abbruch der Operation auf. Die anschließende Wende zugunsten der Putschisten ergab sich aus einer Reihe von Faktoren. Offenbar lehnten viele der zuvor neutral und äquidistant eingestellten Iraner, gerade unter den Offizieren, die exzessive Rhetorik im Anschluss an den gescheiterten Coup, insbesondere die Rufe nach einer Republik, und die nun ungehinderte Präsenz der Tudeh auf den Straßen, ab. CIA und MI6 nutzten parallel zu diesem Stimmungswandel die beiden Dekrete Mohammad Rezās und verbreiteten die Information über die Entlassung Mosaddeğs durch den Schah. Mittels der geheimdienstlichen Netzwerke schuf man zugleich Chaos in Teheran, unter anderem mittels einer vorgeblichen Tudeh-Demonstration im Herzen der Hauptstadt, in Wirklichkeit eine False Flag-Operation der von CIA und MI6 geführten Netzwerke. ${ }^{302}$ Mosaddeg reagierte mit einem Demonstrationsverbot, an das sich am 19. August seine Anhänger hielten, aber nicht die pro-monarchischen Kräfte. Ein größerer Mob, ein weiteres Mal organisiert von den anglo-amerikanischen Agentennetzwerken, machte sich vom Süden Teherans auf den Weg ins Zentrum, im Vorbeigehen Einrichtungen der Nationalen Front und

\footnotetext{
${ }^{299}$ Vgl. GASIOROwSKi, Coup Against Mosaddeq, S. 241f.; zum Aufbau des militärischen Netzwerks vgl. CIA [Donald N. Wilber], Clandestine Service History, Appendix D; zu Farzānegāns zentraler Rolle und seinen vorherigen US-Verbindungen vgl. ebd. S. 4f.

${ }^{300}$ Details in ebd., S. 22-38; GASIOROWSKI, Coup Against Mosaddeq, S. 246ff.; vgl. RueHSEn, 'Ajax' Revisited, S. 477f.; zweifelhaft die Schilderung in FarmanFArmaian, Blood and Oil, S. 292.

${ }^{301}$ CIA [Donald N. Wilber], Clandestine Service History, S. 93, merkt an, dass ,the executors of the plan made brilliant use of the grounds of the Embassy and of houses occupied by US personnel [... $]^{\prime .}$.

${ }^{302}$ Kürzlich freigegebene Passagen der zweiten internen CIA-Geschichte des Coups sprechen explizit davon, dass Ājatollāh Kāšāni Personen bezahlt habe, die dann den Nukleus der entscheidenden Demonstration aus dem Süden Teherans am 19. August stellten. Vgl. CIA History Staff, The Battle for Iran, S. 66.
} 
der Tudeh angreifend und pro-monarchische Offiziere aus den Gefängnissen befreiend. Militärische Einheiten unter Kontrolle des Putschisten-Netzwerks attackierten regierungsloyale Truppen und griffen zudem das Privathaus Mosaddeġs an - Mosaddeg selbst ergab sich am Folgetag den Streitkräften. Zāhedi wurde in das Sendezentrum von Radio Teheran gebracht, von wo er seine Machtübernahme verkündete. Das Militär entmachtete die Nationalisten gleichzeitig in anderen wichtigen Städten des Landes wie Täbris und Isfahan. Iranische Offizielle nannten später die Zahl von 43 Todesopfern im Zuge des Staatsstreichs - tatsächlich sind häufig zu findende Behauptungen über hunderte von Opfern wohl eine Übertreibung. ${ }^{303}$ Schah Mohammad Rezā kehrte am 22. August 1953 im - wenngleich wohlorganisierten Triumph in den Iran zurück. ${ }^{304}$

Angesichts der historischen Langzeitwirkung der Ereignisse im August 1953 - in Iran wird der 28. Mordād als der Schlüsseltag des Coups referenziert - und der weiterhin begrenzten Quellenlage kann es nicht überraschen, dass bis zum heutigen Tag heftig über die Umstände, Triebkräfte und Folgen des Ereignisses gestritten wird. Die wissenschaftliche Debatte ist im Kontext der jüngeren amerikanisch-iranischen Spannungen im Atomstreit ein weiteres Mal angefacht worden. Die offizielle Lesart vonseiten der restaurierten Schah-Monarchie und den anglo-amerikanischen Mächten, Mosaddeġs Regierung sei von einer genuinen und von breiten Bevölkerungsschichten getragenen Aufstandsbewegung aus dem Amt gedrängt worden, konnte nie Glaubwürdigkeit beanspruchen, zumal die CIA selbst Details über TPAJAX der Presse zuspielte, um den eigenen Nimbus als einer effizienten Organisation zur Verfolgung amerikanischer Ziele im Kalten Krieg zu bekräftigen. Dennoch war die Rolle der CIA in der amerikanischen Öffentlichkeit bis in die 1970er Jahre kaum bekannt. ${ }^{305}$ Vermehrte Aufmerksamkeit kam dem Staatsstreich von 1953 erst im Kontext der Iranischen Revolution und der resultierenden Krise in den Beziehungen zwischen beiden Ländern zu, zumal Kermit Roosevelts Memoiren 1979 erschienen, die zuvor unbekannte Details zur Involvierung der CIA enthielten. ${ }^{306}$

Eine Reihe von historiographischen Kontroversen im Zusammenhang mit dem 28. Mordād sind für den in der hier vorliegende Studie untersuchten Gegenstand von Relevanz, zuvorderst die

\footnotetext{
303 Vgl. ebd., S. 70.

304 Über den Verlauf des Staatsstreichs im August vgl. GASIOROwSKI, Coup Against Mosaddeq, S. 248-56; Abrahamian, The Coup, S. 183-203; Roosevelt, Countercoup, S. 136-97; WILBER, Adventures, S. 187-91; KatouZIAN, Struggle for Power, S. 177-93; KInZER, Shah's Men, S. 150-88; die britische Rolle hervorhebend, wenngleich in vielem zweifelhaft die Darstellung in FARDUST, Rise and Fall, S. 81-90.

${ }^{305}$ Insbesondere die Artikelserie von Richard und Gladys Harkness, , The Mysterious Doings of the CIA ', Saturday Evening Post, 30.10./6.11./30.11.54; vgl. Dorman/Farhang, U.S. Press and Iran, S. 49f., 54f.; ThOMAS, Early Years, S. 124; CoTTAM, Nationalism in Iran, S. 227-30; Arthur Schlesinger Jr. kommentierte 1961 die Artikelserie in der Saturday Evening Post: „,...] a gross and repeated CIA failing has been its occasional readiness to succumb to the temptations of favorable publicity. The Guatemalan and Iranian operations were almost nullified by the flood of self-congratulatory publicity which followed them."; Schlesinger Memo to Kennedy, 30.6.61, ,Central Intelligence Agency, General 5/61-8/61‘, NSF, D\&A, Box 271, JFKL; vgl. auch die Beschwerde über, ,excessive publicity“ in Jorden Memo, 27.2.64, ,Central Intelligence Agency, 1962-1963“, Box 442, Harriman Papers, LOC. ${ }_{306} \mathrm{Zu}$ den Hintergründen der Veröffentlichung des Buchs von Roosevelt vgl. NSArch EBBook No. 468; die CIA setzte vielfältige Ânderungen am Manuskript durch, die die Arbeit in ,essentially a work of fiction“ verwandelten. Breiter zum Genre vgl. BALAGHI, Silenced Histories.
} 
Motivationen für die amerikanischen Aktionen sowie die tatsächlichen Auswirkungen derselben. Statt eine Involvierung der USA im Coup zu leugnen, bagatellisiert der moderne Revisionismus - meist aus den Reihen pro-monarchischer iranischer Exilanten bzw. aus dem amerikanisch-neokonservativen Milieu entspringend - die eigentliche Wirkung der externen Aktionen. Autoren wie Ray Takeyh, Dariush Bayandor, Abbas Milani, Patrick Clawson, Barry Rubin, Gholam Reza Afkhami betonen den indigenen Charakter sowie die autonome Stärke der royalistischen und gerade der religiös-konservativen Kräfte im August 1953, den anfangs gescheiterten CIA-MI6-Coup als zweitrangigen Faktor bzw. als vernachlässigbar bewertend. Ardešir Zāhedi, Sohn des Putschistengenerals und späterer Außenminister, mutmaßte später stellvertretend für viele Revisionisten, wie ein „,vodka-drinking American named Roosevelt who spoke no Persian, along with a motley crew of paid agents“ den Sturz einer populären Regierung bewerkstelligt haben sollte. ${ }^{307}$ Nicht zu bestreiten ist, dass nahezu alle relevanten Akteure im Sommer 1953 Iraner waren und die wenigen anglo-amerikanischen Agenten vor Ort vorwiegend eine Koordinierungs- und Planungsfunktion innehatten, selbst aber kaum während der Ereignisse in Erscheinung traten. Zudem steht außer Frage, dass trotz aller anfänglichen Popularität der Nationalen Front und Mosaddeġs selbst nach über zwei Jahren außenpolitischer Isolation, wirtschaftlicher Stagnation und politischer Unruhe einiges an Unterstützung in der Bevölkerung verloren gegangen war. Dennoch ist dem Urteil der Autoren der wichtigsten Arbeiten über den 28. Mordād - u.a. Ervand Abrahamian, Fakhreddin Azimi, Mark Gasiorowski, James Bill, Richard Cottam oder James Goode - zuzustimmen, dass der Sturz Mosaddeġs nur bei Betrachtung der engen Interaktion zwischen externen und internen Akteuren verständlich wird. Wenngleich kontrafaktische Spekulation, bleibt festzuhalten, dass ohne die Koordinierung, Organisation und Finanzierung durch Kim Roosevelts Team wohl kaum das am Ende entscheidende militärische Netzwerk zustande gekommen wäre. Zudem konnten letztlich nur die Zusicherungen von außen - und am Ende direkte Drohungen - den

\footnotetext{
${ }^{307}$ Ardešir Zāhedi, zit. aus MILANI, The Shah, S. 174f.; vgl. ebd., 185-8; ein Blick auf die Fußnoten zeigt, dass Zāhedi selbst offenbar Souffleur für viele der revisionistischen Arbeiten war. Vgl. auch seine zweifelhaften Darstellungen in ZAHEDI, Memoirs, Vol. I, S. 95-241, insbesondere 179-84; Zāhedi gesteht sogar seine Absicht, die historische Darstellung in seinem Sinne zu revidieren, offen ein. Siehe ebd., S. 190f.; eine spätere US-Quelle nennt ihn allerdings selbst einen ,employee“ der CIA in der Zeit des Coups, die mythisierenden Absichten hinter seiner späteren Äußerungen offenlegend. Vgl. unten S. 562 Anm. 1; vgl. die Wertungen in RuBIN, Good Intentions, S. 88ff.; AFKHAMI, Life and Times, S. 155-84; aus geschichtswissenschaftlicher Perspektive inakzeptabel ist BAYANDOR, Iran and the CIA; Bayandors zentrale These einer direkten Involvierung des allgemein anerkannten Marğ $a^{\prime}$ und damit höchstrangigen Klerikers Ājatollāh Boruğerdi überzeugend widerlegt in AzIMI, Overthrow Reconsidered; vgl. auch GASIOROWSKI, Critique of Bayandor; vgl. die Fortsetzung der Debatte in Iranian Studies 45, 5 und 46, 3 (2013); ähnlich zu Bayandors Argument ist MOKHTARI, Coup Revisited; der Einfluss der CIAOperation als ,ultimately insignificant" bewertend TAKEYH, What Happened, S. 2; vgl. die Debatte zwischen Christopher DE BELlaigue, und Ray TAKEYH in Coupdunnit; vgl. auch die scharfen Kritiken an Takeyh in HDIPLO/ISSF Forum on „What Really Happened: Solving the Cold War's Cold Cases“, 9.4.2015, verfügbar auf http://issforum.org/ISSF/PDF/ISSF-Forum-7.pdf; den Missbrauch von Dokumenten durch Takeyh dokumentiert NSArch EBBook No. 477; Patrick Clawson, ein exponierter Vertreter der amerikanisch-neokonservativen Geschichtspolitik, kritisiert die bestehende Forschung als Sprachrohr der ,"blame America first' crowd ", und sieht Mosaddegs Sturz ausschließlich als Folge seiner ,diktatorischen“ Politik und des Vertrauensverlusts seitens der Bevölkerung. Siehe http://www.meforum.org/1246/empire-and-nationhood; weitere Beispiele in ABRAHAMIAN, The Coup, S. 202f.; explizit die interne Ablehnung einer früheren Variante dies revisionistischen These durch Amos Perlmutter aus CIA-Sicht in Scott A. Koch/CIA History Staff, "Zendebad, Shah!", 1998, S. 87: „CIA's role was significant. Without Kermit Roosevelt's leadership, guidance, and ability to put some backbone into the key players when they wanted to quit, no one would have moved against Mossadeq."
} 
Schah überzeugen, die Entlassungsurkunde zu unterzeichnen, die dann für den Erfolg des Staatsstreichs gerade propagandistisch eine wichtige Rolle spielte. ${ }^{308}$

Die in der vorliegenden Studie betonte Einleitung einer permanenten Interventionspolitik ab März 1951 mit dem Ziel der Stärkung des Hofs im internen Machtgefüge Irans und der Berufung einer pro-westlich orientierten Regierung, im Einklang mit dem Vorgehen Großbritanniens, widerspricht allerdings dem etablierten Stand der Forschung. Nur wenige Autoren rücken von der Vorstellung einer im Grunde äquidistanten Haltung Washingtons im Ölkonflikt ab bzw. die allermeisten betonen eher die Widersprüche denn die Gemeinsamkeiten zwischen amerikanischen und britischen Vorstellungen. ${ }^{309}$ Anstelle der gängigen Sichtweise einer Kehrtwende in der US-Politik in der Ölkrise im Gefolge der Amtsübernahme der rigorosideologisch anti-kommunistischen eingestellten Eisenhower-Administration wird hier die grundsätzliche Kontinuität amerikanischer Politik betont. ${ }^{310}$ Hinsichtlich der Verantwortung für den Coup und dessen Salienz treten die Details des 28. Mordād zugunsten der langfristigen Erosion der Handlungsfähigkeit der Mosaddeg-Regierung und des Zerfalls der politischen Kohäsion der Nationalen Front in den Hintergrund. Die finanzielle Notsituation der Regierung war in erster Linie Resultat des anglo-amerikanischen Ölboykotts und der weitgehenden Verweigerung finanzieller Unterstützung seitens der Truman-Administration. Angloamerikanische Diversionstätigkeiten hatten die ohnehin bestehende Heterogenität der Front wenigstens beschleunigt. Ehemalige Parteigänger Mosaddeg̉s wie Ājatollāh Kāšāni, Mozaffar Bag̀āe i, Hosejn Makki oder Abu 1-Hasan Hāerizādeh hatten sich von den Vorteilen eines

\footnotetext{
${ }^{308}$ Beispielhaft AzIMI, Unseating Mosaddeq, S. 28f., GAsionowski, Why Did?; BILL, Eagle and Lion, S. 92ff.; Goode, United States and Iran, S. 123f.; COTTAM, Iran and the United States, S. 102-9; die ausgewogene Position auf den Punkt gebracht in KATOUZIAN, Mosaddeq's Government, S. 16f.: ,[...] the coup was a product of the close collaboration of Mosaddeq's domestic and foreign opponents, even though the role of the two foreign powers, especially the United States, in organizing and financing it was all but indispensable. Mosaddeq's Iranian opponents were too divided and too unsure of themselves as well as each other to organize and act in unison. [...] On the other hand, the foreign powers could not possibly have brought down Mosaddeq by a coup without the cooperation of his domestic opponents."; ausführlich auch in RAHNEMA, Behind the Coup, S. 235-69; ohne Koordinierung eines externen Akteurs wie der CIA wäre die Abstimmung zwischen 40 Offizieren unterhalb der eigentlichen Kommandeursebene wohl kaum gelungen. Vgl. ABRAHAMIAN, The Coup, S. 182f.; zu Zāhedis schwacher Position unter den Offizieren und der entscheidenden CIA-Unterstützung vgl. CIA [Donald N. Wilber], Clandestine Service History, Appendix B, S. 10, 40; CIA History Staff, The Battle for Iran, S. 41; des Weiteren ist die Bedeutung der seitens der Angloamerikaner zur Verfügung gestellten exorbitanten Finanzmittel zu betonen. Bereits im April wurden der Botschaft \$1 Million zur Unterstützung Zāhedis und zur Bestechung von Abgeordneten gesandt. Vgl. CIA [Donald N. Wilber], Clandestine Service History, S. 18f.

${ }_{309}$ Vgl. u.a. MARSH, Cold War Oil, S. 37-104, der zudem alle verdeckten Aktivitäten vor 1953 einfach ignoriert und den Coup dann als Bestätigung der weiteren Gültigkeit der special relationship interpretiert. Ähnlich BYRNE, Regime Change; sowie ROMERO, Decolonization in Reverse; eine jüngere revisionistische Tendenz, den Coup als Resultat einer geschickten Manipulation der USA durch London, analog zu Harold Macmillans berühmten Vergleich zum Verhältnis zwischen Römern und Griechen, zu bewerten, ist mit Chronologie und Quellenlage unvereinbar. Vgl. beispielsweise ISRAELI, Circuitous Nature; ähnlich PEARSON, In the Name of Oil, S. 14-41; die US-Haltung in den Verhandlungen ähnlich zur vorliegenden Studie bewertend HEISS, Empire and Nationhood, S. 77-106.

${ }^{310}$ Die grundsätzliche Kontinuität zwischen beiden Administrationen betont auch Steve Marsh, allerdings angloamerikanische Differenzen überbetonend und die Abfolge der politischen Anpassungen der USA aufgrund unzureichender Quellenkenntnis missverständlich darstellend. Vgl. MARSH, Inverting; ders., Reinterpreting; im Gegensatz zu Marsh die auch unter Truman durchgeführten verdeckten Operationen und überzeugend die Kontinuität der US-Politik betonend GAVIN, U.S. Policy in Iran; Gavin versucht die neue Iranpolitik als Funktion der Aufrüstungsstrategie der USA zu erklären. NSC 136/1 wäre demzufolge bereits Ausdruck einer neuen Gewissheit der eigenen militärischen Superiorität. Die frühe Entscheidung für eine Destabilisierungspolitik im März 1951 widerspricht aber Gavins These.
} 
Seitenwechsels überzeugen lassen, manche von ihnen animiert durch die pekuniären Vorteile einer Zusammenarbeit mit der CIA. ${ }^{311}$ Im Sommer 1953 verfügte Mosaddeg infolgedessen nicht mehr über die Möglichkeit, mit der Mobilisierung von Großdemonstrationen die Straßen von Teheran zu kontrollieren, ein entscheidender Faktor für seinen Sturz. ${ }^{312}$ Einzige Alternative wäre eine Absprache mit der Tudeh gewesen, was der überzeugte Antikommunist Mosaddeg allerdings ausschloss.

Die Einschätzung der tatsächlichen Macht der Tudeh, das Ausmaß der von ihr inzwischen erreichten Penetration der Regierungsbürokratie und der Sicherheitsorgane, vor allem aber die Wahrscheinlichkeit einer kommunistischen Machtübernahme stellen in der gängigen Literatur die konventionelle Achse, entlang derer die Entwicklung der US-Politik während der Ölkrise narrativ ausgerichtet wird. Der Anti-Kommunismus im Sinne der Eindämmungsdoktrin war früh als Agens auf Seiten der US-Administrationen identifiziert worden, durchaus zu Recht, zumal sich die von ökonomistisch denkenden Revisionisten erwartete Konzentration auf die eigenen Ölinteressen in den freigegebenen Quellen kaum finden ließ. ${ }^{313}$ Entgegen der Annahmen früherer Analysen hat aber die jüngere Forschungsliteratur den ideologischen Antikommunismus als treibende Kraft hinter dem Interventionismus der EisenhowerAdministration herabgestuft. ${ }^{314}$ Im iranischen Fall lassen sich bewusste Übertreibungen der Stärke und des Einflusses der Tudeh-Partei nachweisen, offenkundig mit dem Ziel, eine Legitimation für eine Intensivierung der eigenen Intervention bzw. sogar für einen Staatsstreich gegen die nationalistische Regierung zu schaffen. Ein National Intelligence Estimate (NIE) vom November 1952 stellte fest, ,[...] it appears probable that a National Front government will remain in power through 1953, despite growing unrest.“ Das NIE betonte zwar die Gefahr der kommunistischen Penetration der Front bzw. der Bürokratie, schätzte aber die Wahrscheinlichkeit eines verfassungsgemäßen oder auch eines gewaltsamen Umsturzes

\footnotetext{
${ }^{311}$ Für die abtrünnigen Nationalisten vgl. AzIMI, Unseating Mosaddeq, S. 55-65; KATOUZIAN, Struggle for Power, 156-76; laut GASIOROWSKI, TPBEDAMN Operation, S. 13ff., wurde z.B. Bağā i bereits im Herbst 1952 von der CIA kontaktiert. Gasiorowski sieht hier allerdings die „maverick operation culture“ des OPC in Aktion. Vgl. dagegen die Betonung des ,protracted process“ bei AzIMI, Overthrow Reconsidered, S. 694f., 704; im Oktober 1952 hatte die CIA die Straßenkapazitäten Mosaddeġs noch stärker eingeschätzt, allerdings vor dem Überlaufen der Partei Bagāà is. Vgl. CIA, SE-33, 14.10.52, CREST: \#RDP79*002-8.

${ }^{312}$ Vgl. ABRAHAMIAn, The Coup, S. 167ff., 194; GASIOROWSKI, Why Did?, S. 267f., 270f.; die ,entscheidende“ royalistische Demonstration am 19. August umfasste etwa 3.-4.000 Personen, wohingegen die Nationale Front früher bis zu 50.000 mobilisieren konnte. Gerade Kāšāni hatte enge Kontakte zu den käuflichen Schlägerbanden

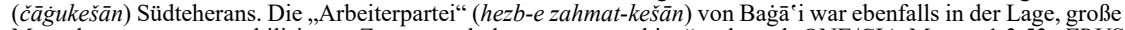
Menschenmassen zu mobilisieren. Zur mangelnden ,street machine“ vgl. auch ONE/CIA Memo, 1.3.53, FRUS $52-54$, X, S. 690.

${ }^{313} \mathrm{Im}$ Gegenteil, die amerikanischen Öl-Majors zeigten so gut wie kein Interesse daran, die Monopolstellung der AIOC in Frage zu stellen und beteiligten sich bereitwillig am Ölboykott gegen Mosaddegs Iran. Die bereits während der Krise angedachte Beteiligung von US-Unternehmen an einem multinationalen Ölkonsortium anstelle der AIOC-Konzession kam auf Initiative der amerikanischen Politik zustande, wohingegen die großen USUnternehmen fast zur Teilnahme gezwungen werden mussten. Vgl. dagegen ABRAHAMIAN, The Coup, S. 83f., 905; für eine Interpretation der Ölkrise aus Sicht der US-Ölinteressen vgl. PAINTER, Oil and the American Century, S. 172-89; die Präferenzen der US-Majors waren eher geprägt von strukturellen Interessen, weniger von Profitabsichten der Konzerne. Eine tatsächliche Kontrolle der O̊lindustrie durch Iran lehnten auch die USA durchweg ab, z.B. in den späten Verhandlungen über ein ,sales agreement“. Vgl. London \#3611, 1.1.53, FRUS 52-54, X., S. 570-3.

314 Prägnant bei YAQUB, Containing Arab Nationalism; vgl. auch BRANDS, Specter of Neutralism, $9 \mathrm{f}$.
} 
weiterhin als gering ein. ${ }^{315}$ Die Passagen über die kommunistische Gefahr in NSC 136/1, nur wenige Tage darauf vom NSC verabschiedet, klangen infolge von Änderungswünschen seitens der CIA dann schon weitaus alarmistischer. Die Lage in Iran enthalte ,very great elements of instability“ - die US-Politik müsse sich für die Gefahr einer kommunistischen Vorherrschaft in Iran wappnen und die Studie nannte eine ganze Reihe denkbarer Szenarios für eine solche wie z.B. einen Machtkampf innerhalb der Nationalen Front, Infiltration der Bürokratie, Schwächung der Sicherheitsorgane oder sogar eine Missernte: „If present trends continue unchecked, Iran could be effectively lost to the free world in advance of an actual Communist takeover of the Iranian Government. “316 Gerade angesichts des Administrationswechsels in Washington sind die ambivalenten Formulierungen in NSC 136/1 von Interesse, welche die wachsende interne Stärke der Interventionisten dokumentieren. ${ }^{317}$ Die EisenhowerAdministration setzte denn auch ihre Politik auf Basis der NSC-Studie fort und verzichtete darauf, die Direktive formell zu ersetzen. Spürbar war eine Verschärfung der Politik gegenüber der Mosaddeg-Regierung insbesondere im Nachgang der Ereignisse vom Februar 1953, einer neuerlichen Konfrontation zwischen Mosaddeg und Mohammad Rezā, in deren Verlauf eine royalistische Koalition mobilisiert wurde, die große Ähnlichkeit aufwies zu dem späteren Bündnis vom August. Azimi spricht daher bezüglich der Ereignisse des 9. Esfand zutreffend von einem „Proto-Coup“ ${ }^{318}$ Die sich wandelnde Einschätzung hatte weniger mit der Rolle der Tudeh in diesen Ereignissen zu tun - sie trat hier nur begrenzt in Erscheinung -, sondern eher mit den politischen Folgen des Umsturzversuchs: der weiteren Entmachtung des Hofs als politischer Faktor und insbesondere der darauffolgenden Säuberungen im Offizierskorps durch Mosaddeg. ${ }^{319}$ Eine CIA-Einschätzung der Lage im Anschluss an den Fast-Sturz Mosaddeġs

315 CIA, NIE-75, 13.11.52, DDRS: CK3100022793; das NIE warnte aber zugleich vor einem Zusammenbruch der Regierungsgewalt für den Fall eines Fortdauerns der Krise über das Ende von 1953 hinaus. Dies könne ,,[...] open the way for at least a gradual assumption of control by Tudeh". Noch optimistischer Department of State, OIR Intel Report N6126, 9.1.53, DDRS: CK3100401261; ein Special Estimate der CIA vom Oktober hatte der Mosaddeg-Regierung nur für das kommende halbe Jahr ein Überleben eingeräumt. Vgl. CIA, SE-33, 14.10.52, CREST: \#RDP79*002-8; auch Botschafter Henderson verwies nun auf die neuen Möglichkeiten für die Tudeh und den Machtverlust der pro-westlichen Institutionen im Iran. Vgl. Tehran \#1850, 5.11.52, FRUS 52-54, X, 513-7; in einem Treffen mit der CIA behauptete er, dass während der Gawām-Affäre im Juli 195220 „,top organizers“ der Tudeh eingereist seien und bei längerer Vorbereitungszeit eine kommunistische Machtübernahme erfolgt wäre. Vgl. Official Diary (Acting DD/I), 2.12.52, CREST: \#RDP79*055-3; zu Hendersons Haltung in der Ölkrise vgl. BRANDS, Inside the Cold War, S. 233-92.

${ }^{316}$ NSC 136/1, 20.11.52, FRUS 52-54, X, S. 531 \{Hervorheb. v. Verf.\}; die CIA hatte am 8.11. noch schärfere Formulierungen vorgeschlagen: ,[...] a deterioration of US-Iranian relations might effectively eliminate any opportunity to prevent Iran's loss to the free world well before an actual communist takeover of the Iranian government took place.“; zu den Änderungswünschen der CIA vgl. ed. note, ebd., S. 528f.; zit. aus CIA Memo, 8.11.52, CREST: \#RDP79*019-0; vgl. CIA Memo, 12.11.52, CREST: \#RDP79*014-3.

${ }^{317}$ Tatsächlich basierte der Beschluss zur Durchführung von TPAJAX formal auf NSC 136/1, wie eine der internen CIA-Geschichten bestätigt. Vgl. CIA History Staff, The Battle for Iran, S. 26; zu NSC 136/1 vgl. ebd., S. 31.

${ }^{318}$ Hintergründe des Konflikts in Tehran \#3627, 10.3.53, FRUS 52-54, X, S. 706ff.; die in der Forschung gängige Kulmination hin zum letzten Endes erfolgreichen Coup vom August 1953 ist irreführend und der Vorstellung eines scharfen Politikwechsels durch Eisenhower geschuldet. Wie oben gezeigt, stellte bereits die Gawām-Episode vom Juli 1952 einen de-facto Coup-Versuch dar, der zudem über 60 Menschenleben forderte. Im Anschluss wurde Zāhedi tatkräftig von den Briten unterstützt, was zu einem weiteren Coup-Versuch im Oktober 1952 führte, dieses Mal unter Beteiligung einiger Offiziere und - eine Parallele zu 1946 - des Baxtijāri-Stammes. Diese führten parallel zum 9. Esfand einen Aufstand im Süden an, offenbar in Absprache mit Zāhedi. Ausführlich bei AZIMI, Unseating Mosaddeq, S. 75-82; die Ereignisse rund um die oben erwähnte Ermordung des Polizeichefs Afšartus im April 1953 sind wohl ebenfalls als weiterer versuchter Staatsstreich zu werten.

319 Mosaddeg hatte den Schah und den Hof im Februar beschuldigt, hinter den fortwährenden Verschwörungen und Coup-Vorbereitungen zu stecken, und forderte daher den Verzicht auf die verbliebenen Prärogativen des Monarchen. Henderson vermutete als Ziel Mosaddegs ,the elimination of the Shah if not the Court as an 
konstatierte eine erhebliche Schwächung des Premiers in der inneriranischen Machtbalance, warnte aber zugleich vor erhöhten Chancen für die Tudeh angesichts des immer sichtbareren Zerfalls der öffentlichen Ordnung. ${ }^{320}$ Ein internes CIA-Memo bezeichnete die Lage in Iran als „more disheartening than ever“ und kam zu dem Schluss, dass ein ,[...] Communist seizure of power remains a possibility.“ ${ }^{\text {(321 }}$

Die Schwächung aller verlässlicher anti-kommunistischer Machtzentren in Iran durch Mosaddeg hatte bereits NSC 136/1 als mittelfristiges Hauptproblem identifiziert: „In wresting the political initiative from the Shah, the landlords, and other traditional holders of power, the National Front politicians now in power have at least temporarily eliminated every alternative to their own rule except the Communist Tudeh Party." ${ }^{\text {322 }}$ Der Satz war auf Betreiben der CIA in die NSC-Studie aufgenommen worden und es war auch die Agency, die im Anschluss darauf drängte, die in den Entwürfen enthaltenen Passagen für spezifische Notfallszenarien im Falle einer kommunistischen Machtübernahme bzw. eines sowjetischen Angriffs auf Iran nun als Handlungsanweisungen für die Gegenwart - also noch vor dem tatsächlichen Eintreten dieser Szenarien - zu interpretieren. ${ }^{323}$ NSC 136/1 hatte für den Fall eines versuchten oder erfolgten kommunistischen Umsturzes in Teheran selbst oder in einer der Provinzen die Vorbereitung von Gegenmaßnahmen angeordnet. Offenbar wurde im Anschluss eine Working Group aus State Department, Defense Department, JCS und CIA gebildet, die im März 1953 einen ersten

institution.“; Tehran \#3334, 22.2.53, FRUS 52-54, X, S. 677 n2; im Anschluss an die Auseinandersetzung beschloss Mohammad Rezā zeitweilig das Land zu verlassen, was zu Rücktrittsdrohungen des Generalstabs und gewaltsamen Demonstrationen führte, die Henderson als „organisiert“ einschätzte. Nach dem Verzicht des Schahs auf seine Reise beruhigte sich die Lage. Bereits hier spekulierte Henderson über die Notwendigkeit, dass ,Zahedi or some other figure with backing of military takes control of situation [...]."; anderenfalls drohe ein Zusammenbruch der Ordnung oder eine Wiederbehauptung von Mosaddegs Macht und Vergeltungsmaßnahmen der Nationalisten. Hendersons Bericht lässt wenig Zweifel an seiner Involvierung in den Coup-Versuch und seine Mitwisserschaft, gerade was die angedachte Rolle Zāhedis anging. Das Verhältnis zwischen Premier und USBotschafter war im Anschluss zerrüttet. Vgl. Tehran \#3449, 28.2.53; Tehran \#3454, 28.2.53, ebd., S. 685-8, 688ff. (Zitat auf 689); zum 9. Esfand vgl. auch RAHNEMA, Behind the Coup, S. 49-59.

320 Vgl. ONE/CIA Memo, 1.3.53, FRUS 52-54, X, S. 689ff.; Version ohne Auslassungen in DDRS: CK3100705159; dasselbe Dokument spielt auf eine Involvierung Hendersons in den Ereignissen an \{geschwärzt in der FRUS-Version $\}$ : „He \{Mosaddeg; R.P.\} might resent Henderson's activities during the crisis."; die CIA sah weitere Maßnahmen Mosaddeġs gegen seine Gegner voraus, verwies aber zugleich auf ,significant elements“ in der Armee loyal zum Schah. Allerdings sei der Premier infolge der Umbesetzungen in der Armeeführung nun in ,control of the chain of command“. Positiv angemerkt wurde zudem, dass die ,[...] institution of the Crown may have more popular backing than was expected.“; die CIA schätzte die Stärke der Tudeh auf etwa 10.000 Mitglieder, davon 4.000 in der Hauptstadt, ging aber zugleich von einer wesentlich höheren Zahl von Sympathisanten aus. Vgl. CIA Memo, 3.3.53, CREST: \#RDP80*006-9; zur Einschätzung der Rolle Hendersons durch Mosaddeg selbst vgl. MUSADDIQ, Memoirs, S. 343-8.

321 CIA Memo, 10.\{?\}.3.53, CREST: \#RDP80*016-7; dasselbe Dokument verwies allerdings auch darauf, dass Mosaddeg , ,[...] has given no indication he will permit Tudeh to collaborate with him.“

${ }_{322}$ NSC 136/1, 20.11.52, FRUS 52-54, X, S. 530.

${ }^{323}$ In den internen Debatten über NSC 136/1 drängte Kermit Roosevelt erfolglos auf die Entfernung einer Passage, die ein US-Eingreifen von einem vorherigen Hilfsgesuch einer nicht-kommunistischen Regierung abhängig machte (offenbar wurde aber auf seinen Wunsch ,legal government" durch „,non-communist government" ersetzt, was somit auch eine Intervention im Falle eines verfassungskonformen Eintritts der Tudeh in die Regierung erlaubt hätte. In derselben Unterhaltung wurde auch bereits ein ,,possible alternative leadership along the lines of Nagib“ diskutiert. Die Referenz bezieht sich auf Muhammad Nağīb, den vermeintlichen starken Mann hinter dem Staatsstreich der „Freien Offiziere“ gegen den ägyptischen König Fārūq I. im Juli 1952, zudem wieder CIAInvolvierung bestätigend im Sinne von NSC 129/1 vom April 1952. Bezüglich Iran bestehe diese Option jedoch nicht. G-2 habe das gesamte Korps von „,moderately senior officers of the Iranian Army“ während des Sommers durchleuchtet, , $[\ldots]$ and found no individual or group appearing to possess the necessary drive and following. [...] even if there were such leaders the situation is very different from that of Egypt, because of the unpopularity of the Iranian Army and the great prestige of the National Front compared to that of Farouk."; \{Name unkenntlich\} Memo to A. Dulles, 17.11.52, CREST: \#RDP79*007-1. 
Progress Report zu NSC 136/1 vorlegten. Die Gruppe plädierte bereits hier für die präventive Einleitung einer Reihe von Maßnahmen ,prior to an identifiable attempted or actual communist seizure of power“ mit der Begründung, dass eine kommunistische Machtübernahme ,,[...] might take place imperceptibly over a considerable period of time.“324 $\mathrm{Ob}$ dem Vorschlag stattgegeben wurde, ist angesichts der Quellensituation nicht abschließend zu klären. Allerdings spricht vieles dafür, da die CIA ebenfalls im März angewiesen wurde, mit den Staatsstreichplanungen zu beginnen. Wichtig für die hier vertretenen Thesen ist aber erneut die Bestätigung politischer Kontinuität zwischen beiden Administrationen und die bewusste Aufhebung der Trennschärfe zwischen einer kommunistischen Machtübernahme und einem Fortdauern der politischen Dominanz der Nationalen Front in Iran. In einem nur teilweise freigegebenen Telegramm an die Botschaft in Teheran konstatierte das State Department bereits Anfang März 1953 eine aus Sicht westlicher Interessen ausweglose Situation und beschrieb die Lage ganz im Sinne einer „unmerklichen Machtübernahme“ der Kommunisten:

Mosadeq is determined either to eliminate Shah or to reduce him to utter figurehead. Although he may not openly seek or welcome Tudeh support, he cannot disassociate himself from it and if he wins present struggle is likely to find himself unable vigorously to defend himself against Tudeh. This will be especially true if disorders take increasingly anti-western tone and Mosadeq victory is based on anti-western appeal to masses. ${ }^{325}$

Letztlich waren es die verdeckten anglo-amerikanischen Operationen und die diversen Coupversuche, die den Machtkampf innerhalb Irans angeheizt und den Premier gezwungen hatten, konsequenter und damit auch autoritärer gegen die konservative Opposition vorzugehen. Zugleich erschien, zumindest in der oberflächlichen Betrachtung, das Amt des Premiers nun als zentraler und letzter Widerstandsort gegen die kommunistische Gefahr. ${ }^{326} \mathrm{Im}$ Kern also wurde aus Sicht Washingtons eine Intervention unumgänglich, nicht aufgrund eines bedrohlichen Anwachsens der Gefahr einer Machtübernahme durch die Tudeh, sondern eher infolge der fortgesetzten Schwächung der Kräfte der Reaktion. Die Hauptsorge der Truman-

\footnotetext{
${ }^{324}$ W. B. Smith Memo, 11./20.3.53, NSArch EBBook No. 126, doc. 2; nun auch in FRUS 52-54, Retrospective Volume: Iran, S. 498-505; der Report bezog sich auch direkt auf die laufenden Operationen in Iran, offenkundig ein Bezug zu TPBEDAMN, und nannte die sieben Zielsetzungen des Programms, allesamt direkt gegen die Tudeh gerichtet, abgesehen von einer, die ein Schlupfloch für anders gerichtete Operationen bot: „Influence the choice of a successor to Mosadeq in the event of his resignation or death."; wie sensibel der Inhalt des Dokuments war, zeigt auch die Rückforderung sämtlicher Kopien durch das Executive Secretariat des NSC. Vgl. Lay Memo to all holders of NSC 136/1 progress report, 23.4.53, ,140th Meeting', Official Meeting Minutes, Box 5, RG 273, NACP; der Report enthält zudem einige Informationen zu bestehenden Absprachen der CIA mit den Gašğā'i über Stay Behind-Operationen und der Aufnahme eines Guerilla-Krieges gegen eine eventuelle kommunistische Regierung in Teheran. Parallel zu dem Staatsstreich leiteten die JCS Notfallplanungen gemäß NSC 136/1 ein, die aber aufgrund der Niederlage der Nationalisten rasch obsolet wurden. Eine längerfristige Konsequenz war der militärische Plan CINCNELM Oplan 207-54 (,A U.S. Joint Plan for Operations in the Middle East'), der eine handstreichartige Besetzung von Ābādan und Teheran in Vorbereitung einer Verlegung umfangreicher Kampfeinheiten in der Größenordnung einer Division vorsah. Vgl. WATSON, History of the JCS: V, S. 333f.; PALMER, Guardians of the Gulf, S. 65f., 71f.; Joint Strategic Plans Committee Report, 31.12.52, in: ALEXANDER/NANES, United States and Iran, S. $241 \mathrm{ff}$.

${ }^{325}$ State \#2266, 2.3.53, FRUS 52-54, X, S. 691; leider sind die anschließenden Instruktionen an Henderson nicht freigegeben. Vgl. ebd., S. $692 \mathrm{n2}$; das Telegramm aus Washington war ironischerweise von John Jernegan verfasst, inzwischen Deputy Assistant Secretary of State for Near Eastern, South Asian, and African Affairs, fast genau zehn Jahre nach dem idealistischen Jernegan-Memorandum.

${ }^{326}$ „Mossadeq appears at present to represent the chief barrier to Communist control [... $]^{“,}$, konstatierte die CIA nach den Februar-Ereignissen. CIA Memo, 5.3.53, CREST: \#RDP80*006-9.
} 
und Eisenhower-Administrationen war somit, wer oder was auf Mosaddeg nach dessen Tod oder Sturz folgen würde. ${ }^{327}$ Allein eine politische Dominanz des Hofs und des Militärs aber garantierte eine fortgesetzte Westorientierung des Landes und die Permanenz amerikanischen Einflusses - diese Einschätzung ähnelte somit in vielem den Beweggründen hinter George Allens Intervention gegen Ġawām im Jahr 1946. ${ }^{328}$ Das amerikanische Eingreifen als in erster Linie durch die Umstände und Zwänge des Kalten Krieges motiviert zu interpretieren, ist daher reduktionistisch. Angesichts der amerikanischen Überzeugungen, dass jede nationalistische Regierung aufgrund dem ihr eigenen Interesse an einem revolutionären Umbau der iranischen Gesellschaft und des politischen Systems letztlich die institutionellen Garanten dauernder proamerikanischer Orientierung - Hof, Bürokratie und Streitkräfte - fundamental schwächen würde, ging das Kalkül über simplen Antikommunismus weit hinaus. Somit war die Restauration eines autoritär-diktatorischen Regimes nicht ein unerwünschtes wenngleich hinzunehmendes Resultat bzw. ein Nebeneffekt des aufgrund der Priorisierung der breiteren strategischen Interessen im Kontext des globalen Systemkonflikts als notwendig begriffenen Eingreifens gegen eine liberal und pluralistisch orientierte Bewegung, sondern vielmehr das eigentliche Wunschergebnis einer Intervention.

So lässt sich auch der Widerspruch auflösen angesichts der Tatsache, dass die zeitgenössischen Quellen der Existenz einer unmittelbaren Gefahr einer kommunistischen Machtübernahme widersprechen. Während die später der New York Times zugespielte interne CIA-Geschichte des Coups und die verschiedenen an der Operation beteiligten Geheimdienstoffiziere eine unmittelbar bevorstehende Machtübernahme der Tudeh als Motivation für den Staatsstreich angaben, hat die spätere historische Forschung diese Behauptungen durchweg in Frage gestellt. ${ }^{329}$ Unmittelbar vor dem Coup schätzte die CIA die Stärke der Tudeh auf 20.-35.000

\footnotetext{
${ }^{327}$ DCI Allen Dulles informierte den NSC über die eigentliche Gefahr in Iran angesichts der nun absehbaren Errichtung einer Mosaddeg-Diktatur: „As long as the latter lives there was but little danger, but if he were to be assassinated or otherwise to disappear from power, a political vacuum would occur in Iran and the Communists might easily take over."; $135^{\text {th }}$ NSC Meeting, 4.3.53, FRUS 52-54, X, S. 693; sein Bruder John Foster behauptete in derselben NSC-Sitzung, man habe Iran bereits an die Sowjetunion verloren, wenngleich Mosaddeg unter Umständen noch 1-2 Jahre ausharren könne. Der PSB konstatierte noch Anfang August 1953: „Up until a few months ago there were several balance-of-power elements to deal with in various combinations: the Shah, the Army and the parliamentary opposition. Now there is only Mossadegh and the great unknown."; MacLean Memo, 4.8.53, ,PSB 091.Iran', WHO, NSCS, PSB Central File Ser., Box 13, DDEL.

${ }^{328}$ Die US-Politik war somit im Grundsatz anti-revolutionär, basierend auf der axiomatischen Sichtweise, dass ein Fortdauern der Regierung der Nationalen Front früher oder später zu einer Machtübernahme der radikalen Linken führen werde. Eines der freigegebenen CIA-Dokumente sprach freimütig von den Folgen einer Machtkonsolidierung der iranischen Nationalisten und Mosaddegs: „His victory would take Iran one step further along its present revolutionary road.“; CIA Memo, 5.3.53, CREST: \#RDP80*006-9; vermutlich erklärt die Tatsache, dass sich der Staatsstreich eben nicht in erster Linie gegen die Kommunisten richtete, die erhebliche interne Kritik. So trat der damalige CIA Station Chief Roger Goiran zwei Wochen vor der Operation zurück. Vgl. GasiorowsKi, Coup Against Mosaddeq, S. 231.

${ }^{329}$ Vgl. CIA [Donald N. Wilber], Clandestine Service History, S. iiif.; Behrooz nennt die Gefahr seitens der Tudeh und der UdSSR als Begründung angesichts der Quellenlage „,implausible“. Siehe ders., Legacy, S. 125; vgl. auch ders., Tudeh Factionalism; Byrne berichtet von den späteren Aussagen eines Analysten der CIA, wonach die „,clandestine branch“ der CIA bewusst die von der Tudeh ausgehende Gefahr überzeichnet habe. Vgl. BYRNE, Road to Intervention, S. 220f.; GASIOROwSKI, 1953 Coup, S. 276, spricht explizit von einer Kampagne der obersten Ebenen von CIA und State Department mit der Absicht, Ängste vor einer kommunistischen Machtübernahme zu schüren. CIA-Einschätzungen der Lage in Iran für den NSC im August dramatisierten die Lage in dem Land, bezeichneten die Tudeh-Partei nun als Mosaddegs „main source of popular strength“ und sagten eine unmittelbar anstehende Annäherung an Moskau voraus. Für ein Beispiel für diese Art von politisierter Geheimdiensteinschätzung vgl. CIA, Briefing Notes, 5.8.53, CREST: \#RDP80*001-0.
} 
Mitglieder, inklusive eines harten Kerns von etwa 1.000 Personen. Beunruhigung ausgelöst hatte aber offenbar die Größe einer seitens der Regierung Mosaddeg tolerierten Großdemonstration der Kommunisten im Juli, an der zwischen 50.-100.000 Personen teilnahmen. Gegen eine ernstzunehmende Bedrohung sprach aber die Tatsache, dass die Partei offenbar erfolgreich vonseiten der anglo-amerikanischen Geheimdienste penetriert worden war und man sich über die internen Entscheidungen der Tudeh gut informiert zeigte. ${ }^{330}$ Somit war man seitens der CIA wohl darüber im Bilde, dass sich die iranischen Kommunisten selbst nicht in einer vor-revolutionären Ära glaubten bzw. eine Machtergreifung als unrealistisch ansahen. Zudem waren die Signale aus Moskau widersprüchlich, wenngleich bis heute kaum Quellen vorliegen, die eine Einschätzung der tatsächlichen sowjetischen Absichten ermöglichen würden. ${ }^{331}$ Wie gering man auf Seiten der CIA-Analysten die eigentliche kommunistische Gefahr in Iran einschätzte, belegen aber verschiedene Entwürfe des Office of National Estimates (ONE) der CIA aus diesem Zeitraum. Noch zu einem Zeitpunkt, als der Staatsstreich als gescheitert angesehen werden musste, und die Flucht Mohammad Rezās als unwiderruflich, glaubte man, dass die ,[...] Tudeh is not yet ready to seize control and will probably feel compelled to confine itself to pressure group tactics for the next few months." Angesichts der zu diesem Zeitpunkt zu erwartenden Zerschlagung der rechten Opposition und der umfassenden Säuberung der Armee von konservativen Offizieren spiegelt die Analyse daher wohl die tatsächliche Lagebeurteilung der CIA-Analysten wider, im Gegensatz zu den alarmistischen und politisierten Analysen in den Wochen vor dem Staatsstreich. ${ }^{332}$ Nur zwei Tage später erklärte die CIA explizit, dass Mosaddeg̀s Position gesichert sei und die unmittelbare kommunistische Gefahr gering: „We do not consider the Tudeh threat to be imminent. “333

\footnotetext{
${ }^{330}$ Vgl. CIA Background Information, o.D. [Juli 1953], CREST: \#RDP80*018-3; die Zahl der Tudeh-Mitglieder in den Streitkräften wurde auf 1.600 Personen, der Anteil von Kommunisten unter den Studenten der Militärschulen auf etwa $20 \%$ geschätzt. So wusste man über den internen Beschluss der Tudeh vom 4 . April, die Mosaddeg-Regierung zu schützen. Offenbar hatte man Informanten innerhalb des ZKs der Partei. Siehe z.B. CIA Information Report, 9.1.52, CREST: \#RDP82*013-8; zur Penetration vgl. auch GASIOROWSKI, 1953 Coup, S. 286 $n 76$; die fortlaufenden TPBEDAMN-Operationen der CIA erzeugten mit ihren zahlreichen „False-Flag“-Aktionen den irreführenden Eindruck einer stärkeren und aktiveren Tudeh. So waren diese offenbar verantwortlich für Umfang und Gewaltbereitschaft der ,kommunistischen“ Demonstrationen während Harrimans Besuch in Iran im Juli 1951. Vgl. GASIOROWSKI, Coup Against Mosaddeq, S. 236; insgesamt zur Einschätzung der kommunistischen Bedrohung vgl. ders., U.S. Perceptions.

${ }^{331}$ Vgl. die bei BeHrooz, Legacy, S. 103-6, zusammengetragenen Fakten. Hier auch weitere Informationen zur inneren Spaltung der Partei und ihrer im Grundsatz feindseligen Haltung zur Mosaddeg-Regierung. Vgl. ebd., S. 106-16; ähnlich ABRAHAMIAN, 1953 Coup in Iran, S. 204f.; die Feindseligkeit spiegelte die offizielle Haltung Moskaus gegenüber dem Premier. Die Sowjets warnten Mosaddeg nicht vor dem bevorstehenden Staatsstreich, obwohl sie über entsprechende geheimdienstliche Informationen verfügten. Vgl. ZuBOK, Soviet Intelligence, S. 466ff.; wenig Neues in ders., Struggle; KALINOvSKY, Soviet Union and Mosaddeq; vgl. CIA Memo, 22.7.53, CREST: \#RDP80*005-8.

${ }^{332}$ CIA/ONE, 17.8.53, CREST: RDP79*013-2; ähnlich die Einschätzung innerhalb des PSB. Vgl. Debevoise Memo, 17.8.53, ,PSB 091.Iran', WHO, NSCS, PSB Central File Ser., Box 13, DDEL.

333 CIA/ONE Draft, SE-49, 19.8.53, CREST: RDP79*011-4; zwar sah ONE weiterhin die Tudeh als den langfristigen Gewinner des gescheiterten Staatsstreiches, da sämtliche Alternativen nun geschwächt seien, kam aber gleichzeitig zur interessanten Einschätzung, dass , ,[...] the defeat of his non-Communist opponents will probably make Mossadeq less tolerant of Tudeh activities then he has been in the past."; im Grunde ist dies ein Eingeständnis, dass die eigenen Operationen für den Aufstieg der Tudeh erfolgreich gewesen waren. MELBOURNE, Conflict and Crises, S. 157, erwähnt eine spätere (und von ihm abgelehnte) Analyse der Gefahreneinschätzungen im Sommer von 1953, derzufolge die Tudeh in Wirklichkeit keine echte Gefahr dargestellt habe.
} 
Zur vielfach erzählten und diskutierten Geschichte des Staatsstreichs gegen Mosaddeg sei abschließend vermerkt, dass die amerikanische Entscheidung, derart tiefgreifend und folgenschwer in die inneren Angelegenheiten Irans einzugreifen, im Kontext der grundsätzlichen Einschätzung über die herausragende strategische Bedeutung Irans betrachtet werden muss. Wie oben bereits beschrieben, wandelte sich die Wahrnehmung Irans vonseiten der amerikanischen Planer bereits Anfang der 1950er Jahre. Insbesondere die militärischen Stellen betonten die zentrale Bedeutung Irans für die Verteidigung der Nahostregion, aber auch im globalen Kontext des Kalten Krieges. Die JCS warnten bereits im Oktober 1951, dass eine Anpassung der amerikanischen Globalstrategie notwendig sei ,[...] in the event that the USSR breached the Truman Doctrine in regard to Iran by measures short of war." ${ }^{334}$ NSC 136/1 vom November 1952 hatte bereits die schwerwiegenden Folgen eines Verlust Irans dokumentiert und die CIA warnte den NSC im März 1953 ein weiteres Mal vor Moskau erwachsenden Vorteilen infolge einer solchen Entwicklung. ${ }^{335}$ Präsident Eisenhower betonte die Notwendigkeit einer unmittelbaren Reaktion der USA für den Fall eines sowjetischen Vordringens in den Iran und gab der strategischen Bedeutung des Landes Ausdruck: „If [...] I had $\$ 500,000,000$ of money to spend in secret, I would get $\$ 100,000,000$ of it to Iran right now. “336 Die nunmehr allgemein akzeptierte herausgehobene strategische Bedeutung Irans im Kontext des globalen Systemkonflikts mit der Sowjetunion reduzierte aus Sicht amerikanischer Entscheidungsträger die Handlungsoptionen. Selbst ohne eine unmittelbar drohende Machtübernahme der Kommunisten in dem Land war die sich abzeichnende vollständige Entmachtung der wenigen zweifelsfrei pro-amerikanisch und pro-westlich eingestellten inneriranischen Fraktionen und Institutionen ein Umstand, der letztlich auch einen völkerrechtswidrigen und normativ zweifelhaften Eingriff in die interne Machtverhältnisse als gerechtfertigt oder wenigstens notwendig erscheinen ließ. ${ }^{337}$ Eine interne CIA-Einschätzung aus den 1970ern brachte es auf den Punkt: „TPAJAX was entered into as a last resort.“338

\footnotetext{
334 JCS Memo, 10.10.51, FRUS 52-54, X, S. 222; interessant auch der nunmehr als axiomatisch betrachtete Einschluss Irans in die Truman-Doktrin. Die JCS plädierten somit früh gegen die in NSC 107/2 festgelegte Unterstützung der britischen Linie im Konflikt: ,Strictly from the United States military point of view, Iran's orientation towards the United States in peacetime and maintenance of the British position in the Middle East now transcend in importance the desirability of supporting British oil interests in Iran."; ebd.; zur internen Kritik vgl. POOLE, History of the JCS: IV, S. 185-9; JCS History Iran, S. 22f., 24ff.; Secretary of Defense Lovett beschwerte sich im August 1952 über die nonchalante britische Haltung in Iran. Vgl. Lovett Letter to Bruce, 16.8.52, Iran Collection, National Security Archive.

${ }^{335}$ Die Errichtung eines kommunistischen Regimes in Iran gefährde die Sicherheit des gesamten Nahen und Mittleren Ostens, aber auch Südasiens, und impliziere möglicherweise einen Verlust des westlichen Zugangs zum gesamten nahöstlichen Öl. Vgl. NSC 136/1, 20.11.52, FRUS 52-54, X, S. 529-34; CIA Briefing Notes, 3.3.53, CREST: \#RDP80*010-4.

336 135th NSC Meeting, 4.3.53, FRUS 52-54, X, S. 698.

${ }^{337}$ Trotz der allgemeinen Einschätzung der Schwäche der Tudeh war man sich des eingegangenen Risikos durch TPAJAX durchaus bewusst. Loy Henderson sagte für den Fall eines gescheiterten Staatsstreichs einen Zerfall der pro-westlichen Kräfte voraus: ,Miscarriage of attempted coup would be likely to complete ruin of Shah and dynasty, to result in increase of arrests of persons suspected of pro-British sympathies, and to strengthen forces antipathetic to west."; Tehran \#3576, 6.3.53, ebd., S. 701f.

${ }^{338}$ CIA History Staff, The Battle for Iran, S. 26; zu NSC 136/1 vgl. ebd., S. 31; recht freimütig fasste die Studie die damaligen Beweggründe zusammen: "When it became apparent that many elements in Iran did not approve of Mosadeq's continuing gamble or the direction in which he as pushing their country, the execution of a U.S. assisted coup d'etat seemed a more desirable risk than letting matters run their unpredictable course."; ebd., S. 28.
} 